\title{
A cross-cultural comparative study of teacher effectiveness: Analyses of award-winning teachers in the United States and China
}

Xianxuan Xu

William \& Mary - School of Education

Follow this and additional works at: https://scholarworks.wm.edu/etd

Part of the Bilingual, Multilingual, and Multicultural Education Commons, Education Policy Commons, and the Teacher Education and Professional Development Commons

\section{Recommended Citation}

Xu, Xianxuan, "A cross-cultural comparative study of teacher effectiveness: Analyses of award-winning teachers in the United States and China" (2011). Dissertations, Theses, and Masters Projects. Paper 1550154197.

https://dx.doi.org/doi:10.25774/w4-m1vm-2c33

This Dissertation is brought to you for free and open access by the Theses, Dissertations, \& Master Projects at W\&M ScholarWorks. It has been accepted for inclusion in Dissertations, Theses, and Masters Projects by an authorized administrator of W\&M ScholarWorks. For more information, please contact scholarworks@wm.edu. 


\section{NOTE TO USERS}

This reproduction is the best copy available.

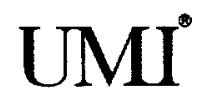



A CROSS-CULTURAL COMPARATIVE STUDY OF TEACHER EFFECTIVENESS:

ANALYSES OF AWARD-WINNING TEACHERS

IN THE UNITED STATES AND CHINA

A Dissertation
Presented to
The Faculty of the School of Education
The College of William and Mary in Virginia
In Partial Fulfillment
Of the Requirements for the Degree
Doctor of Philosophy

by

Xianxuan $\mathrm{Xu}$

April 2011 
A CROSS-CULTURAL COMPARATIVE STUDY OF TEACHER EFFECTIVENESS: ANALYSES OF AWARD-WINNING TEACHERS IN THE UNITED STATES AND CHINA

by

Xianxuan Xu

Approved April 2011 by

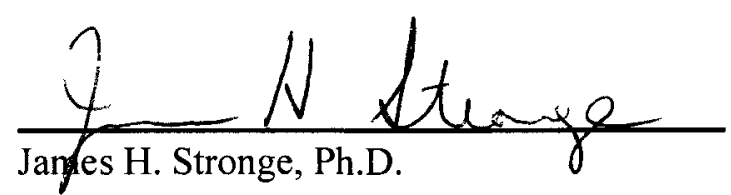

Chairperson of Doctoral Committee

$\frac{\text { Serlui W Rant }}{\text { Lester W. Grant, hD. }}$

Patrica a. Prop

Patricia A. Poop, Ph.D.

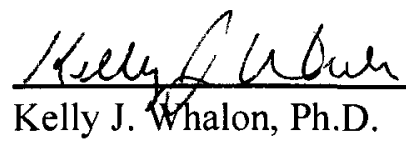

ii 


\section{DEDICATION}

To all of my teachers

For what you taught me and who you are

For leading me, an apparently ordinary person, to unusual endeavors 


\section{Table of Contents}

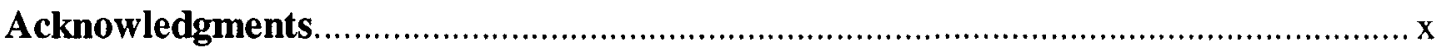

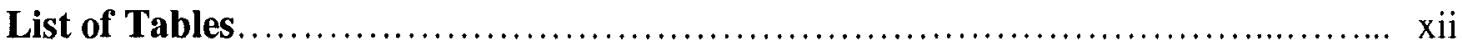

List of Figures....................................................... xiii

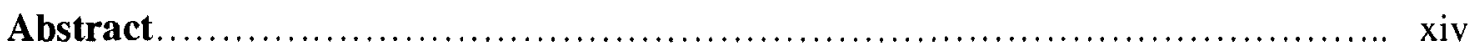

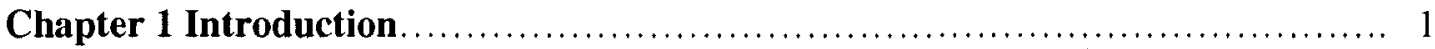

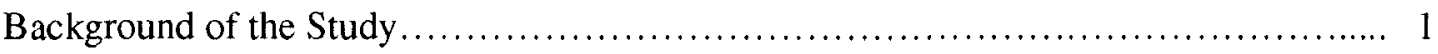

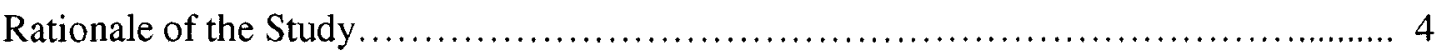

Teachers Matter.................................................................. 5

Variability of Effectiveness across Teachers.............................. 7

What Makes a Teacher Effective? ...................................... 9

Presage Teacher Characteristics.................................. 9

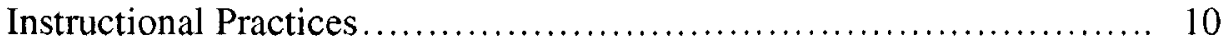

Teacher Dispositions and Beliefs.,.............................. 12

Summary $\ldots \ldots \ldots \ldots \ldots \ldots \ldots \ldots \ldots \ldots \ldots \ldots \ldots \ldots \ldots \ldots \ldots \ldots \ldots \ldots, 13$

Statement of the Problem......................................................... 14

Statement of Purpose....................................................... 16

Research Questions......................................................... 17

Significance of the Study ..................................................... 18

Definition of Key Terms............................................................. 19

Delimitations and Limitations of the Study.................................. 21

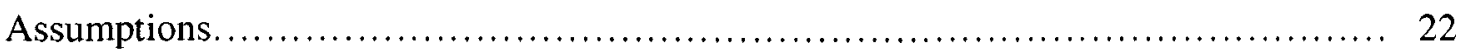


Why Does Teacher Effectiveness matter? ........................................... 23

Teacher Effectiveness and Student Achievement............................ 24

Teacher Effectiveness and School Improvement.................................. 29

Teacher Effectiveness and Educational Equity............................. 31

A Framework For Understanding Teacher Effectiveness............................. 34

How Do Teachers' Background Qualities Affect Student Achievement?............................36

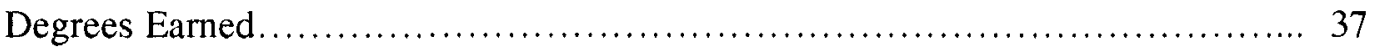

Coursework ......................................................, 40

Certification Status.................................................. 41

Content Knowledge.............................................. 43

Teaching Experience.................................................. 45

Summary: A Priori Background Qualities and Student Achievement............... 46

How Do Teachers' Dispositions Affect Student Achievement?............................. 47

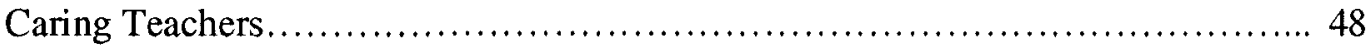

Teacher Efficacy Beliefs........................................... 50

Motivation and Enthusiasm to Teach................................. 51

Summary: Teacher Personal Dispositions and Student Achievement............. 52

How Do Teachers' Skills and Practices Affect Student Achievement?............................. 53

Classroom Management............................................... 54

Planning for Instruction........................................... 58

Implementing Instruction. ........................................... 60 
Summary: Teacher's teaching ............................................... 68

How Teacher Effectiveness is Similar and Different in China?......................... 69

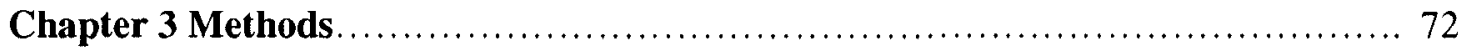

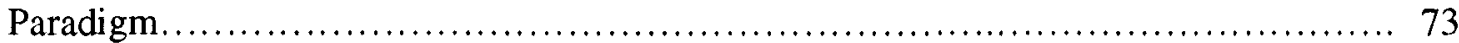

Perspective.............................................................. 77

Research Strategy.............................................................. 79

Sample and Participant Selection................................................. 80

Data Generation/Collection................................................... 84

Triangulation......................................................... 85

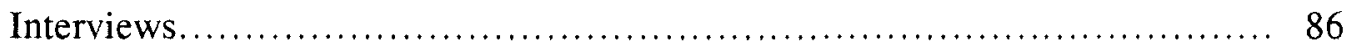

Observations......................................................... 89

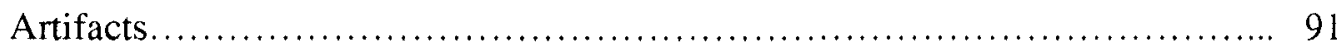

Data Analysis.............................................................. 92

Descriptive Statistics.................................................... 92

Grounded Theory Analysis................................................ 94

Conclusion................................................................. 97

Chapter 4 Findings and Discussions........................................... 98

Demographic Information................................................... 100 
Findings for Research Question 1:

What Are the Similarities and Differences Between Selected

Award-Winning United States and China Teachers in Their

Instructional Practices?

What Types of Instructional Activities Are Used by

Selected Award-winning U.S. and China Teachers?

102

Number of Instructional Activities

Nature of Instructional Activities

How Are Cognitive Levels, Based on Bloom's

Revised Taxonomy (Anderson \& Krathwohl, 2001),

Represented in These Teachers' Classrooms?

To What Degree Is Learning Teacher-Directed in the Classrooms of Selected Award-Winning U.S. Teachers and China Teachers?

Findings for Research Question 2:

How Are Selected National Award-Winning United States and China teachers' classroom practices - Other Than Instructional Activities - Similar and Different (Such as Their Classroom Management Strategies)?

What Are the Student Engagement Levels in the Classrooms

of Selected Award-Winning U.S. Teachers and China Teachers?

What Classroom Management Strategies Are Implemented

by Selected Award-Winning U.S. Teachers and China Teachers?

Findings for Research Question 3:

What Are the Similarities and Differences in Professional Thinking

Between Teachers in the U.S. and China? 116

How Do These Teachers Reflect on Their Practices, Particularly about Their Relationships with Students, Classroom Environment, Instructional Planning, Instructional Strategies, Differentiation, and Assessment and Evaluation of students' learning? 
Planning Based on the Curriculum, Textbooks, and Student Learning Needs.

Variation and Flexibility in Planning and Instruction

Differentiation and Attention to Group and Individual Differences.

Maintaining a Classroom Environment that is

Safe, Fun, and Intellectually Stimulating

Assessing Student Learning and Self-Evaluating

the Success of Teaching....

Personal and Professional Growth and Change........................ 141

Use of Reflection.

Relationships with Students and Parents

Metaphors of Teaching

What Are the Selected Teachers' Perceptions of Why Their

Practice Merited Recognition with a National Award?

Chapter 5 Summary, Discussion, and Implications

Discussion

159

Instructional Planning.

Instructional Delivery. 163

Differentiation. 167

Classroom Management 169

Relationships with Students and Parents. 170

Professional Development. 172

Implications for Practice. 176 
Implications for Research............................................... 178

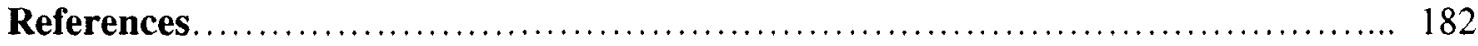

Appendix A Informed Consent Form - English............................. 217

Appendix B Informed Consent Form - Chinese ................................ 219 


\section{ACKNOWLEDGMENTS}

I am truly grateful for my experience at the School of Education, College of William and Mary. This is an incredible place to learn. First and foremost I am forever grateful to Dr. James Stronge, the chairman of my dissertation committee and my academic advisor, and his family. Thank you, Terri, and Sally for your unreserved support, encouragement, and belief that I can succeed.

I am grateful to my committee member, Dr. Leslie Grant. Your words of direction, unfaltering support, and wisdom made me think about being a doctoral student in a different way. For the past three plus years, you molded an insecure learner into a confident thinker and researcher.

Dr. Patricia Popp, I thank you for your tireless commitment to my learning and growth. It has been an honor working with you in Project HOPE-VA over the past few years. For me, you are a model of serving kids who are from the most disadvantaged situations. I will be continually inspired by what you have achieved in making the educational services more accessible to the learners who need them most.

I would also like to thank my other committee member, Dr. Kelly Whalon, who is a phenomenal instructor and whose passion for qualitative research inspired me to learn more about it and finally conduct this study. Thank you for making my head hurt in your class and keeping challenging me to reflect on my ideology and epistemology while conducting educational research.

I am also grateful for the opportunities of graduate assistantship I received from the School of Education, and I have the deepest appreciation for the Galfo Research Fellowship 
and Brickell Partnership Award, which are generously offered by members of this community who are giving and who have a strong belief in education. These financial supports made my graduate studies here possible. They also helped me conduct a much better funded dissertation study. All these will be kept as lifetime fond memories and will continue to remind me what I value most.

Thank you to the teachers who participated in this study. Your dedication to all children inspires me to continue to want to help all teachers teach like you. 


\section{LIST OF TABLES}

Table 1. Impact of Teacher Practices on Student Achievement.

Table 2. Summary Findings of Teacher Effects on Student

Achievement from Selected Studies.

Table 3. Comparison of Stronge's and Chinese Scholars'

Theoretical Frameworks of Effective Teachers

Table 4. Key Characteristics of Learning Environment for Effective Teachers.

Table 5. Key Areas of Instructional Delivery for Effective Teachers.

61

Table 6. Alignment of Research Questions to

Data Collection/Generation and Analysis. 100

Table 7. Participant Background Information. 101

Table 8. Results from the Differentiated Observation Scale,

Number of Instruction Activities, by Country. 102

Table 9. Most Used Instructional Activities by China Teachers,

Compared with United States Teachers

Table 10. Most Used Instructional Activities by United States Teachers, Compared with China Teachers. 105

Table 11. Cognitive Levels of Instructional Activities, by Country....

Table 12. Teacher vs. Student Director of Learning, by Country

Table 13. Student Engagement in Classroom Learning, By Country... 114

Table 14. Major Categories and Themes in Professional Thinking. 117

Table 15. Instructional Planning Similarities, by Subthemes.

Table 16. Instructional Planning Differences, by Subthemes.

Table 17. Self-identified Reasons by Teachers for Receiving Awards.

152

Table 18. A Summary of Similarities and Differences Between China and U.S. Award-Winning Teachers, and Relevant Interpretations 174 


\section{LIST OF FIGURES}

Figure 1. Student Achievement Accounted for by Teacher Effects.................... 28

Figure 2. Most Used Instructional Activities by China Teachers,

Compared with United States Teachers: Percentage of Teachers

Figure 3. Most Used Instructional Activities by China Teachers,

Compared with United States Teachers: Percentage of Observation Segments............. 104

Figure 4. Most Used Instructional Activities by United States Teachers,

Compared with China Teachers: Percentage of Teachers............................... 105

Figure 5. Most Used Instructional Activities by United States Teachers,

Compared with China Teachers: Percentage of Observation Segments................... 106

Figure 6. Cognitive Levels of Instructional Activities, by Country.................... 112 


\title{
A CROSS-CULTURAL COMPARATIVE STUDY OF TEACHER EFFECTIVENESS:
}

\section{ANALYSES OF AWARD-WINNING TEACHERS \\ IN THE UNITED STATES AND CHINA}

\begin{abstract}
The purpose of this study was to develop a richer understanding of teacher effectiveness through cross-cultural analyses of the practices and beliefs of selected China and U.S. teachers who have received national awards for their teaching. This study was based upon an interpretivist, phenomenological design that used semi-structured interviews, classroom observations, and artifacts for data generation/collection. Twelve China teachers and 13 U.S. teachers participated in this study. This study revealed similarities and differences between U.S. teachers and China teachers in their patterns of instructional practices and professional thinking. The major similarities found between them were: using a variety of instructional activities which spanned across different cognitive levels; being opportunistic planners to maximized meaningful student learning; having high student engagement; presenting effective classroom management skills; and maintaining a learning environment that was conducive to optimal learning. Primary differences between U.S. and China teachers' classrooms included the types of instructional activities used and their beliefs and practices in the areas of instructional planning, differentiation, assessment, classroom management, relationships with students and parents, and professional development.
\end{abstract}

\section{XIANXUAN XU}

DEPARTMENT OF EDUCATIONAL POLICY, PLANNING AND LEADERSHIP

THE COLLEGE OF WILLIAM AND MARY IN VIRGINIA

xiv 
A CROSS-CULTURAL COMPARATIVE STUDY OF TEACHER EFFECTIVENESS:

ANALYSES OF AWARD-WINNING TEACHERS

IN THE UNITED STATES AND CHINA 


\title{
CHAPTER 1
}

\section{INTRODUCTION}

\begin{abstract}
From Aristotle and Socrates to Montessori and Piaget to Bruner and Hanushek, philosophers, physicians, psychologists, cognitive scientists, and economists have each attempted to characterize the attributes, dispositions, knowledge, and instructional skills that define effective teachers. The rationale for this 2000-year search is that better teachers produce better learning (Schacter \& Thum, 2004, p. 411).
\end{abstract}

\section{Background of the Study}

Current political and socio-economic circumstances in both the United States and China demand more competitive human capital and, therefore, sustained investment in and development of human capacity. Perhaps one of the best reflections of a policy of human capital investment with enormous potential for payback is continuous improvement of educational opportunities of young people as reflected in improved student development and performance. For many years, researchers, policy makers, and educational practitioners in both educational systems have explored the variables that impact student achievement. The issue of teacher quality has arisen as the focus of discussion and debate time after time, since the classroom teacher is the most influential school-related factor that affects student achievement (Mendro, Jordan, Gomez, Anderson, \& Bembry, 1998; Muijs \& Reynolds, 2003). Teacher effectiveness is the pillar of educational policy agendas. It also mediates the impact that any instruction-related reform or intervention has on student learning (Stronge, 2010). 
With the passing and implementation of No Child Left Behind (NCLB) in 2001, the United States government emphasized the need for states and school districts to ensure that all students — particularly at-risk students, students who are ethnically and linguistically marginalized, and students who are otherwise disadvantaged — have access to "highly qualified teachers" (U.S. Department of Education, 2001). The NCLB law uses three key guidelines to determine whether a teacher is highly qualified: 1) at least a bachelor's degree in the subject taught, 2) full state teacher certification, and 3) demonstrated knowledge in the subject taught (U.S. Department of Education, 2001).

The notion of effective teachers, as reflected in educational policies in the U.S., has evolved considerably. For most of the $20^{\text {th }}$ century, when candidates completed a stateapproved teacher preparation program, they were eligible for teacher certification. In the 1980s, several states implemented performance assessments to ensure that teachers were equipped with a uniform set of teaching competencies regardless of the content areas or grade levels they taught. Those competencies were drawn largely from process-product research ${ }^{1}$ on teaching, and were perceived to be evidence-based. During the past 10 years, the standards used to assess teacher effectiveness have increasingly reflected the complexities of classroom teaching. In particular, these conceptions emphasize the context-specific nature of teaching and the need for teachers to integrate knowledge of subject matter, students, and contextual

\footnotetext{
${ }^{1}$ Process-product analysis is an approach to research on teaching which gained popularity initially in the 1970s (Good \& Brophy, 1973; 2008). Research using this approach usually examines cause-and-effect relationships between process and product variables. Process variables refer to properties of instruction during which students and teachers interact around academic content. Examples of process variables include student time-on-task, instructional strategies, and teacher dispositions. Product variables refer to possible outcomes of teaching, such as student learning (Rowan, Correnti, \& Miller, 2002).
} 
conditions in making instructional decisions, engaging students in learning, and reflecting on practice (Wayne \& Youngs, 2008).

On other side of the globe, China has undertaken a nationwide program of curriculum reform since 2001. This reform is considered to be one of the most ambitious and farreaching sets of changes to schooling in recent Chinese history (Sargent, 2006). In addition to an overhaul of the objectives and content of curriculum materials, it calls for a paradigm shift in educational philosophy, and a corresponding transformation in teaching practices at the classroom level. This represents a significant shift from traditional Chinese teacher practices — which focused primarily upon memorization, drill, and use of prescribed textbooks - to practices that foster individuality, self-expression, inquiry, and creative thinking skills.

In the United States, a host of studies have been conducted to examine the impact that the movements toward standardization, accountability and high-stakes assessment systems have had on teachers' practices, beliefs, attitudes, and their overall effectiveness (e.g., Hamilton \& Stecher, 2004; National Board on Educational Testing and Public Policy, 2003; Parke, Lane, \& Stone, 2006). In China, educators and researchers also are beginning to reconceptualize teacher effectiveness in ways that will fulfill the ambitions of the national curriculum reform, particularly teachers' capacities to incorporate new curriculum standards and new approaches to thinking about student learning and teaching into instruction (e.g., Bo, 2008; Du, 2004; Sun, 2004; Wang, 2006; Zhang, 2008). Against the backdrop of current educational reforms in the United States and China, along with intensified global economic and educational competition, this is an opportune time to conduct international comparative 
studies to shed new light and share new perspectives upon the complex issue of teacher effectiveness (Crossley \& Waston, 2003).

\section{Rationale of the Study}

Student learning is the professional touchstone for all educational programs and teachers. The purpose of teaching is to nurture learning, and both teachers and schools should be evaluated on the basis of what and how much students learn (Schalock, Schalock, Cowart, \& Myton, 1993). The social contract between public education and society requires schools to hire, retain, and improve teachers whose qualities and practices are the most predictive of student achievement.

A better understanding of what constitutes teacher effectiveness has significant implications for decision-making regarding the recruitment, compensation, training, and evaluation of teachers. For example, if administrators need to hire effective or, at least, promising teachers, they need to understand what characterizes them. Recently, educators have begun to emphasize the importance of linking teacher effectiveness to various aspects of district/school personnel administration, including:

1. Recruiting and inducting potentially effective teachers,

2. Designing and implementing professional development,

3. Conducting valid and credible evaluations, and

4. Dismissing ineffective teachers while retaining effective ones (Hanushek, 2008;

National Academy of Education, 2008; Odden, 2004). 
This type of alignment is receiving increasing attention as an important means for providing quality education to all students and improving school performance However, it is not easily attainable

Although researchers have found that student learnıng is not strongly associated with teachers' professional charactenstics, such as type of degree and years of teaching expenence (Nye, Konstantopoulos, \& Hedges, 2004, Rockoff, 2004, Palardy \& Rumberger, 2008, Wayne \& Youngs, 2003), these two attributes have been the predominant critena used to evaluate and compensate teachers in both U S and Chinese educational systems This is reflected in both countries' uniform teacher salary schedules, which differentiate solely based on degree earned and number of years of teaching experience This troubled state of teacher evaluation has been critıcized as "a glanng, and largely ıgnored, problem in public educatıon" and evaluation has become a "superficial, capricious, and often meanıngless exercıse" (Keller, 2008, p 8) Without a robust understandıng about what contributes to teacher quality, however, the critıcal decisions regardıng whom to hire, whom to retain, and what to include in teacher professional development can only be made on the quicksands of untested intuition and experience This is why a deeper understanding of teacher effectiveness is critical to human resources administration, to bulding and supportıng human capital in schools and districts, and ultımately to students' opportunities to learn

\section{Teachers Matter}

A multitude of studies conducted in the United States have documented that teacher quality has a significant ımpact on student achievement (e g , Palardy \& Rumberger, 2008, Rockoff, 2004, Stronge, Ward, Tucker, \& Hindman, 2008, Stronge, Ward, Tucker, \& Grant, 
In press). Findıngs about teacher effectıveness have been remarkably consıstent, statıng "that teachers have large effects on student achievement, that the measures of effectiveness are stable over time, and that the effects teachers have are on an order of magnitude which dwarfs the effects associated with curriculum, staff development, restructuring, and other types of educational interventions" (Mendro et al., 1998, p. 1). In addition, it is argued that varying levels of student achievement due to differences among teachers is substantial in comparison to variances among schools. Much of the disparity in teacher quality, surprisingly, exists withın rather than between schools (Nye et al., 2004; Rıvkin, Hanushek, \& Kain, 2005). The teacher a student has within a school matters more than the school the student happens to attend

Durıng the last decade, many researchers have explored the value-added effects ${ }^{2}$ of a partıcular school or teacher, using sophistıcated statıstıcal models involving longitudinal data on student achievement (e g., Munoz \& Chang, 2007, Rockoff, 2004, Rowan, Correntı, \& Miller, 2002;). These data analysis methods have the advantage of removing the effects of factors not controlled by schools, such as prior student achievement and socioeconomic status, thereby providing more accurate estimates of school or teacher effectiveness. This statistical modeling has taken a number of forms (e.g., hierarchical linear modeling, standard ordinary least squares, or statistical mixed-model methods), each generating different

\footnotetext{
${ }^{2}$ Value-added assessment is a statıstical system that removes the effects of factors not controlled by schools (such as prior student achievement and socioeconomic status) and, thereby, provides more accurate estımates of school or teacher effectiveness on student academic growth over time Value-added assessment is designed based a premise that effective schools/teachers bring about student academic growth in excess of that found with ineffective schools/teachers, and this growth is causally attributed to schools or teachers instructing the students (Betebenner, 2009) An integral part of value-added methods is a massive, longitudinally merged database linking student outcomes to the schools and systems in which they are enrolled, and to the teachers to whom they are assigned, as the students transition from grade to grade
} 
magnitudes of teacher effects (Goldhaber \& Brewer, 1997; Palardy \& Rumberger, 2008;

Rowan et al., 2002). All of these studies conclude, however, that teachers matter. Teacher quality is the most significant factor impacting student learning in schools.

To illustrate, Rowan et al. (2002) found that teachers account for 10-20\% of the total variability in gains in students' achievement test scores. Bembry and colleagues (1998) also found that teachers have significant effects on student achievement, and these effects (either positive or negative) are cumulative over time. Wright, Horn, and Sanders' (1997) longitudinal, multivariate analysis of student achievement gains revealed that teacher effects are dominant factors, while the effects of classroom context variables, such as heterogeneity among students and class sizes had relatively little influence. Teacher effectiveness has been proven consistently to be the most significant school-related variable that has an impact on student learning outcomes (Hattie, 2003; 2009).

Variability of Effectiveness Across Teachers

Research results also indicate that there is a fair amount of variability across teachers in terms of their effectiveness in improving student achievement. Using data from the Tennessee Class Size Experiment (also known as Project STAR, a project that randomly assigned students and teachers to its participant samples), Nye et al. (2004) found that variance in student academic learning due to differences among teachers is substantial in comparison to the differences among schools. These findings suggest that the difference in achievement gains between having a 25 th percentile teacher (an ineffective teacher) and a 75th percentile teacher (an effective teacher) results in more than one-third of a standard deviation (0.35) of difference in achievement scores in reading and almost half a standard 
deviation (0.48) in mathematics. Similarly, the difference in achievement gains between having a 50th percentile teacher (an average teacher) and a 90th percentile teacher (a very effective teacher) is about one-third of a standard deviation (0.33) in reading and slightly less than half a standard deviation (0.46) in mathematics. These researchers determined that the effect of one standard deviation of change in teacher effectiveness on student achievement is larger than student achievement gains that result from reducing class size from 25 to 15 students. Their study also found that variation in student socio-economic status (SES) cannot explain differences in teacher effectiveness within schools. This implies that an effective teacher is effective with all students, regardless of their SES background; conversely, an ineffective teacher is ineffective with all students. These findings regarding teacher quality and its impact on student achievement are supported by many other studies (see, for example, Haycock, 1998; Heistad, 1999; Jordan, Mendro, \& Weerasinghe, 1997; Leigh, n.d., Mendro, 1998; Munoz \& Chang, 2007; Rivkin, Hanushek, \& Kain, 2005; Webster \& Mendro, 1997). Compared to the array of findings available in the United States, the empirical research conducted in China that has examined the statistical power of teacher effects is scarce. Lai's (2005) dissertation study involved a partial random assignment of students to different middle schools. Inclusion in the study's sample was based on a student's residence zone and application, but was independent of his/her characteristics and family background. The study was made possible due to a reform effort initiated by the educational bureau in Beijing. Results revealed that effective teachers matter in China as well. Having more high quality teachers significantly increased students' achievement scores in all subject areas. A one percent increase in the number of high quality teachers at the school studied increased 
students' overall scores by 0.14 to 0.21 of a standard deviation, or 2.73 to 5.67 percentile points. It also led to a $3.5 \%$ to $10.5 \%$ increase in the chances that participating students passed the high school entrance exam.

In a nutshell, studies completed to date in the U.S. and China have found that teachers differ in their performance to enhance student learning. Despite differing methodological controls used and populations tested, researchers in both countries seemed to agree that the impact of teachers upon student achievement is substantial.

\section{What Makes a Teacher Effective?}

Given abundant and convincing research evidence that teacher effectiveness matters and that teachers vary widely in their effectiveness, it would be useful to discern the factors that cause these differences. Empirical studies typically address this issue by examining two types of data: teachers' characteristics that are easily measurable and instructional techniques that they use in their classrooms (e.g., Munoz \& Chang, 2007; Palardy \& Rumberger, 2008; Stronge et al., 2008). However, these studies tend to reach mixed conclusions when examining the impact of specific teacher characteristics and practices upon student achievement. This inconsistency in research findings indicates that much is still to be learned about what constitutes teacher effectiveness.

Presage teacher characteristics. Presage variables are "properties of teachers that can be assumed to operate prior to, but also to have an influence on, the interactive phase of teaching" (Rowan et al., 2002, p. 1538). The most widely studied presage variables include certification status, teaching experience, content knowledge, degree, coursework, verbal skills, subject-matter knowledge, academic achievement, and the prestige ratings of teachers' 
undergraduate institutions. Generally, both U.S. and Chinese studies have found that these characteristics are associated with only small differences in student achievement (e.g., Lai, 2005; Heistad, 1999; Hanushek, Kain, \& Rivkin, 1998; Munoz \& Chang, 2007).

However, teachers vary significantly in how much they appear to influence student achievement. As stated earlier, little of this variation can be attributed to easily measureable characteristics such as certification, years of experience, and highest degree received. Thus, most teacher effectiveness is probably attributable to unobserved differences in instructional methods and/or professional beliefs.

Instructional practices. Instructional practices are examples of "process variables" (Rowan et al., 2002), which are defined as "properties of the interactive phase of instruction-that is, the phase of instruction during which students and teachers interact around academic content" (p. 1538). Based upon a synthesis of over 500,000 studies of student achievement, Hattie (2003) suggested that teachers account for $30 \%$ of student achievement variance. And it is estimated that only about $3 \%$ of the contribution teachers make to student learning is associated with teacher experience, educational level, certification status, and other readily observable characteristics. The remaining $97 \%$ of teachers' effects on student achievement are associated with intangible aspects of teacher quality that defy easy measurement, such as dispositions, beliefs, and classroom practices (Goldhaber, 2002). Numerous studies and literature reviews have begun to focus upon identifying the classroom practices of effective teachers (See, for example, Allington, 2002; Darling-Hammond, 2000; Rowan et al., 2002; Schacter \& Thum, 2004; Stronge, 2007; Stronge, Ward, Tucker, \& Hindman, 2008). Table 1 summarizes the findings of two literature reviews conducted by 
Table 1. Impact of Teacher Practices on Student Achievement

\begin{tabular}{|c|c|c|}
\hline Variables & Effect Size & Source of Influence \\
\hline Providing formative evaluation & 90 & Teacher \\
\hline Acceleration & .88 & School \\
\hline Teacher clarity & 15 & Teacher \\
\hline Feedback & 73 & Teacher \\
\hline Teacher-student relationships & 72 & Teacher: \\
\hline Meta cognitye strategies & 69 & Tedeher \\
\hline Students' prior achievement & .67 & Student \\
\hline Not 1 oeling students & 61 & Teacher \\
\hline Problem-solving instruction & 61 & Teacher \\
\hline Drect instruction & 59 & Teacher \\
\hline Mastery leaming & 58 & Teacher \\
\hline Concept mapping & 57 & Teacher \\
\hline Socioeconomic status & .57 & Home \\
\hline Class environment & .56 & Teacher \\
\hline Challenge level of learning & 56 & Teacher \\
\hline goals & & \\
\hline Peer tutoring & .55 & Teacher \\
\hline Parental involvement & .51 & Home \\
\hline Expectations & .43 & Teacher \\
\hline Matching students' learning & .41 & Teacher \\
\hline styles & & \\
\hline Cooperative learning & .41 & Teacher \\
\hline Advance organizers & 41 & Teacher \\
\hline Highen cognitive level & 46 & Teacher \\
\hline Peer effects & .38 & Student \\
\hline Mime on task & 38 & Teacher \\
\hline Compure-assisted instruction & 37 & Teacher \\
\hline Frequent testing/ Effects of & & Teacher \\
\hline Homework & 29 & Teacher \\
\hline School aims \& policies & .24 & School \\
\hline Affective attributes of students & .24 & Student \\
\hline Finances & .23 & School \\
\hline Individualization & 23 & Teacher \\
\hline Teaching test-taking and & 22 & Teacher \\
\hline Coaching & & \\
\hline Physical attributes of students & .21 & Student \\
\hline Personality & .19 & Student \\
\hline Family structure & .17 & Home \\
\hline Ability grouping & .18 & School \\
\hline $\begin{array}{l}\text { Reducing class size from } 25 \text { to } \\
13\end{array}$ & .13 & School \\
\hline Teacher subject matter & .09 & Teacher \\
\hline knowledge & & \\
\hline Student control over learning & 04 & Teacher \\
\hline Retention & -.16 & School \\
\hline Television & -.18 & Home \\
\hline
\end{tabular}


Hattie $(2003 ; 2009)$ which looked at the influence of variables related to student achievement.

The elements highlighted in the table are descriptions of classroom-level instructional practices and their corresponding effect sizes upon students' learning. This table indicates a more remarkable impact by teacher practices on student academic achievement than most factors not related to teacher classroom instruction.

Teacher dispositions and beliefs. Teacher dispositions and beliefs are two other variables related to student achievement that are not readily measurable. Nevertheless, they play significant roles in teachers' performance. When exemplary teachers were asked to report two strengths they possess, the most frequently mentioned strengths included being hard-working and dedicated; possessing excellent communication skills; being enthusiastic and energetic; and being caring and kind (Carter, 2003). Caring (Walls, Nardi, von Minden, \& Hoffman, 2002, Lumpkin, 2007), self-efficacy (Goddard, Hoy, \& Hoy, 2004; Hoy, Tarter, \& Hoy, 2006), and enthusiasm (Kunter et al., 2008; Patrick, Hisley, Kempler, \& College, 2000) are just a few examples of teacher characteristics that have been demonstrated to influence both cognitive and affective learning.

In particular, effective teachers are described as warm, friendly, and caring. Conversely, ineffective teachers often are said to create a tense classroom and are described as cold, abusive, and uncaring (Walls, Nardi, von Minden, \& Hoffman, 2002). Classroom observations often reveal that effective teachers demonstrated more respect and caring for students than did less effective teachers (Stronge et al., 2008). Effective teachers use care and respect to build relationships with their students that are conducive to academic learning. When students perceive that their teachers care about them, they respond by "optimizing their 
commitment to learning and putting forth greater efforts to reach their potential" (Lumpkin, 2007, p. 160). In addition, researchers found positive associations between student achievement and three types of teacher efficacy-related beliefs: academic emphasis ( 1 e , a press for student achievement), faculty trust in students and parents, and teachers' collective efficacy beliefs about the school system (Hoy, Tarter, \& Hoy, 2006) Teacher interest or motivation is another significant factor in classroom success Teacher interest typically is expressed in a range of teacher behaviors that are perceived to be conducive to student learning, such as enthusiasm in content area taught, interest about students' personal and developmental needs, participation in content-related activities outside of class time, and displaying value and emotion for students (Long \& Hoy, 2006). Individually, those teacher personality traits may not be strong predictors of student learning outcomes. However, when they are combıned together into a larger category of "non-cognitive skills," they can help to predict whether a teacher is effectıve in a classroom (Rockoff, Jacob, Kane, \& Staiger, 2008)

Summary Despite extensive efforts to explain effective teaching, there are comparatıvely few clear answers to the questıon of how effectıve and ineffectıve teachers differ- and few clear indicators as to how effective teachers develop (Redfield, 2000) The extant empirical research has been particularly effective in estimating the magnitude of teachers' effects on student learning, as well as identifying higher- and lower-performing teachers. This research is also helpful when comparing teachers' instructional strategies and personality characteristics. Nevertheless, these lines of research do not explain differences in teacher quality in terms of teachers' actions in their classrooms and thoughts about their teaching The next stage of research about teacher effectiveness must go inside classrooms to 
develop deeper understanding of how highly effective teachers manage the complexities of teaching, and how they interact with students to help them learn. As one research team reported:

The time has come to move beyond variance decomposition models that estimate the random effects of schools and classrooms on student achievement. These analyses treat the classroom as a black box, and although they can be useful in identifying more and less effective classrooms, and in telling us how much of a natural variation in classroom effectiveness can make to student achievement, variance decomposition models do not tell us why some classrooms are more effective than others...We would argue that future large-scale research on teaching move to directly measuring instructional conditions inside classrooms, assessing the implementation and effectiveness of deliberately designed instructional interventions, or both. (Rowan et al., 2002, pp. 1554-1555)

If we are to understand how teachers impact student learning, we must open the black box of the classroom and peer inside.

\section{Statement of the Problem}

The problem investigated in this study is what makes a teacher effective in the cultural settings of the United States and China. Distinctive teaching cultures are formed and nurtured in specific educational systems (Stigler \& Hiebert, 1999). Teaching practice, as a cultural action, occurs in specific cultural settings and also evolves in ways that can reflect the underlying cultural values advocated and nurtured by the wider society (Li \& Shimizu, 2009; Leung, 1995). The U.S. and China - two nations that are drastically different in 
demographics, history, political systems, and socio-economic status — also differ dramatıcally in teaching systems and practıces

Compared with the abundance of research done in the US, the field of teacher effectıveness is stıll largely uncharted in China, although it is gaining increasing attention Earlier studies (e g, Hiebert et al, 2003, Huang \& Leung, 2004) identıfied a salient feature of classrooms in Confucian culture as the dominance of the teacher in the teaching and learning process However, whole-class direct instruction, 1 e , lectunng, is not typically associated with teacher effectiveness in U S studies Lecture often is criticized for its apparent assumptıons that students are passive receivers in the process of learnıng, and for emphasizıng learnıng at lower cognitıve levels Yet, contrary to some contemporary Western educatıonal beliefs, high-quality teaching and learning and actıve student engagement can stıll occur in teacher-controlled classrooms, even when the class size is large (Hıebert et al, 2003, Huang \& Leung, 2004) A cross-culture study could contribute specifically to our understandıng of Chınese teachers' effectıveness, uncovenng possible simılanties to and differences from teacher effectıveness in the U S, thus, deepenıng our understanding of how culture may influence thıs ımportant aspect of teacher performance Findıngs about teacher effectiveness in understudied areas of the world can shed new light on the teacher effectiveness construct

This study was based on the fundamental premıse that strong teaching by talented teachers is at the heart of educational quality, and that understanding the elements of good teaching requires thorough exploration of both the practices and the professional thinking of exemplary teachers It yielded cross-case analyses of teachers in the Unıted States and China 
who have won national awards for their teaching. It generated these findings from interviews with and observations of the teachers, focusing on the teachers' beliefs about and patterns of teaching in their respective classrooms.

\section{Statement of Purpose}

This study built upon Stronge's (2007) framework of teacher quality, and incorporated conceptual frameworks developed in parallel by Chinese researchers on teacher effectiveness (e.g., Bai, 2000; Cui \& Wang, 2005). Synthesizing findings of studies on teacher effectiveness that were conducted across several decades, Stronge (2007) conceptualized key qualities and behaviors of effective teachers. His framework includes six domains: 1) prerequisites for effective teaching; 2) the teacher as a person; 3) classroom management and organization; 4) planning and organizing for instruction; 5) implementing instruction; and, 6) monitoring student progress and potential. Several Chinese scholars (Cui, 2001; Cui \& Wang, 2005; Sun, 2004) also explored the concept of teacher effectiveness and developed corresponding theoretical frameworks, although most of those efforts were based on conventional wisdom rather than on the evidence generated by empirical studies. Nonetheless, the framework proposed by Cui and Wang (2005) also is comprised of six major domains, with substantial overlap with Stronge's framework: 1) developing an environment that is conductive to learning; 2) studying and understanding students; 3 ) clarifying goals and organizing learning content; 4) providing varied learning opportunities; 5) helping students learn how to learn; and, 6) continuous reflection and innovation on instruction. The supporting literature for this study was grounded in a broad review of research that has explored the qualities and behaviors of effective teachers. This study sought 
evidence of these qualities in practice across multiple teaching contexts and, eventually, across two quite different educational cultures. Specifically, the study explored U.S. and Chinese teachers in an effort to discover similarities and differences in their teaching behaviors and dispositions. Further, the study was designed with the intent of developing a richer understanding of teacher effectiveness through cross-cultural case studies of the practices and beliefs of selected U.S. and China teachers who have received national awards for their teaching.

\section{Research Questions}

This study addressed the following research questions:

1. What are the similarities and differences between selected award-winning United States and China teachers in their instructional practices?

a) What types of instructional activities are used by selected award-winning U.S. and China teachers?

b) How are cognitive levels, based on Bloom's revised taxonomy (Anderson \& Krathwohl, 2001), represented in these teachers' classrooms?

c) To what degree is learning teacher-directed in the classrooms of selected award-winning U.S. teachers and China teachers?

2. How are selected national award-winning United States and China teachers' classroom practices - other than instructional activities - similar and different (such as their classroom management strategies)?

a) What are the student engagement levels in the classrooms of selected awardwinning U.S. teachers and China teachers? 
b) What classroom management strategies are implemented by selected awardwinning U.S. teachers and China teachers?

3. What are the similarities and differences in professional thinking between teachers in the U.S. and China?

a) How do these teachers reflect on their practices, particularly about their relationships with students, classroom environment, instructional planning, instructional strategies, differentiation, and assessment and evaluation of students' learning?

b) What are the selected teachers' perceptions of why their practice merited recognition with a national award?

\section{Significance of the Study}

Strengthening quality in education is about enhancing learning opportunities and results for students. One of the challenges perennially facing educators and societies is the need to provide increasing numbers of young people with opportunities to reach levels of skill and competence once thought to be reachable by only a few. While various policy initiatives may offer promises of improving education, nothing is more fundamentally important to improving schools than improving the teaching that occurs every day in classrooms (Darling-Hammond, 1996). This requires a more thorough understanding of what effective teachers do that results in being recognized nationally, and how these teachers reflect on their daily experiences of interacting with students within classroom. This dissertation study, by observing in the classrooms of great teachers and soliciting their perceptions via interviews, can contribute to this type of understanding. Findings about great 
teachers' practices and beliefs can then be grounded in knowledge from existing literature, building a composite, operationalized sketch of the elusive concept of teacher effectiveness, as it is framed and enacted by highly effective teachers.

\section{Definitions of Key Terms}

Assessment of student learning: Gronlund (2006) described assessment as "a broad category that includes all of the various methods for determining the extent to which students are achieving the intended learning outcomes of instruction" (p. 3). Assessment of student learning can emerge in various formats, such as teacher observation, oral questioning, journal entries, portfolio entries, exit cards, skill inventories, homework assignments, project products, student opinions, interest surveys, criterion-referenced tests, or norm-based tests.

Educational culture: Educational culture refers to frameworks of expectations, attitudes, values, beliefs, and practices regarding how to teach and learn successfully, which are oftentimes taken for granted by groups residing in a specific culture (Jin \& Cortazzi, 2006).

Classroom management: Classroom management includes actions taken by teachers to establish order, engage students, elicit student cooperation, with an ultimate purpose to establish and maintain an environment conducive to instruction and learning (Emmer \& Stough, 2001).

Instructional delivery: Instructional delivery is a process in which teachers apply a repertoire of instructional strategies, to communicate and interact with students around academic content, and to support student engagement. 
Instructional practices: Instructional practices are examples of "process variables"

(Rowan et al., 2002), which are defined as "properties of the interactive phase of instruction - that is, the phase of instruction during which students and teachers interact around academic content" (p. 1538).

Learning environment: Learning environment consists of both instructional and noninstructional interactions (either teacher-student or student-student interactions) that occur in a classroom. It also refers to the activities and tasks used to establish a respectful, safe, and intellectually stimulating classroom environment and a culture for learning (Hindman, Grant, \& Stronge, 2010).

Planning of instruction: When a teacher plans his/her instruction prior to each lesson, unit, semester, or school year, he/she is preparing the content of instruction, selecting teaching materials, designing the learning activities and grouping methods, deciding on the pacing and allocation of instructional time, and identifying methods to assess student new learning.

Presage (or a priori) teacher characteristics: Presage variables are "properties of teachers that can be assumed to operate prior to, but also to have an influence on, the interactive phase of teaching" (Rowan et al., 2002, p. 1538). Some examples of presage variables include certification status, teaching experience, content knowledge, degree, coursework, verbal skills, subject-matter knowledge, academic achievement, and the prestige ratings of teachers' undergraduate institutions.

Teacher Effectiveness: Teacher effectiveness can be defined in many ways including, teacher behavior (warmth, civility, clarity), teacher knowledge (of subject matter, of 
pedagogy, of students, and/or of curriculum), teacher beliefs, and teacher qualifications (educational background, licensure type, coursework). In this study, teacher effectiveness is defined by the six qualities in Stronge's (2007) teacher effectiveness model.

Teacher knowledge: Teacher's professional knowledge encompasses knowledge of subject matter - an understanding of subject facts, concepts, and principles. However, in addition to the knowledge about the subject content, it also includes the knowledge about curriculum, pedagogy, and the developmental needs and academic readiness of the students.

Teacher dispositions and beliefs: Teacher dispositions and beliefs refer to values and attitudes that teachers hold toward their work, their students, their subject matter, and their role and responsibilities. Furthermore, they also refer to teachers' behavior in the classrooms that enact those beliefs (Pajaras, 1992).

Teaching: Teaching involves activities that impart knowledge and skills. It a complex form of work, characterized by uncertainty, intangibility, and ambiguity, and requiring a high degree of initiative, thought, judgment and skill to do well (Ingersoll, 2007).

\section{Delimitations and Limitations of the Study}

This study will focus only on selected national award-winning teachers in the United States and China. The sample size will be relatively small and the sample selection is purposeful to include teachers with diverse socio-demographic characteristics. There are three limitations of the study should be recognized:

Firstly, this study uses winning a national award as the major criterion to select highly effective teachers. This process can be flawed since teachers probably receive awards for 
reasons other than exhibiting the qualities in Stronge's framework, which is the operational definition of teacher effectiveness in this study (2007).

Secondly, although it is believed that the substantive understanding of the phenomenon (i.e., teacher effectiveness) that will be generated by this study should be replicable by other studies examining highly effective teachers in the United States and China, it is possible that the relatively small size used in this study limits the generalizability of the findings. In addition, this study only considered elite teachers who received national awards for their teaching in China and the United States. Therefore, the findings of this study may not be typical in all teachers and, thus, not generalizable to regular teachers in these two countries.

Thirdly, the observation and interview data were collected from a single school visit, lasting a maximum of one day per teacher, which may not have allowed the researcher to build a rapport with the participants. Furthermore, the observation data were limited by the range of options on the observation instrument.

\section{Assumptions}

In this study, the researcher assumes that national award-winning teachers in the United States and China are, in fact, effective teachers. It also is assumed that the sample selected in this study is representative of other national award-winning teachers in the United States and China, respectively. 


\section{CHAPTER 2}

\section{LITERATURE REVIEW}

\section{Why does teacher effectiveness matter?}

Teachers, as the most powerful school-related factor, matter massively to student learning outcomes and school performance. Indeed, among the factors within the control of school systems, teachers offer the greatest opportunity for improving the quality of life of students. As noted in How the World's Best-Performing School Systems Come Out on Top, an international study comparing data from the Organization for Economic Co-operation and Development's (OECD) Programme for International Student Assessment (PISA), "The quality of an education system cannot exceed the quality of its teachers" (Barber \& Mourshed, 2007, p. iii).

If we want to improve the quality of our schools and positively affect the lives of our students, we must change the quality of our teaching. This is our best hope to systematically improve education. We can reform curriculum but, ultimately, it is teachers who implement it; we can provide professional development on new instructional strategies but, ultimately, it is teachers who deploy them; we can focus on data analysis of student performance but, ultimately, it is teachers who produce the results we are analyzing.

The research suggests that, "while schools have powerful effects on student achievement differences, these effects appear to derive most importantly from variations in teacher quality" (Hanushek et al., 1998, p. 1). In other words, heterogeneity in teacher effectiveness dominates school quality differences and is a significant source of student achievement variations. Furthermore, there is more variability in teacher quality across 
classrooms than across schools. This chapter provides an overview of what literature in both of the United States and China found about the impact of teachers on student and school performance, and what qualities constitute teacher effectiveness.

\section{Teacher Effectiveness and Student Achievement}

The following bullets illustrate how the quality of teachers influences the most essential indicator of the well-being of an education system—student academic achievement:

- Teacher effectiveness is the dominant factor influencing student academic growth (Sanders \& Rivers, 1996; Wright, Horn, \& Sanders, 1997).

- A post hoc analysis of achievement test gains indicated that the gains made by students taught by exemplary teachers outpaced expected levels of growth (Allington \& Johnston, 2000).

- Value-added estimates of teacher quality are not correlated to student initial test scores. Highly effective teachers were generally effective with all student achievement levels. (Sanders \& Rivers, 1996). In other words, an effective teacher performs well among both low- and high-ability students (Aaronson, Barrow, \& Sander, 2007).

- Ineffective teachers were found to be ineffective with all students, regardless of their prior achievement level. The average teachers facilitated achievement gains with lower achieving students, but not higher student achievers (Sanders \& Rivers, 1996).

These sobering findings are derived from assessments of the teacher's measurable impact on student achievement using value-added methodologies. For the last several years, 
numerous researchers have explored the "value-added effects" of a particular school or teacher through the use of sophisticated statistical models involving longitudinal data on student achievement These value-added methods have the advantage of removing the effects of factors not under the control of the school, such as proor student achievement and socioeconomic status, and thereby providing more accurate estımates of school or teacher effectiveness This statıstıcal modeling approach has taken a number of forms and each generated differentıal statıstıcal power of teacher effects (Palardy \& Rumberger, 2008, Rowan et al , 2002) However, final conclusion of all these value-added studies is that teachers matters and teacher quality is the most signıficant schooling factor impactıng student learnıng This effect is not just of statıstıcal significance, more importantly, it is of practical significance ${ }^{3}$ Consıder the outcomes of teacher effectiveness on student achievement drawn from a samplıng of studies presented in Table 2

Table 2 Summary Findings of Teacher Effects on Student Achievement from Selected Studies

\begin{tabular}{ll}
\hline \multicolumn{1}{c}{ Study } & \multicolumn{1}{c}{ Key Findings } \\
\hline $\begin{array}{l}\text { Sanders \& Rivers } \\
\text { (1996) }\end{array}$ & $\begin{array}{l}\text { Teacher effect on student achievement is cumulatıve With an } \\
\text { even start at the second grade, differences in student } \\
\text { achievement of } 52 \text { to } 54 \text { percentile points were observed as a } \\
\text { result of two extreme teacher sequences after only three years } \\
\text { (low-low-low sequence versus high-high-high sequence) }\end{array}$ \\
\hline Sanders \& Rivers & $\begin{array}{l}\text { Teacher effects on student achievement have been found to be } \\
\text { both cumulatıve and residual Subsequent assignment of } \\
\text { effective teachers cannot offset the effects of prior ineffective } \\
\text { ones } \\
\text { The residual effects of both effective and ineffective teachers } \\
\text { are measurable two years later, regardless of the effectiveness } \\
\text { of subsequent teachers }\end{array}$ \\
\hline
\end{tabular}

\footnotetext{
${ }^{3}$ In educational research, statistical significance is used to determine if certain observed differences exıst beyond a chance occurrence However, statıstical significance does not determine the magnitude of the differences or the likelihood of obtaining simular results in the future On the other hand, practical significance refers to the fact that the research findings can be viewed as information of value to teachers, school administrators, polıcy makers, and others who are involved in day-to-day educational practıce (Gall, 2001) Practical significance indicates that results are of a magnitude that would make a real-world difference
} 


\begin{tabular}{|c|c|}
\hline $\begin{array}{l}\text { Hanushek, Kain, \& } \\
\text { Rivkin (1998) }\end{array}$ & $\begin{array}{l}\text { Lower bound estimates suggest that variations in teacher } \\
\text { quality account for at least } 7.5 \% \text { of the total variation in } \\
\text { measured achievement gains, and there are reasons to believe } \\
\text { that the true percentage is considerably larger. }\end{array}$ \\
\hline $\begin{array}{l}\text { Mendro, Jordan, } \\
\text { Gomez, Anderson, \& } \\
\text { Bembry (1998a, } \\
\text { 1998b). }\end{array}$ & $\begin{array}{l}\text { The research findings in these studies on teacher effectiveness } \\
\text { found not only that teachers have large effects on student } \\
\text { achievement, but also the measures of effectiveness are stable } \\
\text { over time. } \\
\text { Ineffective teachers have negative longitudinal effects on } \\
\text { student learning. If the students have a less effective teacher in } \\
\text { the first year and the highest level teachers for remaining years, } \\
\text { their achievement could never exceed that of the students who } \\
\text { have been assigned with effective teachers for all the years. }\end{array}$ \\
\hline $\begin{array}{l}\text { Nye, Konstantopoulos, } \\
\text { \& Hedges (2004) }\end{array}$ & $\begin{array}{l}\text { - If primary grade teacher effects are normally distributed, the } \\
\text { difference in achievement gains between having a } 25 \text { th } \\
\text { percentile teacher (a not so effective teacher) and a } 75 \text { th } \\
\text { percentile teacher (an effective teacher) is over one third of a } \\
\text { standard deviation in reading and almost half a standard } \\
\text { deviation in mathematics. } \\
\text { The difference in achievement gains between having a 50th } \\
\text { percentile teacher (an average teacher) and a 90th percentile } \\
\text { teacher (a very effective teacher) is about one third of a } \\
\text { standard deviation in reading and somewhat smaller than half a } \\
\text { standard deviation in mathematics }\end{array}$ \\
\hline Rockoff (2004) & $\begin{array}{l}\text { Drawing from a data set of approximately } 10,000 \text { students, the } \\
\text { researcher found that a one-standard-deviation increase in } \\
\text { teacher quality raises student test scores by approximately } 0.1 \\
\text { standard deviations in reading and math on nationally } \\
\text { standardized distributions of achievement. }\end{array}$ \\
\hline $\begin{array}{l}\text { Rivkin, Hanushek, \& } \\
\text { Kain (2005). }\end{array}$ & $\begin{array}{l}\text { Differences between teachers explained about } 15 \% \text { of the } \\
\text { measure variance in student test scores. } \\
\text { In both reading and mathematics, a one standard deviation } \\
\text { increase in teacher quality for a grade raises student } \\
\text { achievement by about one-tenth of standard deviation. }\end{array}$ \\
\hline $\begin{array}{l}\text { Aaronson, Barrow, \& } \\
\text { Sander (2007) }\end{array}$ & $\begin{array}{l}\text { A standard deviation increase in teacher effectiveness over a } \\
\text { full year raises student math test scores by } 0.15 \text { standard } \\
\text { deviations. } \\
\text { Controlling for sampling error, a one standard deviation, one } \\
\text { semester improvement in math teacher quality raises student } \\
\text { math scores by } 0.15 \text { standard deviations. Thus, over two } \\
\text { semesters, a one standard deviation improvement in math } \\
\text { teacher quality translates into an increase in math achievement } \\
\text { equal to } 22 \% \text { of the average annual gain. } \\
\text { Estimates of teacher effects are relatively stable over time, } \\
\text { reasonably impervious to a variety of conditioning variables, } \\
\text { and do not appear to be driven by classroom sorting (i.e., } \\
\text { student/teacher assignment) or selective use of test scores. }\end{array}$ \\
\hline
\end{tabular}




\begin{tabular}{|c|c|}
\hline $\begin{array}{l}\text { Stronge, Ward, } \\
\text { Tucker, \& Hindman } \\
\text { (2008) }\end{array}$ & $\begin{array}{l}\text { Based on prediction models developed through the use of } \\
\text { regression analyses with third-grade teachers, most students' } \\
\text { actual achievement scores were within a close range of their } \\
\text { predicted scores. However, teacher effectiveness scores ranged } \\
\text { from more than a standard deviation above predicted } \\
\text { performance to more than a standard deviation below, } \\
\text { indicating a wide dispersion of teacher effectiveness. } \\
\text { Teachers who were highly effective in producing higher-than- } \\
\text { expected student achievement gains (top quartile) in one end- } \\
\text { of-course content test (reading, math, science, social studies) } \\
\text { tended to produce top quartile residual gain scores in all four } \\
\text { content areas. Teachers who were ineffective (bottom quartile) } \\
\text { in one content area tended to be ineffective in all four content } \\
\text { areas. }\end{array}$ \\
\hline Leigh, 2010 & $\begin{array}{l}\text { - Moving from a teacher at the } 25 \text { th percentile to a teacher at the } \\
\text { 75th percentile would raise test scores by one-seventh of a } \\
\text { standard deviation. Since a } 0.5 \text { standard deviation increase in } \\
\text { test scores is equivalent to a full year's learning, this implies } \\
\text { that a } 75 \text { th percentile teacher can achieve in three-quarters of a } \\
\text { year what a } 25 \text { th percentile teacher can achieve in a full year. } \\
\text { Moving from a teacher at the } 10 \text { th percentile to a teacher at the } \\
\text { 90th percentile would have even more dramatic effects, raising } \\
\text { test scores by one quarter of a standard deviation. This implies } \\
\text { that a teacher at the 90th percentile can achieve in half a year } \\
\text { what a teacher at the 10th percentile can achieve in a full year. }\end{array}$ \\
\hline $\begin{array}{l}\text { Stronge, Ward, } \\
\text { Tucker, \& Grant (In } \\
\text { press) }\end{array}$ & $\begin{array}{l}\text { - After controlling for variables such as class size, prior student } \\
\text { achievement and a host of individual student variables (e.g., } \\
\text { gender, ethnicity, socio-economic level, English Second } \\
\text { Language learners), the students residual gain scores (difference } \\
\text { between predicted and actual achievement levels) were } \\
\text { calculated. In reading, students taught by bottom quartile } \\
\text { teachers could expect to score, on average, at the } 21^{\text {st }} \text { percentile } \\
\text { on the state's reading assessment, whereas students taught by } \\
\text { the top quartile teachers could expect to score at approximately } \\
\text { the } 54^{\text {th }} \text { percentile. This striking difference, more than } 30 \\
\text { percentile points can be attributed to the quality of teaching } \\
\text { occurring in the classrooms during one academic year. Similar } \\
\text { results were reached for mathematics, with the students in the } \\
\text { bottom quartile teachers' classrooms scoring, on average, at the } \\
38^{\text {th }} \text { percentile; while students in the top quartile teachers' } \\
\text { classrooms scored at the } 70^{\text {th }} \text { percentile. In both reading and } \\
\text { math, there were no statistically significant differences in } \\
\text { student achievement levels at the beginning of the school year } \\
\text { between the top and bottom quartile teachers' classes. }\end{array}$ \\
\hline
\end{tabular}

Various studies have estimated how much of the variability of student achievement

can be explained by the quality of the teacher. To say that student achievement is variable

means that it is not the same across individual students. Variability provides a quantitative 
measure of the degree to which the academic achievement differs among students. The desire to understand what factors account for the variability in student academic performance plays a central role in educational research design (Gall, Gall, \& Borg, 2007). Figure 1 summarizes selected research studies regarding how much variability in student achievement can be attributed to the effectiveness of the teacher:

Figure 1. Student Achievement Accounted for by Teacher Effects

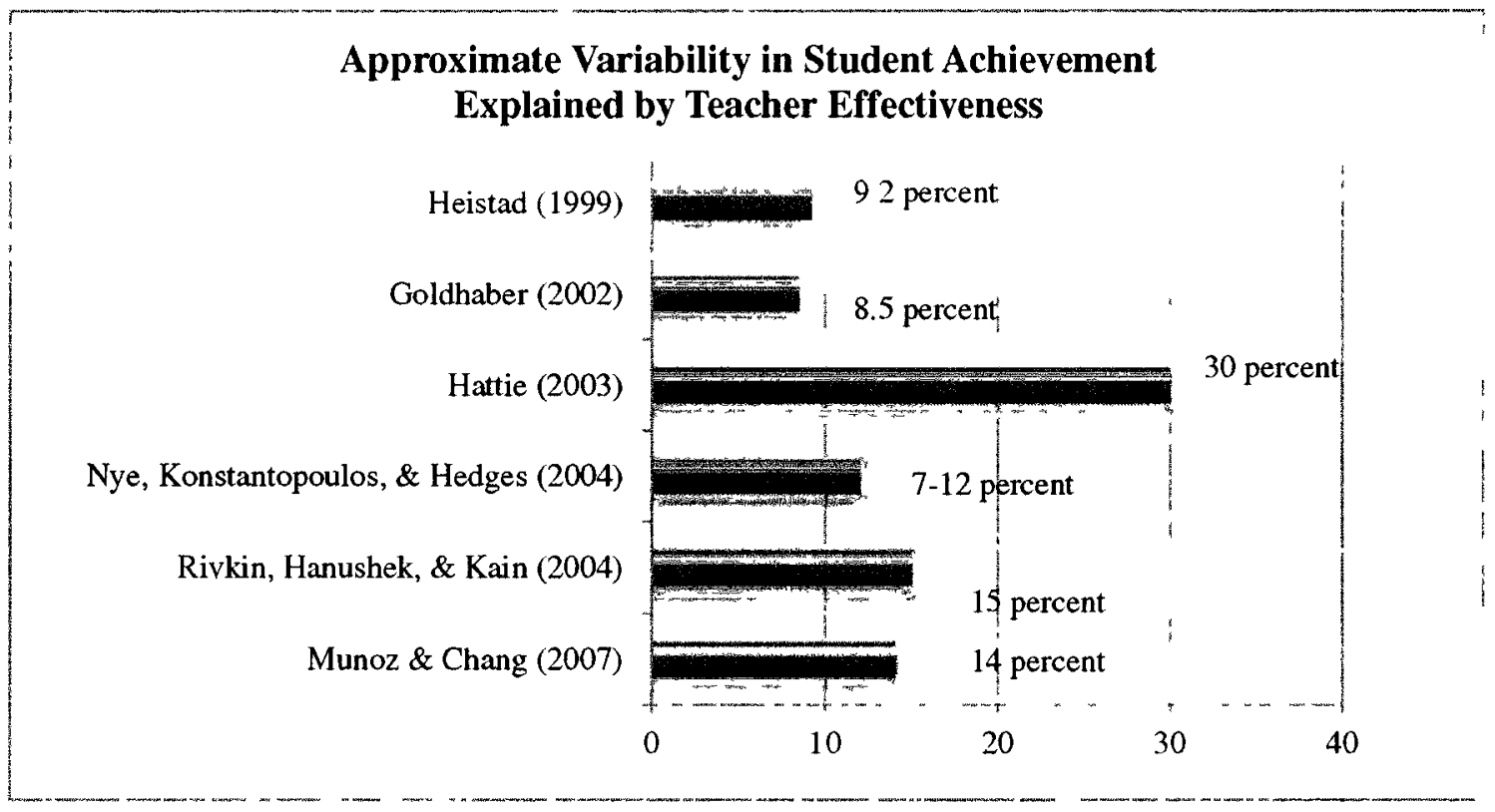

Compared to the abundant literature in the U.S., the empirical research conducted in China to examine the statistical power of teacher effects is scarce. In rural China, Park and Huannum (2001) discovered that approximately one quarter of the difference in student-tostudent mathematics and language achievement could be attributed to overall teacher differences. Lai's (2005) dissertation which used random assignment of students to different middle schools, which was possible due to the educational reform initiated by the government in Beijing, China, also examined how school and teacher characteristic affected students' test scores. Research findings revealed that the teacher matters. Having more high quality teachers significantly increased students' achievement scores in all subjects. The school with 
a one percent increase in the number of high quality teachers ${ }^{4}$ increased students' overall scores by 014 to 021 standard deviation of the overall test score, or 273 to 5.67 percentile points That also leads to a $35 \%$ to $105 \%$ increase in the chances of students passing the high school entrance threshold.

Findıngs from Laı's study also revealed that teacher effectiveness is moderated by student academic ability level, as measured by course grades and city-wide high school entrance exam test scores Teacher effects varied among students, being stronger for those with weaker academic performance. When student test scores were divided into quartıles, both positive and negative teacher effects were found to be larger for students in the lower range of the overall test score distribution, but were insignificant for students in the top quartile. The magnitude of teacher effects for students in the $25^{\text {th }}$ quartile was twice as strong as for students in the $50^{\text {th }}$ and more than three tımes as strong as for students in the $75^{\text {th }}$ quartile This means the students with lower academic performance in La1's study were more subject to teacher effects than their better-performing peers

\section{Teacher Effectiveness and School Improvement}

Across the globe, neither resources nor ambitious and well-intentioned reform efforts have answered the need for school improvement (Barber \& Mourshed, 2007). In an international study, Barber and Mourshed (2007) argued that substantial increases in spending and popular reforms - most noticeably, class-size reduction and decentralization of decisıon-making — have failed to budge student achievement much In contrast, high-

\footnotetext{
${ }^{4}$ In this study, the status of teacher quality was identıfied by a teacher's rank in an official evaluation, which links teacher quality to educational outcomes as measured by students' test scores This evaluation system took the following teacher charactenstics into account a teacher's former education level, trainıng, expenence, honors, opınion survey from headmasters, colleges, students, and parents, lecture skills
} 
performing school systems, such as those in Canada, Finland, Japan, New Zealand, and Singapore, maintained a strong focus on improving instruction in daily classroom because of its direct impact upon student learning. As an example supporting investment in classroom teachers, some high-performing East Asian countries found that mechanisms to encourage high levels of student achievement include ongoing professional development and the equalization of instructional resources - policies targeting classroom teachers (Akiba, LeTendre, \& Scribner, 2007).

The research findings indicating the magnitude of teacher effects are larger than schools effects shed light on the policy issue of educational resource allocation. Since the classroom teacher is a larger source of variance in student achievement than the school (Hanushek et al., 1998), policies focusing on teacher effects should be more promising than policies tinkering with school effects. Many school-level policies that attempt to improve achievement by substituting one school for another (e.g., school choice, charter school) or changing the structure of the schools themselves (e.g., whole school reform; reform on curriculum standards) have had disappointing results (Barber \& Mourshed, 2007; Nye, Konstantopoulos, Hedges, 2004).

It appears that few, if any, school-level reforms or improvement plans can bring forth the intended changes in student achievement unless they make a difference in teacher effectiveness. To illustrate, some expensive innovations, like the US $\$ 1.6$ billion Comprehensive School Reform, were found to be not cost-effective in engendering improved student academic performance (Gross, Booker, \& Goldhaber, 2009). In another instance, the effect of one standard deviation change in teacher effectiveness is larger than the effects of a 
costly reduction of class size from twenty-five to fifteen (Nye et al., 2004; Rivkin et al., 2005). Furthermore, school-level reform on instruction, without directly tackling the issue of classroom teacher effectiveness, generally has no detectable association with higher student achievement (Le, Lockwood, Stecher, Hamilton, \& Martinez, 2009). Given the undeniable influence of teachers on student success, Rockoff (2004) concluded, "raising teacher quality may be a key instrument in improving student outcomes" (p. 251). Similarly, Goldhaber (2006) posited that the effect of increases in teacher quality overrides the impact of any other educational investment, such as reductions in class size. In the private sector, human capital is generally defined as the "accumulated value of an individual's intellect, knowledge, experience, competencies, and commitment that contributes to the achievement of an organization's vision and business objectives" (Sigler \& Kashyap, 2008, p. 1). Extrapolating this idea to public education, the "business objective" is student achievement and future success, and "human capital" should refer to the knowledge and skill sets of teachers who interact with students every day in classroom. Not much advance could be accomplished in students learning and school performance unless were there a dramatic improvement in "what teachers know and are able to do - their talent level"' (Sigler \& Kashyap, 2008, p. 1).

\section{Teacher Effectiveness and Educational Equity}

All students deserve quality education, but equal access to quality education is jeopardized for students who are assigned to less effective teachers. Research around the globe has confirmed that teaching quality is characterized by great unevenness. There are dramatic differences in teacher quality within regions, communities, schools, and even within grades. In American public school systems, effective teachers are among the most inequitably 
distributed resources. Oftentimes disadvantaged poor, non-white, and low-achieving students have the least access to effective teachers (Haycock \& Crawford, 2008; Sigler \& Kashyap, 2008). The students who need the strongest instruction often are taught by teachers with the least experience and expertise (Boyd, Lankford, Loeb, \& Wyckoff, 2005; Lankford, Loeb, \& Wyckoff, 2002; Rothman, 2008). In addition, low income and minority students face higher teacher turnover and tend to be taught more frequently by beginning teachers (Hanushek et al., 2004; Rivkin et al., 2005; Scafidi, Sjoquist, \& Stinebrickner, 2008). Among 39 countries, the Unites States ranked $36^{\text {th }}$ in its ability to provide equal access to qualified math teachers for low- and high-SES students. In fact, $67.6 \%$ of high-SES students were taught by high qualification teachers compared with $53.2 \%$ for low-SES students, showing an opportunity gap of $14.4 \%$ which is significantly larger than the international average of $2.5 \%$ (Akiba et al., 2007).

Year after year, decade after decade, countless studies told us that on these measures, we didn't have a fair distribution of teacher talent. .... Poor children and black children were less likely to be taught by the strongest teachers and more likely to be taught by the weakest. (Gordon, Kane, \& Staiger, 2006, pp. 15-16)

A similar pattern of uneven distribution of teacher quality was identified in China. In China, recent research suggests that socio-economically disadvantaged, rural communities lack the resources needed to recruit, develop, and retain good teachers (Park, Wen, \& Wang, 2003). Evidence has established a connection between local economic status, such as village per capita income with the percentage of qualified teachers in a school (Park et al,, 2003). Similarly, research points to the unequal distribution of newly qualified teachers. Recent 
graduates of teacher training institutions are assigned disproportionately to township central schools, which tend to serve high-achieving students and students from families with high socio-economic status (Paine, 2003).

In a value-added study conducted by Bembry and her colleagues (1998), the researchers found through a bias analysis of the data that students with low achievement tend to be assigned to less effective teachers. Additionally, they discovered that uneven distribution of quality teachers is not a random or occasional occurrence, but a systemic bias. The cumulative effects of such a pattern of biased assignment of students to teachers partially explain the widening gap between the achievement of black and white student populations (Sanders \& Horn, 1997). Additionally, research indicated that between-teacher variance is always larger in low socio-economic (SES) schools (Nye et al., 2004). This suggests that the distribution of teacher effectiveness is much more uneven in low-SES schools than in highSES schools. Furthermore, the proportion of the total variance in student achievement gains accounted for by the teacher effect is higher in low-SES schools. Thus, it matters more which teacher a child receives in low-SES schools than it does in high-SES schools.

School policy on teacher quality can be an important lever for raising the achievement of low income students. In particular, successive assignment of good teachers can be a big step toward closing achievement gaps cross income groups (Rivkin et al., 2005). For all students of all achievement levels, teacher assignment sequences should be determined in a manner to ensure that no student is assigned to a teacher sequence (high effectiveness versus low effectiveness teachers) that will unduly diminish the student's academic achievement (Sanders \& Rivers, 1996). Based on the teacher effects estimates by Gordon, Kane and 
Staiger (2006), the average achievement difference between being assigned to a top quartile teacher and a bottom quartile teacher is 10 percentile points. Currently, the national blackwhite achievement gap in the United States is around 30 percentile points. African-American students and white students make comparable academic progress when they are assigned to teachers of comparable effectiveness (Sanders \& Horn, 1997). Since the teacher impact is cumulative, having a top quartile teacher for three to four years in a row would help substantially in closing the achievement gap. Rivkin and colleagues (2005) posited that high quality instruction throughout primary school could substantially offset disadvantage associated with low socio-economic background. The benefits of even access to effective teacher for all subgroups of students were evidenced by the highest-performance schools systems around the world, which were found consistently doing three things well: 1) they get the right people to become teachers; 2) they develop these people into effective instructors; and 3) they put in place systems and targeted support to ensure that every child is able to benefit from excellent instruction (Barber \& Mourshed, 2007, p.13).

\section{A Framework for Understanding Teacher Effectiveness}

Stronge (2007) presented a framework for six teacher qualities based on a metareview of the extant research on teacher effectiveness:

- Prerequisites for Effective Teaching, including characteristics such as a teacher's educational background, professional preparation, verbal ability, content knowledge, educational coursework, and teacher certification.

- Teacher as a Person, with an emphasis on a teacher's nonacademic interactions with students and professional attitude. 
- Classroom Management, with the purpose of establishing a classroom environment that is conducive to teaching and learning.

- Planning for Instruction, including the practices of maximizing the amount of time allocated for instruction, communicating expectations for student achievement, and planning for instructional purposes.

- Implementing Instruction, including the practices of using instructional strategies according to partıculars of students needs, understandıng the complexities of teachıng, using questioning techniques and supporting student engagement

- Assessing Student Progress, such as using homework and ongoing assessment to solicit data of student learning, providing meaningful feedback, and applyıng the findings of student learning outcomes to improve instruction.

This framework will be used to organize what extant research says about specific teacher characteristics.

Several Chinese scholars (Cui, 2001; Cui \& Wang, 2005; Sun, 2004) also explored the concept of teacher effectuveness and developed correspondent theoretical frameworks, although most of those efforts were based on conventional wisdom rather than on the evidence generated by empirical studies Nonetheless, the trameworks proposed by Chinese scholars have considerable overlaps Table 3 below provides an overview of the sımılarities among the reviews of effective teacher beliefs and practices in both the United States and China. 
Table 3. Comparison of Stronge's and Chinese Scholars' Theoretical Frameworks of Effective Teachers

\begin{tabular}{|c|c|c|c|}
\hline Stronge, 2007 & Bai, 2000 & Cui \& Wang, 2005 & Sun, 2004 \\
\hline \multicolumn{4}{|l|}{$\begin{array}{l}\text { Prerequisites of } \\
\text { Effective Teaching }\end{array}$} \\
\hline Teacher as a Person & $\begin{array}{l}\text { Reflective } \\
\text { Practitioner }\end{array}$ & $\begin{array}{l}\text { Study and understand } \\
\text { students; } \\
\text { Continuous reflection } \\
\text { and innovation on } \\
\text { instruction }\end{array}$ & \\
\hline Classroom & Classroom & Learning & Classroom \\
\hline Management & $\begin{array}{l}\text { Management and } \\
\text { Student Engagement }\end{array}$ & Environment & $\begin{array}{l}\text { Observation and } \\
\text { Management }\end{array}$ \\
\hline $\begin{array}{l}\text { Planning for } \\
\text { Instruction }\end{array}$ & $\begin{array}{l}\text { Instructional } \\
\text { Planning }\end{array}$ & $\begin{array}{l}\text { Clarify intended } \\
\text { learning outcomes } \\
\text { and organize learning } \\
\text { content }\end{array}$ & $\begin{array}{l}\text { Objectives of } \\
\text { Teaching and } \\
\text { Learning }\end{array}$ \\
\hline $\begin{array}{l}\text { Implementing } \\
\text { Instruction }\end{array}$ & $\begin{array}{l}\text { Effective Instruction } \\
\text { Models and Teacher- } \\
\text { student Interactions }\end{array}$ & $\begin{array}{l}\text { Learning } \\
\text { Opportunities }\end{array}$ & $\begin{array}{l}\text { Learning Activities } \\
\text { and Instructional } \\
\text { Delivery }\end{array}$ \\
\hline $\begin{array}{l}\text { Monitoring Student } \\
\text { Progress and } \\
\text { Potential }\end{array}$ & $\begin{array}{l}\text { Feedback and } \\
\text { Review }\end{array}$ & & $\begin{array}{l}\text { Monitoring of Both } \\
\text { Learning and } \\
\text { Teaching }\end{array}$ \\
\hline
\end{tabular}

\section{How Do Teachers' Background Qualities Affect Student Achievement?}

How do teachers' background qualities affect student achievement? Several lines of educational economic research provide some tentative answers to this question. The background characteristics that have been examined in the research literature include degrees, coursework, certification status, experience, verbal skills, subject-matter knowledge, academic achievement, and the prestige ratings of teachers' undergraduate institutions.

However the research literature has not produced consistent findings and no consensus has been reached regarding what aspects of teachers matter most. For instance, certain studies have found that teacher background characteristics are positively associated with student 
achievement (e.g., Goldhaber \& Brewer, 2000); others have found they are negatively related (e.g., Hanushek et al., 1997); and still others have found they are positively associated only in certain specific circumstances (e.g., Rowan et al., 2002).

In an extensive literature review, Hanushek (1997) synthesized the education production function research on the association between school resources (in terms of teacher qualifications) and student achievement. He found that the data assembled did not provide evidence of a strong and consistent relation between teacher characteristics (as a form of school resource) and student learning. On the other hand, a review conducted by Greenwald, Hedges, and Laine (1996) found that the relationship between school resource inputs and student outcomes are much more consistent and positive. In this study, resource variables that capture the quality of teachers - such as teacher ability, teacher education, and teacher experience - showed strong relations with student achievement.

Despite the variability in research regarding teacher background characteristics and student achievement, there are a number of well-supported findings that should be considered, especially teacher background factors that serve as inputs at the classroom level, but also to have an influence on, the interactive phase of teaching that occurs within classrooms (Rowan et al., 2002). Selected teacher background qualities and their relationship to student achievement will be explored in turn.

\section{Degrees Earned}

Degree level and area of degree attained by the teacher have been widely examined in quantitative studies. Generally, the research has been inconclusive as to how degrees contribute to student achievement. Several studies found no statistically significant effect of 
teacher degree level on teacher effectiveness as measured by student achievement gains, while controlling for confounding effects of student background and other teacher-related characteristics (Hanushek et al., 1998; Leigh, 2010; Munoz \& Chang, 2007; Rivkin et al., 2005; Wayne \& Young, 2003).

Hanushek, Kain and Rivkin (1998) analyzed a large sample of student achievement data in Texas and used value-added regression to disentangle the separate factors influencing achievement. The study revealed that there was no evidence that post-graduate education improved the quality of teaching. Actually, the estimates for the effects of a master's degree were generally negative and always statistically insignificant. A more recent study conducted by the same research team (Rivkin et al., 2005) also found that teacher quality cannot be attributed to observable characteristics like teacher education level - there was no evidence that a master's degree raised teacher effectiveness. Another study conducted by Munoz and Chang (2007) reached a similar conclusion — teacher educational level did not add to the prediction in students' growth rates of achievement; in other words, teacher education was not significantly related to their students' growth rates.

\section{Elementary School Teacher Degree Attainment and Student Achievement. Rowan,}

Correnti, and Miller (2002) used a large-scale student achievement data base of reading and math for Grades 1 through 6, drawn from Prospects: The Congressionally Mandated Study of Educational Growth and Opportunity 1991-1994. The researchers found in elementary grade level reading, teachers' degree status had statistically significant effects on growth in students' achievement. In elementary mathematics, students who were taught by a teacher with an advanced degree in mathematics did worse than those who were taught by a teacher 
without a mathematics degree. Thus, the evidence regarding the impact of advanced degrees at the elementary level is, to some extent, counterintuitive.

\section{Secondary School Teacher Degree Attainment and Student Achievement.}

Contradictory to the findings related to elementary school teachers, the studies that focused on high school mathematics have been quite consistent in their findings of a positive association between advanced degrees and student achievement. Rowan, Chiang, and Miller (1997) examined student achievement data on 8th through 10th grade math drawn from the longitudinal files of the National Education Longitudinal Study of 1988 (NELS: 88). They found students assigned to teachers who majored in mathematics at the undergraduate and/or graduate level had higher levels of mathematics achievement than those whose teachers did not, although the effect was quite small. Goldhaber and Brewer $(1997 \mathrm{a}, 2000)$ conducted two studies, both of which found that high school student achievement gains in secondary mathematics were positively related to teachers who held a bachelor's and/or master's degree in mathematics. Both studies drew on the dataset of National Educational Longitudinal Study of 1988 (NELS: 88). The study done in 1997 found that 10th-grade mathematics students taught by teachers having master's degrees in mathematics had higher achievement gains than those whose teachers had no advanced degrees or advanced degrees in non-mathematics subjects. This study also found that students whose teachers had bachelor's degrees in mathematics achieved more than students whose teachers had bachelor's degrees in nonmathematics subjects. The study conducted in 2000 found that 12 th-grade mathematics students learn more from teachers with mathematics majors and from teachers with master's degrees in mathematics. 


\section{Coursework}

Another teacher attribute that is closely related with degree is teachers' course-taking.

Over the last several decades, policy makers and researchers have used measures of the level and type of coursework taken by teachers as proxies for what teachers know and can do in their classrooms.

In a review of the literature on teacher attributes that are linked to student achievement gains, Wayne and Youngs (2003) cited the following two studies focused on teacher coursework:

- Controlling for student background and other teacher-related characteristics, Eberts and Stone (1984) found no relationship between 4th graders' mathematics achievement and the number of college-level, mathematics-related courses taken by their teachers.

- Monk and King (1994) used hierarchical linear modeling to analyze achievement data in mathematics and science. Although the study yielded many indeterminate findings, the relationship between high school mathematics gains and teacher coursework was quite strong. They found 10th and IIth-grade students made more achievement gains when their mathematics teachers had more mathematics courses.

Another study by Monk (1994) is often cited in the discussion about the effects of teacher coursework. Monk (1994) found that the number of college-level mathematics or science courses taken by teachers had a positive effect on student learning gains in mathematics and science. The more traditional teacher inputs, such as teacher experience or degree level, proved unrelated to student achievement. Interestingly, the evidence from this 
study also suggests that effects of subject matter preparation diminish with time and vary across types of students (such as advanced versus remedial) - the effect of content coursework levels off after five courses for high school teachers. However, the effects of coursework on pedagogy are more stable over time.

In a synthesis of literature on the association between teacher attributes and student learning, Rice (2003) found coursework in both the subject area taught and pedagogy have a positive impact on student achievement, particularly the impact of subject-specific coursework for high school mathematics. However, in other subjects and grade levels, the impact of teacher content course-taking on student achievement was found to be indeterminant and inconsistent. In addition, pedagogical coursework contributed to teacher effectiveness at all grade level, mostly when coupled with content knowledge.

\section{Certification Status}

Historically, policy on teacher certification has been used as an important leverage to manipulate the quality of the teaching profession, and it is one of the most widely tested teacher attributes in educational research. The extant evidence indicates a relationship between certification in mathematics and students' high school mathematics achievement. In a study focusing on high school level, among a range of teacher inputs, teacher certification was the most significant factor that contributed to student mathematics achievement at 10 th grade (Goldhaber \& Brewer, 1997b). However, there is little evidence of this association to student achievement in lower grades of mathematics (Rice, 2003). Rowan, Correnti, and Miller (2002) used three-level hierarchical linear modeling to examine the impact of teacher 
certification on elementary student achievement gains in mathematics and reading. The study found no apparent influence from teacher certification.

Another value-added study found having full certification (effect size $=0.09, p<.01$, $2.4 \%$ of the classroom-level variance) was the only teacher background variable (versus teaching experience and race) associated with reading achievement gains during first grade, and none was significantly associated with math achievement gains (Palardy \& Rumberger, 2008). This study conducted a follow-up analysis to examine whether fully certified teachers differ from those with less than full certification on key variables - such as instructional behavior and attitudes. The results showed that teachers in these two certification categories used surprisingly similar classroom practices. In addition, there was no significant difference in attitudes, such as efficacy and expectations.

Types of teacher certification also have been studied at several levels. Goldhaber and Brewer (2000) examined the relationship between student performance on 12th-grade mathematics related and various teacher certification statuses - standard certification, probationary certification, emergency certification, private school certification, and no certification in subject area taught. They found teachers holding standard certification have a positive impact on student test scores compared with those holding no certification or private school certification. Interestingly, they also found little difference in student performance in mathematics between teachers who acquire alternative-route certification and those with standard certification. However, a study in Houston, Texas, (Darling-Hammond, Holtzman, Gatlin, \& Heilig, 2005) found that the teachers with standard certification and more education 
training do better in producing student achievement compared to uncertified teacher and those with nonstandard certification.

\section{Content Knowledge}

A teacher's understanding of subject facts, concepts, principles, and the methods through which they are integrated cognitively determine his/her pedagogical thinking and decision-making. A specialized body of knowledge is a hallmark of any true profession and, indeed, teaching can lay claim to a specialized, complex, intricate, and constantly changing and renewing body of knowledge. Researchers have addressed the issue of teacher content knowledge through the measurement of coursework, questionnaire, and observation. The literature has been consistent in the findings about the positive association between teacher content knowledge and students' learning at all grade levels, particularly in mathematics. ${ }^{5}$

Students whose teachers answered a high school-level mathematics test item correctly made larger mathematics gains between 8 th and 10th grades, even after controlling for whether teachers held mathematics-related degrees (Rowan et al., 1997). Harris and Sass (2007) used panel data on all public school students and teachers in Florida for two time periods (1995-06 and 2003-204) to examine the relationship between teacher education and student achievement. They found teachers' pedagogical content knowledge positively associated with student test scores at the elementary and middle school levels but only in mathematics.

\footnotetext{
${ }^{5}$ Note Extant research only points to the positive impact of teachers' mathematics knowledge on student achievement in math. The apparent lack of relationship in other content areas is very probably due to insufficient research to date.
} 
Hill, Rowan, and Ball (2005) examined first and third graders' achievement gains in mathematics. They found that teachers' mathematical knowledge significantly contributed to student mathematics learning, after controlling for other key student- and teacher-related characteristics. Insightfully, Hill et al, cautioned that effectiveness in teaching resides not simply in the knowledge a teacher has accrued, but how this knowledge is used in classrooms. For instance, teachers highly proficient in mathematics or writing will help others learn mathematics or writing only if they are able to use their own knowledge to enact learning activities that are appropriate to students. Not surprisingly, the content knowledge of expert teachers is oftentimes characterized by "automaticity" and "routinization," and meanwhile, stays "opportunistic," "flexible," "situated," "extensive," and "accessible" (Berliner, 2004, pp. 200-201). Moreover, a deep disciplinary understanding of the subject taught, exerts a significant influence on a teacher's classroom behavior. Various studies suggest that teachers with stronger content knowledge are more likely to use practices that can help students construct and internalize knowledge (Weiss \& Miller, 2006; Wenglisky, 2000), such as:

- Asking higher-level questions;

- Encouraging students to explore alternative explanations;

- Involving students in more inquiry learning;

- Allowing more student-directed activities;

- Better engaging students in the lessons. 


\section{Teaching Experience}

Teacher experience is a crucial criterion for teacher compensation in most public school systems. Moreover, policymakers and researchers have shown increasing interest in investigating its impact on student achievement. Putting available evidences together, it seems that the relationship between years of teaching and teacher expertise is not linear. Teachers' experience matters only for the first few years of teaching — in particular, the first three years. During these first few years, teachers appear to gain cumulatively in their contribution to student learning. After three years, however, the contribution of experience to student learning levels off.

At high school level, the teaching experience was not found to be predictive of student growth rates in reading (Munoz \& Chang, 2007). At the elementary school level, research also found no significant correlation between teacher experience and student achievement. It seems that the effectiveness of 2 nd grade reading teachers is independent of their years of service (Heistad, 1999).

However, experience of more than ten years' teaching does seem to make a difference in a teacher's effectiveness. Rockoff (2004) found that teaching experience significantly raises student test scores for both reading and math computation (but not math concepts) at the elementary level, particularly in reading subject areas. Ten years of teaching experience is expected to raise vocabulary and reading-comprehension test scores, respectively, by about 0.15 and 0.18 standard deviation. Put another way, on average, reading test scores differ by approximately 0.17 standard deviations between beginning teachers and teachers with ten or more years of experience. For mathematics subject areas, the effects of experience are 
smaller The first two years of teaching experience appear to raise scores signuficantly in math computation However, in this study, subsequent years of experience appear to have a negatıve ımpact on test scores Rivkın, Hanushek, and Kain (2005) also noted that at the elementary level, teacher effectiveness increased dunng the first year or two but leveled off after the third year Similar conclusion was reached in the study by Hanushek et al (2005), Leigh (2010), and Odden et al (2004)

While the extant research generally supports the impact of teaching expenence on student learning only for the first few years, this issue remains to be further explored There are some studies that suggest a longer impact on student achievement Additionally, studies outside the education field have found that, in general, it takes ten years for professionals in complex jobs (e g, medıcıne) to reach mastery (Cloud, 2008) Interestıngly, a recent study revealed that type of expenence, rather than total years of expenience, is important for effectıveness (Huang \& Moon, 2009) Specifically, teaching expenence at grade level had a much larger effect on student achievement than overall years of experience

\section{Summary A Priorı Background Qualttes and Student Achievement}

Although the research has not generated a solid connection between the measurable teacher background characteristıcs and student learnıng, partıcularly in non-mathematics subjects, these attributes have been the driving criterıa used for identıfying effectıve teachers in educational policies as expressed in unform teacher salary schedules Teacher characteristics found in the payroll databases account for only a small portion of the vanance in teacher performance (Leigh, 2010) 
Rockoff (2004) cautioned that policies that reward teachers based on conventional qualifications (e.g., certification, teaching experiences, etc.) may be less effective than policies based on teacher characteristics that are less measured or harder to measure, like classroom performance. This caution also resonated in other empirical studies (for example, Munoz \& Chang, 2007; Rivkin et al., 2005), finding that variance in student achievement is not attributable to easily measurable teacher characteristics, like degree and certification status. The research seems to be in agreement that NCLB provisions for highly qualified teachers (i.e., a bachelor's degree, full state certification, and content knowledge) are insufficient to ensure that classrooms are led by highly effective teachers. Palardy and Rumberger (2008) suggested "ensuring that classrooms are led by highly effective teachers will require going beyond the screening of teachers based on background qualifications to implementing policies aimed at improving teaching effectiveness" (p. 129). This implies that more policy attention should be directed toward efforts to improve effectiveness once teachers are in service, rather than just focusing on teachers' prior-to-service characteristics.

\section{How Do Teachers' Dispositions Affect Student Achievement?}

Although teachers vary significantly in their ability to improve student achievement gains, little of this variation can be attributed to observable characteristics such as degree and teaching experience (Rivkin et al., 2005). For instance, Goldhaber (2002) pointed out that only about $3 \%$ of the contribution teachers make to student learning is associated with teacher experience, educational level, certification status, and other readily observable characteristics. The remaining $97 \%$ of teachers' effects on student achievement are associated with 
intangible, unobserved aspects of teacher quality such as dispositions, attitudes, and classroom practices.

Carter (2003) used multiple data collection instruments, such as surveys, interviews, observations, and personal records, to develop a better understanding about the characteristics and dispositions of 99 effective teachers. When these teachers were asked to list three characteristics of exceptional teachers, the most mentioned themes are as follows:

- Flexible, adaptable, will search for what works

- Excellent management skills, organized, discipline issues, etc.

- Caring, compassionate

- Love working with children, love children

- Believe all children can learn at high levels, high expectations

When these effective teachers were requested to report two strengths they possess. The most frequently mentioned strengths were: having classroom management skills and organization; being hard-working and dedicated; possessing excellent communication skills; being enthusiastic and energetic; and being caring and kind (Carter, 2003).

Caring Teachers.

Caring about students and respecting them as individuals are prevalent in the literature descriptions of effective teachers (Cassidy \& Bates, 2005; Chaskin \& Rauner, 1995; Nodding, 1992). Noblit, Rogers and McCadden (1995) stated that "caring is central to education - the glue binds teachers and students together and makes life in classrooms meaningful" (p. 680). Caring fosters a type of teacher-student connections that encourage possibilities for learning that may not otherwise occur (Peart \& Campbell, 1999). When 
students perceive that their teachers care about them, they exert higher levels of motivation, social responsibility, and affective learning (Comedena, Hunt, \& Simond, 2007; Wentzel, 1997).

Exemplary teachers regard the ethic of care and respect as a vital foundation for students' best learning and a prerequisite for effective teaching. They reach out to know their students by using multiple sources of knowledge (e.g., solicited critique, dialogues and questions, knowing students informally, knowing from colleagues, and knowing students' cultures) (Collison, Killeavy, \& Stephenson, 1998). A study by Stronge, Ward, Tucker, and Hindman (2008) divided teachers into quartiles based on student achievement gains. Five highly effective teachers and six less effective teachers participated in a cross-case analysis, including classroom observations, interviews, and other instructional analyses. They found there was a difference in the overall personal qualities between the effective teachers and the ineffective teachers studied: the effective teachers demonstrated more respect and caring for students than did the less effective teachers.

Effective teachers use care and respect to build relationships with their students that are conducive to academic learning. Caring can make an immediate impact on the lives of the students and their perceptions of self and others. In classroom learning, when students are prompted by caring, they are more likely to ask questions, to take chances, and to share their inner thoughts in creative writing and through other forms of expression (Cassidy \& Bates, 2005). 
Teacher Efficacy Beliefs.

Self-efficacy refers to the belief in one's ability to accomplish intended outcomes. This belief influences an individual's behavior, motivation, effort, ultimately their success or failure. Extrapolating this concept to teacher effectiveness, a teacher's self-efficacy is her perceived capability to impart knowledge and develop the ethics and behavior of students, including those who are unmotivated and challenging (Bandura, 1997; Tschannen-Moran, 2009). The reviews of research on teacher self-efficacy have summarized that teachers' selfefficacy was linked to teaching practices in their classrooms and student outcomes such as students' self-efficacy beliefs and student engagement, motivation, and achievement (Midgley, Feldlaufer, \& Eccles, 1989; Shahid \& Thompson, 2001; Tschannen-Moran \& McMaster, 2009). Compared to teachers with lower self-efficacy beliefs, teachers with stronger perceptions of self-efficacy tend to use more challenging teaching techniques, try innovative strategies, and employ classroom instruction that are more organized and better planned, student centered, humanistic (Tschannen-Moran, 2009). Efficacy is also a personal resource that can protect teachers from experiences of job stress and burnout (Schwarzer \& Hallum, 2008).

Effective teaching requires teachers who not only have efficacy beliefs about themselves but also the entire faculty. Goddard, Hoy, and Hoy (2004) examined on the association between teacher collective efficacy and student achievement in elementary level mathematics and reading. The findings supported the role of collective efficacy in promoting school achievement. More studies in this line of inquiry have consistently supported the 
association between teacher collective efficacy and teacher success (Hoy, Sweetland, \& Smith, 2002; Goddard, LoGerfo, \& Hoy, 2004).

\section{Motivation and Enthusiasm to Teach.}

Motivation and enthusiasm are contagious in classrooms. Teachers who display enthusiasm and energy in the classroom often increase student interest and motivation to learn. Among various teacher variables, enthusiasm was the most powerful unique predictor of students' intrinsic motivation and vitality. The students who received instruction from an enthusiastic teacher reported greater intrinsic motivation regarding the learning material and experienced higher levels of vitality (Kunter et al., 2008). Students who are under the tutelage of motivated and enthusiastic teachers are more likely to be enthusiastic toward the learning materials and exhibit higher rate of on-task behavior (Bettencourt, Gillett, Gall, \& Hull, 1983; Mastin, 1963).

Rowan, Chiang, and Miller (1997) examined the extent student mathematics achievement can be explained by their teachers' interest and motivation. Teachers' studentspecific expectancy motivation did have a statistically significant effect on students' achievement. Specifically in this study, students whose mathematics teachers expected them to go to college outperformed students whose teacher did not expect them to go to college by about .07 standard deviations. That means students whose teachers had higher outcome expectations for them had higher levels of mathematics achievement than did students whose teachers did not hold such expectations for them.

Teacher interest or motivation is a significant factor in classroom success. Teacher interest typically is expressed in a range of teacher behaviors that are perceived to be 
conducive to student learning, such as enthusiasm in content area taught, interest about students' personal and developmental needs, participation in content-related activities outside of class time, and displaying value and emotion for students (Long \& Hoy, 2006).

Kunter et al. (2008) made a distinction between teachers' enthusiasm for subject matter of mathematics from enthusiasm for teaching mathematics, and investigated how they relate to instructional behaviors. They found that teachers who were more enthusiastic about teaching showed higher quality instructional behavior than those who were more enthusiastic about mathematics, from both the teacher and the student perspectives. Specifically, the more teachers were interested in teaching: 1) the more monitoring they reported; 2) the more cognitive autonomy support they claimed to provide for students; 3 ) the more social support provided for students; 4) the more monitoring perceived by the students; 5) the more social support perceived by students; and 6) higher levels of cognitive challenge reported by the students.

Summary: Teacher Personal Dispositions and Student Achievement.

A report, released by the National Bureau of Economic Research, rendered a synthesized study on the characteristics discussed above: teacher professional background qualities and teacher dispositions (Rockoff, Jacob, Kane, \& Staiger, 2008). Individually, the teachers characteristics of cognitive ability, content knowledge, personality traits, and feelings of self-efficacy generally did not predict teacher effectiveness, but when they were categorised into cognitive and non-cognitive skills, both categories were shown to have a modest positive relationship with student outcomes. The cognitive domain included the following presage characteristics: being a Teach For America (TFA) corp member, attending 
a more selective college, SAT math score, SAT verbal score, IQ test scores, and math knowledge for teaching. And the category of "non-cognitive skills" included teacher dispositions such as extraversion, conscientiousness, personal efficacy, and general efficacy. It seems that certain teacher characteristics are not quite predictive when they stand alone, while in combination, they can add value in predicting whether a teacher would be more effective in a classroom.

The research in China also points toward the importance that dispositions hold in teacher effectiveness. To investigate Chinese students' percetpions of good teachers, Cortazzi and Jin (1996) asked 135 Chinese students to write essays on the topic of what makes a teacher effective. In their open-ended reponses, $67 \%$ of the participants mentioned that a good teacher has deep knowledge, $25 \%$ included is patient, $23.7 \%$ mentioned is humorous, $21.5 \%$ is a good moral example and is friendly. Other qualities ferquently mentioned were that a good teacher teaches students about life (17.5\%), arouses students' interest (17\%), is warm-hearted and understanding or uses effective teaching methods (16.2\%), and is caring and helpful (14.8\%) and explains clearly $(6.7 \%)$.

\section{How Do Teachers' Skills and Practices Affect Student Achievement?}

Although there is general agreement that teachers have a significant impact on student learning and teachers vary in their ability to help student learn, there is a lack of consensus about which aspects of teachers' instructional practices matter most. This section of the chapter focuses on what Rowan, Correnti, and Miller (2002) referred to as "process variables," which was defined as "properties of the interactive phase of instruction - that is, 
the phase of instruction during which students and teachers interact around academic content" (p. 1538).

\section{Classroom Management}

Caring, supportive, safe, challenging, academically robust: These attributes help define what it means to have a positive learning environment that is conducive to student success (Hamre \& Pianta, 2005; Hattie, 2009; Pressley, Rapael, Gallagher, \& DiBella, 2004). The most prevalent criteria used to define learning environment are probably the physical arrangement of the classroom, discipline and routines, organization of learning activities, and the engagement of students with tasks, among others (Camron, Connor, Morrison, \& Jewkes, 2008; Zahorik, Halbach, Ehrle, \& Molnar, 2003). Students need an engaging, stimulating, and enriching learning environment to grow and thrive. In order to achieve this type of rich environment, effective teachers establish and communicate guidelines for expected behavior, monitor student behavior, keep students on tasks, and infuse humor, care, and respect into the classroom interactions, so as to develop a climate that contribute to student learning (Emmer \& Stough, 2001; Kunter, Baumert, \& Koller, 2007).

As a result, research has indicated that a positive learning environment can shape student outcomes in cognitive, motivational, emotional, and behavioral domains (Fraser \& Fisher, 1982; Ludtke, Robitzsch, Trautwein, \& Kunter, 2009). Classroom management includes actions taken by teachers to establish order, engage students, elicit student cooperation, with an ultimate purpose to establish and maintain an environment conducive to instruction and learning (Emmer \& Stough, 2001). Two key features of effective classroom management are: 
1. Good management is preventive rather than reactive; and

2. Teachers create well-managed classrooms by identifying and teaching desirable behaviors to students.

Effective teachers were found to maintain their management system by "monitoring and providing prompt feedback, pacing class activities to keep them moving, and by consistently applying classroom procedures and consequence" (Emmer \& Stough, 2001, p. 105).

Wang, Haertel, and Walberg (1994) analyzed a knowledge base comprising 11,000 statistical findings connecting a variety of variables and student achievement in order to answer the question: What helps students learn? Twenty-eight categories of factors, classified into six broad types of influences (i.e., student aptitude, classroom instruction and climate, context, program design, school organization, state and district characteristics) were scored based on their positive impact on learning. Of the 28 categories, classroom management ranked first and was the most influential variable, just ahead of student metacognitive processes and cognitive processes. In the researchers" view, "effective classroom management increases student engagement, decreases disruptive behaviors, and makes good use of instructional time" (p. 76). Their definition of effective classroom management included effective questioning/recitation strategies, learner accountability, smooth transitions, and teacher "with-it-ness."

Taylor et al. (1999) observed 104 kindergarten through third-grade teachers and then categorized them as "most accomplished," "moderately accomplished," and "least accomplished" based on the degree to which they demonstrated elements of effective instruction. They found the "most accomplished" teachers were experts at classroom 
management In general, they had well-establıshed classroom routınes and procedures for handlıng behavior problems, smooth transitions between activities, and a rapid rate of instruction, thus, allowing for high instructional density They managed, on average, to engage virtually all (96\%) of their students in the work of the classroom

Stronge, Ward, Tucker, and Hindman (2008) found that compared with bottom quartıle teachers, top quartıle teachers (as determıned by their abılity to effect student achievement gains) were more organızed than ineffectıve teachers with efficient routınes and procedures for daily tasks And they communicated higher behavioral expectations to students The top teachers also were found to have less disruptive student behaviors (once every 2 hours) than did the less effectıve teachers (a disruption every 12 minutes) Another research team noted that teachers who spend more tıme establıshıng instructıonal routınes at the beginning of the school year did not need to exert as much effort on similar tasks later in the year (Cameron et al , 2008) Some key features of effectıve classroom management are highlighted in Table 4

Based on a review of studies in the past 20 years, in Western countries, Beaman, Wheldall, and Kemp (2007) found that "talk out of turn" to be the top student behavior that causes disruption in the classroom However, compared with the Western countries, where about $55-65 \%$ of the teachers report they spend too much dealing with problems of classroom order, in Chına the majority of teachers $(656 \%)$ do no think that classroom management is a great concern According to the Chinese teachers' perceptions, the most frequent and most troublesome student behavior is "daydreaming" (Ding, L1 , L1, \& Kulm, 2008, Shen et al, 2009) Ding et al (2008) posited that teaching for testing is the major reason that results in 
Chinese students' low mental engagement. In classrooms taught by effective teachers,

authority is often more distributed than centralized (Allington \& Johnston, 2000), but in

Table 4. Key Characteristics of Learning Environment for Effective Teachers

Defining Characteristics of Focus

Positive Learning Environment

Physical arrangement of the

classroom

The teacher develops functional floor plans

with teacher and student work areas and furniture/materials placement for optimal benefit (Stronge, 2007).

Discipline and routines

The teacher establishes classroom rules and procedures early on in the school year (Emmer, Evertson, \& Worsham, 2008).

Organization of learning activities Classroom activities have an academic focus. The teacher orchestrates smooth transitions and maintains momentum throughout teaching and learning (Marzano, Marzano, \& Pickering, 2003).

\begin{tabular}{ll}
\hline Engagement of students & $\begin{array}{l}\text { The teacher uses effective questioning, } \\
\text { smooth transition, and challenging but } \\
\text { interesting activities to increase student } \\
\text { engagement in learning and student } \\
\text { accountability (Wang, Haertel, \& Walberg, } \\
1994) .\end{array}$ \\
\hline Maximizing instructional time & The teacher protects instruction from \\
& disruption and use appropriate instructional \\
& pace to makes the most out of every \\
instructional moment (Cruickshank \& \\
Harfele, 2001; Good \& Brophy, 2008; Wang \\
et al., 1994). \\
\hline The teacher assumes responsibility for \\
student learning, sets high (but reasonable) \\
expectations for all students, and supports \\
students in achieving them (Corbett, Wilson \\
\& Williams, 2002; Johnson, 1997). \\
The teacher establishes rapport and \\
trustworthiness with students by being fair, \\
caring, respectful, and enthusiastic \\
(Allington \& Johnson, 2000; Carter, 2003; \\
Walls, Nardi, von Minden, \& Hoffman, \\
2002). \\
\hline
\end{tabular}

Confucian-heritage culture, teaching students to be respectful and obedient to their superiors is the foundation for growing up to be good citizens. Additionally, for the student who were raised with a collectivist attitude, asking low quality questions, not to mention taking out of 
turn, could be considered as a waste of others' time but also put the students at a risk of losing face (Ding et al., 2008).

\section{Planning for Instruction}

Teaching is a complex activity that involves careful preparation and planning, both for short-term learning purposes or long-term learning purposes. Misulis (1997) commented "regardless of the teaching model and methods used, effective instruction begins with careful, thorough, and organized planning on the part of the teacher"' (p. 45). A solid planning process is integral to a teacher's efforts in identifying appropriate curriculum, instructional strategies, and resources to address the needs of all students. Furthermore, teachers' planning influences the content of instruction, the sequence and cognitive demands of subject topics, learning activities and students' opportunities to learn, and the pacing and allocation of instructional time. Research indicates differences in planning behaviors adopted by effective and less effective teachers. Research found that effective teachers:

- Construct a blueprint of how to address the curriculum during the instructional time (McEwan, 2002).

- Facilitate planning units in advance to make intra and interdisciplinary connections (McEwan, 2002).

- Sequence material to promote student's cognitive and developmental growth (Panasuk, Stone, \& Todd, 2002).

- Use knowledge of available resources to determine what resources they need to acquire or develop (Buttram \& Waters, 1997).

- Plan instruction in a multi-sourced manner (Allington \& Johnston, 2000). 
Haynie (2006) examined practices of the ten most effective and ten least effective Biology teachers, whose effectiveness were identified by their students' achievement gains. Most top teachers collaborated with one or more teachers while planning lessons; however, the bottom teachers reported they always planned lessons alone. The top teachers also were not restricted by pacing guides, and reached beyond prepared resources to plan their own activities, while most bottom teachers used resources already prepared. Top teachers used student assessment data in the planning of instruction. Based on data drawn from frequent assessments, they made data-driven decisions about what goals and objectives to address.

Allington and Johnston (2000) found that the instruction of effective teachers was multi-sourced. Exemplary teachers were inclined to stretch the reading and writing beyond the textbooks. Although effective teachers did use prescribed textbooks, they rarely ever followed traditional plans for these materials. For instance, while planning for a lesson in social science, the effective teachers usually used historical fiction, biography, information on the Internet and in magazines, and other nontraditional content sources.

Borko and Livingston (1989) investigated the pedagogical expertise in instructional planning by comparing novice teachers and experienced teachers. They found that novices showed more time-consuming, less efficient planning. While implementing the planned lessons, their attempts to be responsive to students were likely to lead them away from scripted lesson plans. The novice teachers were less successful in translating their instructional plans into actions than expert teachers. The expert teachers were better able to predict where in a course the students were likely to have problems and predict 
misconceptions the students would have and areas of learning these misconceptions were likely to affect.

Implementing Instruction

Instructional delivery is a process in which teachers apply a repertoire of instructional strategies, to communicate and interact with students around academic content, and to support student engagement. An array of studies have found that the actual practice of teaching is a critical factor for student learning (Palardy \& Rumberger, 2008; Rowan, Correnti, \& Miller, 2002; Stronge, Ward, Tucker, \& Hindman, 2008). Teachers with the same background qualifications and same schooling resources do different things in their classrooms and, consequently, enable their students to achieve at different levels. To discover what makes a teacher effective, one need to look into the black box of the classroom and see how teachers translate their content knowledge, pedagogical skills, and resources into opportunities for student learning.

Cohen, Raudenbush, and Ball (2003) argued that the key causal agents for student achievement reside in instruction, and teachers' classroom teaching has the most immediate causal effects on student learning compared with other school-related factors. A similar point was made by Palardy and Rumberger (2008). They noted that of three aspects of teachers discussed in the literature (i.e., background qualifications, personal dispositions such as attitudes, and instructional practices), instructional practices have the most proximal association with student learning. That is, "instructional practices are theorized to influence student learning directly, whereas teacher background qualifications and teacher attitudes are theorized to influence learning indirectly through their association with instructional 
practices" (p. 115). Table 5 highlighted some key instructional practices that have been supported by literature in improving student learning.

Table 5. Key Areas of Instructional Delivery for Effective Teachers
Area
Focus

\begin{tabular}{|c|c|}
\hline Differentiation & $\begin{array}{l}\text { The teacher uses multiple instructional materials, } \\
\text { activities, strategies, and assessment techniques to } \\
\text { meet students' needs and maximize the learning of } \\
\text { all students (Tomlinson, 1999). }\end{array}$ \\
\hline Cognitive challenge & $\begin{array}{l}\text { The teacher provides in-depth explanations of } \\
\text { academic content and covers higher-order concepts } \\
\text { and skills thoroughly (Wenglinsky, 2002). }\end{array}$ \\
\hline Student engagement & $\begin{array}{l}\text { The teacher is supportive and persistent in keeping } \\
\text { students on task and encouraging them to actively } \\
\text { integrate new information with prior learning } \\
\text { (Cotton, 2000). }\end{array}$ \\
\hline Questioning & $\begin{array}{l}\text { The teacher uses multiples levels (particularly } \\
\text { higher cognitive levels) of questioning to stimulate } \\
\text { student thinking and monitor student learning } \\
\text { (Cawelti, 2004; Walsh \& Sattes 2005). }\end{array}$ \\
\hline Relevance & $\begin{array}{l}\text { The learning process and the outcomes of learning } \\
\text { have authentic "bearing" on students' life } \\
\text { (Schroeder, Scott, Tolson, Huang, \& Lee, 2007; } \\
\text { Wenglinsky, 2004). }\end{array}$ \\
\hline
\end{tabular}

Students arrive at school with a variety of backgrounds, interests, and abilities. This means that a one-size-fits-all approach to instruction is ineffective, probably counterproductive, and perhaps even unethical. If the goal of instruction is to provide an opportunity for all students to learn, then the instructional practices that teachers choose to employ in the classroom matter - and matter greatly (Calson, Lee, \& Schroll, 2004). In an analysis of educational productivity in the United States and other countries, teacher classroom instruction was identified as one of the most significant variables that have great effect on student affective, behavioral, and cognitive outcomes (Walberg, 1984). For instance, the instructional practice of reinforcement has a magnitude of 1.17 standard 
deviatıons on educational outcomes The effect of cues, engagement, and correctıve feedback, is approxımately one standard deviation each Personalızed and adaptıve instruction, tutoring, and diagnostıc-prescriptive methods also have strong effects on student learning, with effect sizes of 57, 45, 40, and 33, respectively (Walberg, 1984)

Instead of using uniform strategies for all students, effective teachers design instruction that motivates each student and they communicate content in such a way that students are able to comprehend based on their indıvidual prior learning and ability Because students learn in a variety of ways and at a variety of rates, teachers should deliver their lessons with appropriate vanety, also A meta-analysis of the extant research suggests that instruction based on learning styles is positıvely related to student attıtudes and achievement (Lovelace, 2005) Dunn et al (2009) extended thıs findıng to at-rısk students, reportıng that mean achievement increased nearly one standard deviatıon (1 e, approxımately $84^{\text {th }}$ percentıle versus $50^{\text {th }}$ percentıle) when teachers accommodated for learnıng styles Implementıng a variety of classroom techniques and strategies also enhances student motivation and decreases discipline problems (Dolezal \& Welsh, Pressley, \& Vincent, 2003) Furthermore, dıfferentıated instruction enables teachers to adjust theır curnculum, matenals, learnıng activities, and assessment techniques to ensure that all students in a mixed-ability classroom can have different avenues to process new knowledge and develop skılls, whıle having equal access to hıgh-qualıty learnıng (Tomlınson, 2001)

Makıng instruction relevant to real-world problems is among the most powerful instructional practices a teacher can use to increase student learning (Schroeder et al , 2007, Wenglınsky, 2004) This kınd of instruction allows students to explore, inquire, and 
meanngfully construct knowledge of real problems that are relevant to their life Moreover, students are motıvated and engaged when theır learning is authentic, especially when the realworld tasks performed have personalized results

Questioning can be another highly effectıve instructional tool when used properly (Guo, Tsa1, Chang, \& Huang, 2007) In partıcular, the types of questıons asked, walt tıme, and types of responses play a role in the propitious use of questioning (Walsh \& Sattes, 2005) There are substantıal differences in the adept use of questıonıng between effectıve teachers and ineffectıve teachers On the negatıve side, in a study of mathematics classrooms Craig and Carro (2005) tound that teachers ask more than $99 \%$ of the questions They also found that teachers tended to provide little wait tume, asked recall and use questions, and designated a particular student to answer a question On the positive side, one case study found that teachers deemed effective asked approximately seven tımes more higher cognitive-level questıons than those considered ineffectıve (Stronge et al , 2008)

Chinese researcher, Wang (2000), found that effectıve teachers ask questions that are sensitıve to students' differential levels of learning abilities, and that the questions are more closely alıgned with concrete learnıng outcomes and learnıng actıvities Effective teachers tried to accommodate their teaching to students of different levels They took students' ındıvidual needs into account whıle differentıatıng the learnıng objectıves, learnıng actıvities, and assessments, so that ALL students can engage with meanıngful learnıng Interestingly, Ineffectıve teachers were more attentıve to students of hıgher learnıng levels and asked questions that could only be answered by hıgher learnıng-ability students Effective teachers also were found to be more self-reflective and cntical about their own classroom instruction 
They seemed to have more knowledge on education, instruction, and instructional strategies. They were more adept in planning, evaluating, and modifying their instructional process, and more skillful in deploying strategies flexibly to attain their instructional goals.

\section{Assessment for Learning}

Gronlund (2006) described assessment as "a broad category that includes all of the various methods for determining the extent to which students are achieving the intended learning outcomes of instruction" (p. 3). Assessment of student learning can emerge in various formats, such as teacher observation, oral questioning, journal entries, portfolio entries, exit cards, skill inventories, homework assignments, project products, student opinions, interest surveys, criterion-referenced tests, or norm-based tests (Tomlinson, 1999). The practice of assessing student progress is essential for effective instruction and learning. High quality assessment provides teachers with the information regarding the extent to which students have attained the intended learning outcomes, and it informs teachers' instructional decision making (what to teach and how to teach) as well. The goals of assessment are to provide teachers with day-to-day data on students' mental preparedness for certain learning targets and to facilitate teachers in making data-based decisions for instruction modification. Research has indicated that teachers who introduce formative assessment into their classroom practice can effect substantial achievement gains. In their 1998 research review, Black and Wiliam (1998) examined a multitude of empirical studies to determine whether improvement in classroom assessments can lead to improvement in learning. They found that formative assessment has substantial positive effects on student achievement, with effect size ranging from 0.3 to 0.7 standard deviations. Particularly, they found that formative assessment is 
more effective for low achievers than other students, thus, reducing an achievement gap while raising achievement overall at the same time (Black \& Wiliam, 1998). Hattie (2003) found that compared to their ineffective colleagues, effective teachers were adept at monitoring student problems and assessing their level of understanding and progress, and they provided much more relevant, useful feedback. The research also shows that effective teachers were more adept at developing and testing hypotheses about learning difficulties or instructional strategies. Wenglinsky (20002) found that teachers' use of frequent assessment and constructive feedback had a positive effect on student mathematics and science achievement at all grade levels. Another research team noted that effective teachers and ineffective teachers differed in their student assessment practices (Stronge et al., 2008). In particular, effective teachers were found to provide more differentiated assignments for students than those deemed ineffective. Assessments are more likely to have a positive influence on student learning when teachers:

- aligned them with the framework of learning targets and instruction;

- maintained sufficient validity and reliability to produce an accurate representation of student learning;

- provided frequent informative feedback, rather than infrequent judgmental feedback;

- involved students deeply in classroom review and monitoring;

- communicated processes and results timely and effectively; and

- documented learning results through proper record keeping (Black \& Wiliam, 1998; Stiggins \& DuFour, 2009). 
Student progress monitoring is a practice that helps teachers use student performance data to continuously evaluate the effectiveness of their teaching and make more informed instructional decisions (Safer \& Fleischman, 2005). To implement student progress monitoring, the teacher first pre-assesses a student's current competency level on skills covered by the curriculum, sets up ultimate achievement goals for the school year, and establishes the rate of progress the student must make to attain those goals. Then the teacher uses ongoing, frequent, brief, and easily administered measures to monitor the student's academic progress (Safer \& Fleischman, 2005). Fuchs, Deno, and Mirkin (1984) used an experimental design to investigate the effects of frequent curriculum-based assessments. Thirty-nine education teachers in the area of reading were randomly assigned to a frequent curriculum-based assessment group and a conventional assessment group. Over the 18-week implementation, pedagogical decisions were surveyed; instructional structure was observed and measured; and students' knowledge about their learning was assessed through an interview. Analyses indicated that:

- Teachers in the experimental group, who adopted systematic assessment procedures, effected greater student achievement than those who used conventional monitoring methods.

- Teachers in the experimental group had more improvement in their instructional structure.

- Experimental teachers' pedagogical decisions reflected greater realism and responsiveness to student progress.

- The students taught by experimental teachers were more knowledgeable of their own 
learning and more conscious of learning goals and progress.

Student progress monitoring facilitates teachers tracking students' academic growth on a regular basis. It can continually provide teachers with the data and evidence about students' performance to evaluate the effectiveness of their instruction and make adjustments in their pedagogical behavior.

Teachers who monitor their students' progress exhibit greater concerns about student learning and higher academic emphasis in their instruction. They also are better at supervising the adequacy of student learning, identifying students in need of additional or different forms of instruction, and determining what instructional modifications are necessary. Progress monitoring also can help teachers set meaningful student achievement goals to tap into greater student potential of learning. Empirical research found that when progress monitoring is combined with goal-setting, student learning profiles, and appropriate instructional modifications, it could help teachers build stronger instructional programs that are more varied and more responsive to students' learning needs, and effect better academic performance for students (Fuchs \& Fuchs, 2003). Stecker, Fuchs, and Fuchs (2005) noted that teachers effected significant growth in student learning with progress monitoring only when they modified instruction based on progress monitoring data; however, frequent progress monitoring alone did not boost student achievement.

Given the prevalence of standardized assessments at the state, regional, and national levels, both in the United States and in numerous countries around the globe, a brief comment on this particular type of assessment seems in order. The extant literature has documented both positive and negative impacts of standardized assessments on teachers' instruction and 
assessment at the classroom level. The positive evidence indicates that standardized tests motivate teachers to:

- align their instruction to standards,

- maximize instructional time,

- work harder to cover more material in a given amount of instructional time, and

- adopt a better curriculum or more effective pedagogical methods (Borko \& Elliot, 1999; Shepard \& Dougherty, 1991; Thayer, 2000; Vogler, 2002).

However, other research reveals that high-stakes assessments force teachers to:

- narrow the curriculum;

- focus on memorization, drills, and worksheets,

- allocate less time to higher-order skills; and

- restrict their teaching to formulated approaches of instruction (Hamilton, Stecher, 2004; Jones \& Egley, 2004; Jones et al., 1999; Stecher \& Mitchell, 1995).

Standardized assessment is not primarily concerned with what is going on in the daily classroom. Consequently, teachers should maintain a balance between state/national level assessments and classroom level assessments to optimize student learning (Stiggins, 2002). Summary: Teacher's Teaching

Studies on teacher effectiveness provide some insights into the qualities that connect teacher effectiveness and student achievement. The outcomes of these studies, while informative, have not led to a standard definition of teacher effectiveness. Neither have they generated a commonly agreed-upon list of effective teaching qualities. Generally, effective teachers plan carefully, use appropriate materials, communicate goals to students, maintain a 
brisk pace, assess student work regularly, and use a variety of teaching strategies. They use class time well and have coherent strategies for instruction. They hold the expectations that their students can learn and they believe they have a large responsibility to help (Cohen, Raudenbush, \& Ball, 2003). This list is far from complete. In essence, teaching is highly complex work with a multitude of teacher-related, as well as other, variables that affect student success.

\section{How Teacher Effectiveness is Similar and Different in China?}

Similar qualities of effective teacher were also identified in literature in China (Liu, 2006; Liu \& Meng, 2008). For instance, Liu (2006) found that the instruction of exemplary teachers in China was characterized by: 1) conducive learning environment, 2) maximization of instruction time, 3) effective classroom management strategies, 4) effective instructional delivery, 5) presentation of appropriate content, 6) opportunities for student involvement, 7) assessment of student progress, 8) time-on-task, 9) interactive time-on-task. Liu's findings on effective teaching in China were similar to those identified in the U.S. literature. Also, Liu found certain processes of effective classroom teaching in Chinese classrooms and schools different from those indentified in international literature, including:

- Chinese teaching behaviors are more uniform across classes.

- Effective instruction in China emphasizes whole class activities over small group activities. Demonstration/lecture is the prevalent instructional strategy adopted.

- Chinese teachers were found to be stricter with students in both discipline and studies.

- Students respect their teachers' authority to a greater extent than found in U.S. and 
other western schools.

- Chinese teachers exert more efforts to maximize classroom instruction time due to the exam-driven system which links student tests scores to teacher evaluation. While this matter has gained attention in U.S. education systems, nonetheless, it still does not equal the emphasis found in the Chinese educational system.

Literature has documented that the teaching in Chinese culture is defined by demonstration, modeling, repeated drilling, and ultimately memorization (Jin \& Cortazzi, 2006). Typically, the classes in China are large, in excess of 50 students, and appear to Western observers as highly authoritarian. The classroom interaction in Chinese classes is teacher-centered and text-based. Instructional methods are largely expository, and overtly driven by external high-stakes examinations (Biggs, 1996; Cortazzie \& Jin, 1996). The teacher is often deemed to be an authoritative model, having expert knowledge and skills, moral behavior, and the one who always has an answer for questions. On the part of students, they are quiet and careful listeners (Jin \& Cortazzi, 2006). Paine (1990) described that lessons in China were dominated by teacher talk - teachers act as artistic performers and students are the audience. Such a learning environment is opposite to the ideal learning environment defined in Western literature. Western intuitive thinking would perceive that Confucianheritage culture results in rote learning and low student achievement (Biggs, 1996). However, students of Asian origin have been able to excel on international examinations. This phenomenon has attracted much attention since1980s (e.g., Sue \& Okazaki, 1990; Stigler, Lee, Lucker \& Stevenson, 1982; Stevenson, Lee, \& Stigler, 1986; Stevenson \& Stigler, 1992). It seems the strategy of memorization used by Chinese students are not simply rote-learning, 
but an important way for deep understanding in which subject content is internalized and actıvely reflected upon (Watkins \& Biggs, 1996; 2001) The success of East Asıan students has attracted worldwide attention to the cultural traits that could support student academic development (On, 1996). Westerner observers of classroom instruction in China are usually impressed by the discipline and concentrated attention of students, and the rapid pace and intensity of teacher-centered interaction (Jin \& Cortazzi, 2006; Marton, Dall'Alba, \& Kun, 1996).

Teacher authonty and suppression of student individual expression are deeply rooted in Confucian culture and collectrvistıc culture (Ho, 2001) In Chınese classrooms, there is higher expectation for members to conform to more uniform standards of behavior As Ho (2001) suggested, unlike Western cultures where harmonious social relations rest upon the satisfaction of individual needs or individual rights and fairness to all, "proper behavior in the Confucian collectivistic culture is defined by social roles, with mutual obligation among members of society and the fulfillment of their duties for each other being emphasized" (p.100). Another characteristic of Chinese education is its emphasis on basic knowledge and skills. The Chinese teachers and learners tend to believe that basic skills are fundamental and must precede any efforts to encourage higher-level learning (Chen, 2004; Soh, 1997). In Chinese culture, learnıng is believed to occur through contınual, careful shaping and modelıng, and higher-order learnıng, such as analysıs, evaluation and creatıvity, is demonstrated only after the child has perfected prescribed and approved performances (Chen, 2004). 


\section{CHAPTER 3}

\section{METHODS}

This chapter presents the research design of this study, addressing its paradigm, research strategy, sampling method, data generation and collection, data analysis, and study quality indicators. The study was based upon an interpretivist, phenomenological design that used semi-structured interviews, classroom observations, and artifact analysis for data generation, and grounded theory (Strauss \& Corbin, 1998) for data analysis. This design made it possible to compare the instructional practices and beliefs of award-winning teachers in the U.S. and China in classroom-specific ways. The primary research questions guiding this research study were:

1. What are the similarities and differences between selected award-winning United States and China teachers in their instructional practices?

a) What types of instructional activities are used by selected award-winning U.S. and China teachers?

b) How are cognitive levels, based on Bloom's revised taxonomy (Anderson \& Krathwohl, 2001), represented in these teachers' classrooms?

c) To what degree is learning teacher-directed in the classrooms of selected award-winning U.S. teachers and China teachers?

2. How are selected national award-winning United States and China teachers' classroom practices - other than instructional activities - similar and different (such as their classroom management strategies)?

a) What are the student engagement levels in the classrooms of selected awardwinning U.S. teachers and China teachers? 
b) What classroom management strategies are implemented by selected award-

winning U.S. teachers and China teachers?

3. What are the similarities and differences in professional thinking between teachers in the U.S. and China?

a) How do these teachers reflect on their practices, particularly about their relationships with students, classroom environment, instructional planning, instructional strategies, differentiation, and assessment and evaluation of students' learning?

b) What are the selected teachers' perceptions of why their practice merited recognition with a national award?

\section{Paradigm}

Paradigms are belief systems or world views that guide research and practice. They encompass general theoretical assumptions and laws and suggest techniques for applying them to a variety of situations (Willis, 2007). In this dissertation study, interpretivism was the paradigm used to explore the practices and beliefs of selected China and U.S. award-winning teachers. The interpretivist paradigm "holds status quo assumptions about the social world and subjectivist assumptions about epistemology" (Rossman \& Rallis, 2003, p. 46).

Due to the varied social and cultural contexts of teaching, dynamic interactions that happen daily in classrooms, differing philosophies and experiences among individual teachers, and other factors, the researcher assumed that no universal or absolute truths about teacher effectiveness exist. Verloop, Van Driel, and Meijer (2001) posited that the knowledge and insights that give rise to teachers' actions in practice are strongly related to individual 
experiences and contexts. Teachers' instructional practices in classrooms entail "a large variety of cognitions, from conscious and well-balanced opinions to unconscious and unreflected intuitions...[I]n the mind of the teacher, components of knowledge, beliefs, conceptions, and intuitions are inextricably intertwined" (p. 446). This line of thinking supports a key principle of interpretivist research, which rejects the positivist idea that human behavior can be studied objectively as in the fields of chemistry and physics.

Interpretivism argues that humans behave in the ways they do in part because of their environments. Environmental influences on human behavior are not direct; instead they are based on individuals' subjective perceptions. A primary purpose of interpretivist research is to develop understanding of these subjective realities and lived experiences (Willis, 2007). Aligning with this proposition, this study was based upon the assumptions that multiple realities describe what make a teacher effective, and these need to be understood from the perspectives of the individuals who experience the phenomena. Guba and Lincoln (1994) posited that such lived realities are apprehensible in the form of abstract mental constructions that are experientially based, local, and specific. Accordingly, this study focused on the immediate and local meanings of teacher effectiveness as perceived by participants who are exemplary teachers.

Interpretivism is a paradigm that is particularly congruent with my research questions. Intrepretativist research is committed to the detailed examination of what is happening to participants and what sense they make of what is happening to them (Smith, Flowers, \& Larkin, 2009). Therefore, the researcher assumed interpretivism is a more appropriate paradigm to investigate the practices and beliefs of exemplary (i.e., national award-winning) 
teachers in the U.S. and China, as compared with the paradigms used in conventional teacher effectiveness research. Current research on teacher effectiveness has developed according to a number of discrete phases, from presage-product studies to new paradigms focusing on teacher beliefs, then to process-product studies, and most recently to large-scale, longitudinal studies involving variance decomposition modeling to determine the statistical value of teacher effects on student achievement scores (Campbell, Kyriakides, Muijs, \& Robinson, 2004; Rowan, Correnti, Miller, 2002). Presage-product studies attempted to identify the association between psychological characteristics and teacher effectiveness. The most widely studied of these personality characteristics include authoritarianism and flexibility, attitudes like motivation to teach, years of teaching experience, degree, race, and certification status. However, this line of studies failed to produce robust findings on factors that could affect teacher quality (Campbell et al., 2004).

Thus, researchers turned to process-product studies to examine specific teacher behaviors as a possible cause of student achievement. Typical methods used in processproduct research involved testing pupils at the beginnings and ends of studies using standardized achievement tests. Teachers were then observed by researchers using structured observation instruments or, alternatively, the teachers completed questionnaires about their teaching methods. Correlational methods were then used to relate teaching behaviors observed with student learning outcomes or growth measures. Generally, findings from process-product studies did not indicate that there were any "silver-bullet practices" that would lead to higher levels of teacher effectiveness (Campbell et al., 2004). 
Conceptualizations of teacher effectiveness in conventional research have been criticized for being narrow and simplistic. Among many other shortcomings, they are criticized "for the lack of attention given to teachers' own beliefs about, and attitudes toward, teaching and the subjects they teach, arguing that these deeper structures are more important to teaching quality than immediate observable behaviors" (Campbell et al., 2004, p. 49). Another important shortcoming of teacher effectiveness research lies in its tendency to perceive effectiveness in a generic way-assuming that as long as a teacher possesses certain dispositions and exhibits certain behaviors, he/she will be effective with all students, in all contexts, and in all content areas of the subject taught (Campbell et al., 2004).

Schalock, Schalock, Cowart and Myton (1993) noted that simplistic conceptions of a teacher as an artist, applied scientist, decision maker, or reflective practitioner fail to portray the complexity of teaching. Effective teaching is much more than implementing a number of pedagogical principles and content knowledge. It involves a dynamic interplay among content to be learned, pedagogical methods to be applied, characteristics of learners, and the contexts in which the learning will occur. For instance, a teacher's effectiveness may be contingent upon the subject subtopics he/she teaches or the type of students he/she works with (Campbell et al., 2004; Schalock et al., 1993). A teacher who is effective in improving students' vocabulary development may not necessarily be effective in helping students improve their comprehension. Also, one teacher may be more effective in teaching gifted and talented students as compared with teaching students with average learning abilities. A study residing in the interpretivist paradigm can garner a richer understanding of the multi-faceted experiences of effective teachers in their daily complex and dynamic classrooms. An 
interpretivist inquiry can capture the fullness of teacher effectiveness in a more holistic manner than can conventional teacher effectiveness research by giving greater attention to the "nuance, setting, interdependencies, complexities, idiosyncrasies, and context" in the natural classrooms (Patton, 2002, p. 60).

\section{Perspective}

This study built upon Stronge's (2007) teacher effectiveness framework, which has strong correlations with teacher quality frameworks in China (e.g., Bai, 2000; Cui \& Wang, 2005). The framework was grounded in a broad review of research that explored qualities of effective teachers. In this study, it served as a lens to help the researcher to understand the essential qualities of each selected award-winning teachers, and ultimately, shared qualities across cultures through phenomenological examination of patterns of instruction and belief in the United Stated and China. The framework contains following domains:

- Prerequisites for Effective Teaching, including characteristics such as a teacher's educational background, professional preparation, verbal ability, content knowledge, educational coursework, and teacher certification.

- Teacher as a Person, with an emphasis on a teacher's nonacademic interactions with students and professional attitude.

- Classroom Management, with the purpose of establishing a classroom environment that is conducive to teaching and learning.

- Planning for Instruction, including the practices of maximizing the amount of time allocated for instruction, communicating expectations for student achievement, and planning for instructional purposes. 
- Implementing Instruction, including the practices of using instructional strategies according to particulars of student needs, understanding the complexities of teaching, using questioning techniques and supporting student engagement.

- Assessing Student Progress, such as using homework and ongoing assessment to solicit data of student learning, providing meaningful feedback, and applying the findings of student learning outcomes to improve instruction.

This theoretical framework links different parts of this study's design. For example, it guided the generation of interview questions and it also guided the selection of an appropriate classroom observation instrument. It was also used to generate an a priori set of codes for data analysis, and served as a lens through which to view and interpret data, helping to generate categorical and thematic interpretations. As mentioned earlier, the six qualities in Stronge's model are distilled based on an overview of extant literature that examined what constitutes teacher effectiveness, thus this framework can be considered as having a sound construct validity (i.e., the framework is a valid measure of an intended hypothetical construct—-teacher effectiveness in this case) and content validity (i.e., the items in Stronge's framework represent the existing literature that examined qualities of effective teachers). Numerous research studies using classroom observation have found that teachers exhibiting the qualities in Stronge's (2007) model are associated with students' learning progress in various subject areas (e.g., Borman \& Kimball, 2005; Gallagher, 2004; Heneman, Milanowski, Kimball, \& Odden, 2006; Holtzapple, 2003; Jacob \& Lefgren, 2008; Kimball, White, Milanowski, \& Bowman, 2004), therefore, Stronge's model has fairly robust criterion validity (i.e., a consistency with performance on another criterion, such as student learning 
achievement gain scores) . Additionally, Williams (2010) found the perceptions of teachers' and administrators' agreements with Stronge's model as an operational definition of teacher effectiveness are highly consistent and strong. Further results showed that demographic factors played a minimal role influencing teachers' and administrators' perceptions. These findings suggest Stronge's teacher effective model has solid concurrent validity (i.e., consistency of results by tests that are administered at the same time but on different groups of participants).

\section{Research Strategy}

To investigate teacher practices and perceptions of effectiveness, this study used a phenomenological approach. Phenomenology is a tradition in philosophy that focuses upon the essence of lived experiences. Van Manen (1990) argued that phenomenology examines the "the very nature of a phenomenon, for that which makes a some- 'thing' what it is-and without which it could not be what it is" (p. 10). Studies using a phenomenological strategy "focus in depth on the meaning of a particular aspect of experience, assuming that through dialogue and reflection, the quintessential meaning of the experience will be revealed" (Rossman \& Rallis, 2003, p. 97). The purpose of phenomenological inquiry is to understand phenomena in context-specific settings, developing description, interpretation, and reflection upon participants' lived experiences (Hoepfl, 1997; Van Manen, 1990).

Phenomenology is a promising strategy for exploring my research questions with a small pool of informative participants. It involves examining the world "as it appears to individuals when they lay aside the prevailing understanding of those phenomena and revisit their immediate experience of the phenomena" (Gall, Gall, \& Borg, 2007, p. 495). By 
"experience of the phenomena," the researcher meant the "various sensations, perceptions, and ideations that appear in consciousness when the self focuses attention on an object" ( $p$. 495). In this study, the phenomenon of interest is teacher effectiveness.

Phenomenological study was an appropriate way to uncover, construct and report the meaning-based structures that participants used to organize and make sense of their effective teaching experiences. This study carefully captured and described how award-winning teachers conceptualized and experienced the phenomenon of teacher effectiveness-how they actualized it in the classroom, perceived it, described it, judged it, remembered it, made sense of it, and talked about it with the researcher (Patton, 2002). These meaning structures were hidden from direct measurement and often taken for granted by participants. A phenomenological study could surface these meanings. Additionally, the phenomenological design of this study was naturalistic in the sense that the study occurred in authentic, realworld contexts, and the researcher did not attempt to manipulate the phenomenon of interest (Patton, 2002). Thus, this study was an investigation of what award-winning teachers do in the natural environments of their classrooms and how they "make sense of experience and transform experience into consciousness" (Patton, 2002, p. 104).

\section{Sample and Participant Selection}

This research study involved a comparative analysis of national award-wining American and Chinese teachers. In order to examine individual teachers' practices and beliefs in depth, while keeping the research manageable in scope, a small, but diverse, sample of effective teachers was drawn. Given this focus, the participants should satisfy a level of scrutiny to be considered representative of excellent teaching in their respective countries. 
Primary Criterion for Sample Selection. Sampling began with identifying criteria for constructing the sample (Patton, 2002). A substantial limitation of identifying excellent teachers was, first, how to define excellence and, second, how to find excellent teachers. In defining excellence, the researcher was guided by the Stronge (2007) framework, along with Chinese researchers' criteria (Bai, 2000; Cui \& Wang, 2005) mentioned earlier. The researcher chose national award-winning teachers as the operational definition of excellence. Thus, participants were invited based on having received a teaching award from a national organization granting recognition across content areas and grade levels.

Accepting national award-winning teachers as excellent teachers is not a proof-perfect process. It is entirely possible that teachers received awards for reasons other than exhibiting the qualifying criteria of excellence that the researcher adopted. No doubt, many deserving, truly outstanding, teachers were overlooked in the award selection processes. Nonetheless, absent a more perfect method for identifying teacher excellence (e.g., teacher effectiveness indices as measured by teachers' effects on student academic growth), the researcher chose to accept the risk of equating national teacher awards with teacher excellence. In defense of this assumption, all awards that were considered, in both the U.S. and China, have a rigorous vetting process for identifying and determining their award-winners. The U.S. awards considered in this study included the Milken National Award, Disney Teacher Award, and National Teachers Hall of Fame. The Chinese award that was used to identify potential participants is the National Teacher Award, bestowed by the Ministry of Education. In both nations, reviews of these major national awards revealed that their criteria included some or all of the following: 
1) Contributions to education;

2) Recognition by the community and use of community resources;

3) Being a role model for students and other teachers;

4) Innovation in education;

5) Professionalism, and

6) Excellent teaching practices.

Among these criteria, contributions to education and excellent teaching practices are the most commonly cited, so recipients of awards highlighting these criteria were chosen for this study.

To illustrate, the Milken National Award, given in the United States, identifies and selects outstanding elementary and secondary school teachers "as evidenced by effective instructional practices and student learning results in the classroom and school" or as evidenced by "accomplishments beyond the classroom that provide models of excellence for the profession" (Milken Family Foundation, n.d., p. 1). In China, the National Teacher Excellence Award emphasizes the exceptional roles played by teachers in inspiring the development of their students as whole people and in exploring innovative instructional strategies that have positive impact upon their classroom effectiveness and student learning outcomes (Ministry of Education of the People's Republic of China, n.d.).

Secondary Criterion for Sample Selection. Maximum variation sampling was used to select participants. Maximum variation sampling "involves selecting cases that illustrate the range of variation in the phenomena to be studied" (Gall, Gall, \& Borg, 2007, p. 182). In using maximum variation sampling, the researcher selected teachers that vary widely in their 
years of teaching experience, levels of teaching (e.g., elementary, secondary), content areas, geographic regions (e.g., urban, rural), and gender. In this study, maximum variation sampling served two purposes: to document the range of variation in the selected awardwinning teachers, and to determine whether common themes, patterns, and outcomes cut across this variation (Gall, Gall, \& Borg, 2007; Patton, 235). Lincoln and Guba (1985) suggested that maximum variation sampling is the most useful sampling strategy for phenomenological inquiry.

For a sample as small as the one used in this study, however, heterogeneity can be a concern because individual cases are so different from each other. Any potentially transferable findings across cases may, therefore, be difficult to apply. However, the maximum variation sampling strategy "turns that apparent weakness into a strength by applying the following logic: Any common patterns that emerge from great variation are of particular interest and value in capturing the core experiences and central, shared dimensions of a setting or phenomenon" (Patton, 2002, p.235).

Since the award-winning teachers may have different characteristics in terms of the geographic regions they come from (e.g., urban, rural), grade levels (e.g., elementary, secondary), years of teaching experience, gender, and other relevant factors that may influence their practices and beliefs, the researcher purposefully selected a list of teachers that vary widely in these elements. While analyzing the data and reporting the results, the researcher attended to the uniqueness of each participant, but also looked for common themes across participants. Such patterns can take on added importance because they emerge out of great heterogeneity (Patton, 2002). 
Selecting an appropriate sample size for a phenomenological study involves a tradeoff between breadth and depth. Patton (2002) stated:

With the same fixed resources and limited time, a research could study a specific set of experiences for a larger number of people (seeking breadth) or a more open range of experiences for a smaller number of people (seeking depth). In-depth information from a small number of people can be very valuable, especially if the cases are information-rich. Less depth from a larger number of people can be especially helpful in exploring a phenomenon and trying to document diversity or understand variations. (p. 242)

Since the primary purpose of this phenomenological inquiry was to both quantify and uncover a richer meaning of a phenomenon - teacher effectiveness - which is a multifaceted and complicated construct, both depth and breadth are essential to this study. Twelve award-winning teachers from China, and thirteen from the United Stated participated in this study. Patton (2002) suggested that the ideal sampling procedure is to keep selecting cases until one reaches the point of redundancy — that is, until no new information is forthcoming from new cases. Thus, about 3 to 5 teachers from each country were kept on a waiting list. If more cases were needed, these teachers would have been included as participants. It turned out that the sample used in this study was large enough to generate the amount of data that sufficed the purpose of this study.

\section{Data Generation/Collection}

As stated above, this study focuses upon the practices and beliefs of its participants. Given the importance of triangulating data, multiple types of data were generated and 
collected. Data generation and collection involved one-day visits to each teacher's school, with at least one hour of formal observation, a 45-minute to one-hour interview, a review of selected teaching artifacts (e.g., lesson plans, student work, handouts), and informal observation and conversation. The data were gathered until enough had been amassed to reach theoretical saturation - that is, when newly generated findings essentially replicate earlier ones (Strauss \& Corbin, 1998). Until that point, more participants from the waiting list would have been recruited for extended data generation and collection.

Triangulation. Triangulation is important to phenomenological inquiry, as it can help to uncover the intricacies of complex phenomena from multiple sources of evidence from which the researchers wish to draw conclusions, thus "improving the probability that findings and interpretations will be found credible" (Lincoln \& Guba, 1985, p. 305; Willis, 2007). In this study, methodological triangulation was the specific strategy that was implemented (Willis, 2007). Methodological triangulation involves confirmation across multiple and different data generation and collection methods.

The data types used in this study included interviews, classroom observations, and artifacts. Denzin (1989) argued that the major justification for triangulation is that the flaws of one data generation method are often the strengths of another, and by combining multiple methods, researchers can create deeper interpretations of phenomena, drawing conclusions that are supported by multiple types of data. In this study, information generated by the participants during semi-structured interviews would be limited by their knowledge, memory, and abilities to convey information clearly and accurately, and will be affected by how they wish to be perceived by the interviewers (Gall, Gall, \& Borg, 2007). Observations and 
artifacts allowed the researcher to perceive what was occurring, then checked the researcher's interpretations with the participants during post-observation interviews. Just as importantly, the interviews provided an additional type of data for verifying the information generated by observation. Observations recorded teachers' patterns of behaviors, while interviews provided information regarding their underlying rationales for those behaviors, based upon the teachers' interpretations of their classroom experiences.

Data sources were also triangulated in this study. That was achieved through using a wide range of participants. Through generating data with varied informants, individual experiences and viewpoints could be compared with others and, ultimately, a rich picture of the phenomenon under scrutiny might be constructed.

Interviews. Phenomenological interview serves two primary purposes (Van Manen, 1990). Firstly, it can be used as a means to explore and gather experiential narrative material that may serve as a resource for developing a richer understanding of a human phenomenon. Secondly, interviewing is an effective method for prompting participants to articulate and converse with the interviewer their understandings of phenomena being studied. In this study, the interview questions were designed to elicit participants' reflections on their own practice, exploring subjective experiences of the profession of teaching.

Each interview lasted between 45-60 minutes, depending on the lengths of participants' responses. Semi-structured interviews were used, which involved asking a set of pre-determined questions, but also allowed for the flexibility to ask follow-up questions that were helpful in encouraging respondents' deeper thinking on ideas and issues that emerged during the interview (Kvale, 1999). Conducting semi-structured interviews enabled the 
researcher to enter interview settings with pre-designed questions in mind to ensure that the conversations covered key areas of the research focus, as well as allowed the researcher to generate questions during the interview based on informants' responses. In this way, the semi-structured interview format could allow for some standardization, which was useful in across-participant analysis (Kvale, 1999). Simultaneously, the open-ended format and use of follow-up question could elicit aspects of teachers' experiences about effectiveness, including those not previously conceived by the researcher.

In this study, interview data were generated until data saturation was reached - when emerging categories or relevant themes began to be repetitive. Member checking was also implemented during the interviews. The researcher reflected participants' comments back to them to check the understanding of their perceptions of teacher effectiveness. The pre-set questions for the semi-structured interview protocol were linked to the six categories of the qualities in Stronge's framework (2007). Several additional questions were asked so that the teachers could reflect further upon their practices and their perspectives regarding the studied phenomenon. Specifically, the following interview protocol was used to prompt participants' responses, which included major questions and sample follow-up probes: 


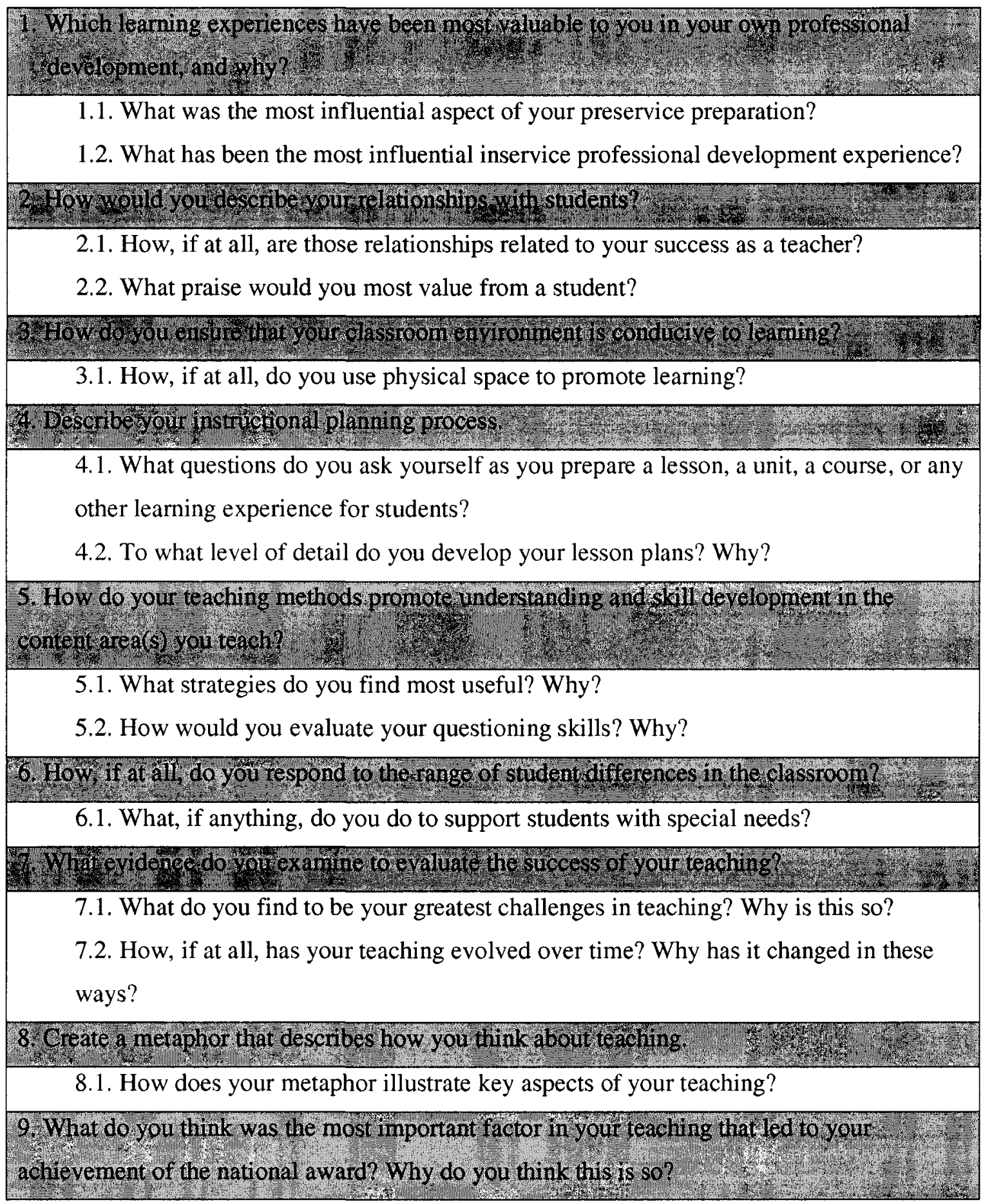

This interview protocol was developed and field-tested in a small-scale, preliminary investigation (Grant, Xu, Stronge, Little, \& Sun, 2009). The protocol was found to be 
effective in encouraging the participants to explore and communicate their perceptions of teacher effectiveness.

Observations. Each of the participants was observed within their authentic teaching environment. The Differentiated Classroom Observation Scale (Cassady et al., 2004) was used as the instrument for collecting observation data. The Differentiated Classroom Observation Scale was developed by researchers at Ball State University as a way to examine instructional practices related to differentiation and high ability learners. However, the researchers noted that the instrument is valuable for examining instructional practices with any group of students (Cassady et al., 2004).

The Differentiated Classroom Observation Scale (DCOS) includes three components: the pre-observation interview, the observation period, and the post-observation debrief and reflection. The pre-observation contact allowed the observer to gather contextual factors. The observation phase was an in-depth examination of the classroom environment and learning experiences that occurred during the observed period of time. The post-observation debrief allowed the observed teacher to have a chance to provide additional information that may help a more robust understanding of the observation (such as a deviation from the planned activities). And the post-observation reflection was an opportunity for the observer to explore her impressions of the classroom environment that may not have been fully represented in the standard observation protocol, which will be described in more details in the following section,

The standard observation protocol enabled the observer to record several data points at 5-minute intervals: instructional strategies employed, percentage of students engaged, 
director of the activity (e.g., primarily teacher-directed or primarily student-directed), and levels of cognitive demand. Using this scale, all instructional activities employed within each 5-minute interval were recorded during each formal observation, using a set of codes provided with the protocol (e.g., lecture, teacher questioning, student response, independent seat work, group discussion, assessment activity, etc.). The researcher also assessed the extent to which levels of conceptual difficulty were evident within each interval, using the revised version of Bloom's cognitive taxonomy - knowledge, comprehension, application, analysis, evaluation, creation (Anderson \& Krathwohl, 2001). Each of the six cognitive levels were rated on a three-point scale: "1" - not evident; "2"- evident; "3"- well-represented. Two other two data points will also be rated within each 5-minute segment. "Student engagement" was recorded based on noting the percentage of students who were on-task engaged at each pre-determined point of time within the observation interval (e.g., at the beginning of third minute in each five-minute interval). Student engagement was rated on a three-point scale: " 1 " - low engagement (20\% of fewer of students engaged in learning); " 2 "” - moderate engagement (21-79\% of students engaged in learning); " 3 " - high engagement ( $80 \%$ or more students engaged in learning). "Learning director" was recorded as a general observation across the interval. It was scored on a scale that has five points: "1" - Teacher directs all learning; "2" - Teacher directs most learning; "3" - Teacher and students share learning decisions; "4" - Student directs most learning; and "5" - Student directs all learning.

One limitation of using the observation of students' behavioral performance to determine their engagement level is that the observer may note that a student that is "on-task" because the student appears to be engaged, but, for example, may be daydreaming while 
looking at the teacher or writing a note to a friend when tasked with writing an essay. Student engagement can be determined using different sets of criteria, including cognitive (e.g., student effort to grasp the information), behavioral (e.g., attending to class activities or timeon-task), and affective (i.e., student attitude toward a task) (Chapman, 2003). Each of these criteria each has a place in determining student engagement. Yet behavioral criteria, or time on task, are supported in the literature as being directly related to student achievement (Stronge, Ward, Tucker, \& Hindman, 2008; Taylor, Pearson, Peterson, \& Rodriguez, 2003). Additionally, behavioral criteria can be applied through direct observation, whereas other engagement indices are not observable.

The disadvantage of using a standardized observation form was that it might not include all the variables that the observer would like to observe, therefore, the researcher kept field notes to document contextual information and specific aspects of teachers' behaviors that were not captured by the observation form (Gall et al., 2007). Based on suggestions from Denzin (1989) and Merriam (1998), field notes in this study were used informally to record the following aspects of classroom observation: participants within classrooms (i.e., teachers and students), interactions among participants, routines, temporal elements (e.g., the subject content taught during the period of time under observation), social organizations within classrooms, the physical environment, and the professional context (e.g., the curriculum and instructional strategies encouraged and discouraged within the school system), as well as subtle factors (e.g., the affective learning environment and nonverbal communication). Although observation field notes were not the primary data source for this study, they were important in complementing the standardized observations generated, providing a more 
complete and credible representation of what was happening in the classrooms being observed.

Artifacts. Additionally, participants were asked to share an artifact that they felt best represents their effectiveness as teachers during the individual face-to-face interview that occurred prior to the classroom observation. The purpose of including the artifact was twofold. First, the researcher wanted the participants to have opportunities to think about their experiences concerning effectiveness prior to the interview. In addition, artifact analyses were conducted to provide greater depth and breadth to the data generated. Others types of artifact that were examined include lesson plans, student workbook, handouts, and blackboard/computer displays. The participants were given opportunities to share their perceptions about the artifacts during interviews. The primary advantage of using artifacts was that it did not influence the social setting being examined. Since what teachers said they believe might differ from what they actually did sometimes, artifact analysis offered an alternative insight into the ways in which the exemplary teachers experienced and perceived the phenomenon under study (Hatch, 2002).

\section{Data Analysis}

Data analysis in phenomenological inquiry is a process intended to "grasp and elucidate the meaning, structures, and essence of the lived experience of a phenomenon for a person or group of people" (Patton, 2001, p. 482). This section addresses the methods of data analysis that move from the raw data to researcher's interpretations and general explanations. Descriptive Statistics. Once the observation data of teacher teaching practices were collected, they were summarized to provide a meaningful representation of what happened in 
the observed classrooms. The data from form-based, in-class observations were analyzed using descriptive statistics, with a particular focus on describing what American and Chinese award-winning teachers do similarly and differently. Descriptive statistics are mathematic techniques for organizing, summarizing, and displaying a set of numerical data (Gall, Gall, \& Borg, 2007). In this study specifically, means were calculated to compare the average numbers of different types of instructional strategies used by participants from the U.S. and China. Categorical data were used to summarize observation data by creating frequency counts of each type of classroom activity, so as to identify the most frequently occurring learning activities in the classrooms of U.S and China award-winning teachers (Gall, Gall, \& Borg, 2007). In order to do that, for each observed lesson, the total number of 5-miniute intervals in which each instructional activity (i.e., lecture, class discussion, small group discussion, student presentation, cooperative earning, role planning, technology use, etc.) occurred was calculated. Then for each instructional activity, the numbers of intervals in which it occurred were divided by total number of intervals recorded in that particular observed lesson. That led to a percentage number - the percentage of the total lesson time during which each instructional activity occurred. The researcher averaged the percentages for each variable across participants in the U.S. and China that were observed, and compared the similarities and differences between the award-winning teachers in the two nations.

In addition, means were calculated to summarize and compare the degree of student engagement, cognitive level of learning activities observed, and "learning director" in the classrooms of U.S. and China. For each teacher, the average score of these three variables 
were calculated. These numbers for individual teachers were averaged across all participants in the U.S. and China, in order to the similarities and differences between these two nations.

Grounded Theory Analysis. The data generated with one-to-one interviews were recorded and transcribed verbatim and were examined using grounded theory. The term "grounded theory" refers to a method of inquiry and to the product of inquiry. It also refers to a specific mode of data analysis (Charmaz, 2008) — this is the approach how "grounded theory" was used in this study. Essentially, grounded theory is an emergent categorizing strategy which codes and sorts data into appropriate categories through successive but flexible levels of data analysis and conceptual development (Charmaz, 2008; Erlandson, Harris, Skipper, \& Allen, 1993; Rossman \& Rallis, 2003). Strauss and Corbin (1998) defined grounded theory as a process that

denotes a set of well-developed categories (e.g., themes, concepts) that are systematically interrelated through statements of relationship to form a theoretical framework that explains some relevant...phenomenon. The statements of relationship explain who, what, when, where, why, how, and with what consequences an event occur...A theory usually is more than a set of findings; it offers an explanation about phenomena. (p. 22)

The essential of the techniques and procedures involved in the analysis of interview data is the interplay between the researcher and the data. Grounded theory offers a framework of coding procedures, which serve as "analytical tools for handling masses of raw data" and to "help provide some standardization and rigor" to the process of data analysis (Strauss \& 
Corbin, 1983, p. 13). These coding procedures include open coding, axial coding, and selective coding.

First, a priori codes were established before the data were analyzed, based on Stronge's (2007) model of teacher effectiveness. These codes supplied the framework to facilitate initial understanding. The researcher transcribed the interview, read interview data carefully, and divided them into segments. Each segment was a meaningful whole, dealing with one aspect of the phenomenon of interest. The segments were examined, compared with each other, and labeled with initial code names. Then, the researcher used axial coding to organize the initial codes into categories and subcategories based on their properties and dimensions as discovered in the data. Finally, selective coding was used to formulate "a logical, systematic, and explanatory scheme" (Strauss \& Corbin, 1998, p. 21). At the stage of selective coding, the researcher determined the most salient and important categories, formulated a model that best represents how those categories were related, and used the themes that emerged from that analysis to reassemble the data so as to answer proposed research questions and provided illustrations of the study's results.

Grounded theory analysis was an appropriate tool to use to uncover the underlying meanings hidden in the pages of interview transcripts. It enabled the researcher to conduct a thorough coding of the data and moved the researcher from descriptive to more theoretical levels as she represented and interpreted participants' perspectives on teacher effectiveness. The generated data were broken down, compared, conceptualized, and examined closely so that constructs, themes, and patterns could be identified to capture the fullness of the practices and beliefs of teacher effectiveness being studied. 
To ensure that the interpretation made of the research was credible in representing the participants' actual perceptions (Guba \& Lincoln, 1994; Schwandt, 2007), after transcribing the interviews, summaries of interviews were emailed to each participant, which also included initial interpretations of the interview data, for review and correction. Necessary changes were made based on their feedback. Peer reviews provided by the faculty researchers in the School of Education who were members of my dissertation committee also helped strengthen the research design, interview procedures, data analysis and interpretation.

Rossman and Rallis (2003) suggested that researchers can write analytic memos to trace "emergent insights, potential themes, methodological questions, and links between themes and theoretical notions" (p. 291). In accordance with their suggestion, the researcher used analytic memos to record the methodological decisions that are made, the definitions of the codes used, the evidence that supports each code, and thoughts about the codes individually and in relationships to each other during the process of data analysis and interpretation. The raw data generated by observations, interviews, and artifacts, along with the researcher's analysis notes and the products of the researcher's reconstruction and synthesis could serve as a confirmability audit to demonstrate the neutrality of the researcher's interpretations (Lincoln \& Guba, 1985). Overall, verbatim transcription, field notes, and the researcher's research journal entries were used to maintain an audit trail, with the purpose of representing the processes of how the study is executed and how the researcher make inferences. As overarching themes were generated that synthesized codes and categories into a systematic and explanatory scheme, a richer understanding of teacher effectiveness were generated that can be logically transferrable to other contexts. 


\section{Conclusion}

The intent of the present study was to uncover the key elements in the professional practice and thinking of teachers who have been recognized through external review as merıtıng awards from natıonal award-grantıng organızatıons, in partıcular, to verify how well-establıshed domains of effectıve teachers (Stronge, 2007) are represented by selected United States and China teachers This study used classroom observation data to 1dentify the practices of great teachers, and qualitatıve interview data to reveal the perceptions of highly effectıve teachers as they reflected on their expenience of teachıng This interpretıvist, phenomenological study provided a holistic portrait of teacher effectiveness This portrait was more descriptive compared with the results of existing teacher effectiveness research, which has examıned only isolated aspects of teachers' practices Although it would be premature to conclude what makes a teacher effectıve based on the findings of this one study, the researcher trusts that this study's results will contribute to a richer understanding of a vital 1ssue teacher effectiveness 


\section{CHAPTER 4 \\ FINDINGS}

This study explored teacher effectiveness through cross-cultural analyses of the instructional practices and beliefs of selected U.S. and China teachers who have received national awards for their teaching. Data were collected or generated through classroom observations, semi-structured interviews, and artifacts. Thirteen U.S. and 12 China awardwinning teachers participated in this study. The participants were diverse in their years of teaching experience, geographic regions, and the grades and subject areas they taught. Classroom observation data were analyzed through descriptive statistics. The data generated by interview were examined using grounded theory. Artifacts were analyzed by holistic coding. In this chapter, results of analyses will answer the following research questions:

1. What are the similarities and differences between selected award-winning United States and China teachers in their instructional practices?

a) What types of instructional activities are used by selected award-winning U.S. and China teachers?

b) How are cognitive levels, based on Bloom's revised taxonomy (Anderson \& Krathwohl, 2001), represented in these teachers' classrooms?

c) To what degree is learning teacher-directed in the classrooms of selected award-winning U.S. teachers and China teachers?

2. How are selected national award-winning United States and China teachers' classroom practices - other than instructional activities — similar and different (such as their classroom management strategies)? 
a) What are the student engagement levels in the classrooms of selected awardwinning U.S. teachers and China teachers?

b) What classroom management strategies are implemented by selected awardwinning U.S. teachers and China teachers?

3. What are the similarities and differences in professional thinking between teachers in the U.S, and China?

a) How do these teachers reflect on their practices, particularly about their relationships with students, classroom environment, instructional planning, instructional strategies, differentiation, and assessment and evaluation of students' learning?

b) What are the selected teachers' perceptions of why their practice merited recognition with a national award?

As indicated in Chapter 3, data were collected via triangulated data sources, including classroom observations, interviews, and artifacts. Table 6 indicates the major data sources that were used to answer each of the research questions noted above. 
Table 6 Altgnment of Research Questions to Data Collectıon/Generatıon and Analysts

\begin{tabular}{|c|c|c|}
\hline Research Question & Data Collection/Generation & Data Analysis \\
\hline \multirow{2}{*}{$\begin{array}{l}\text { 1 a) Types of instructional } \\
\text { activities }\end{array}$} & Classroom Observation & Descriptıve statıstıcs \\
\hline & Interviews & Grounded theory \\
\hline \multirow[t]{2}{*}{ 1 b) Cognitive levels } & Classroom observation & Descriptıve Statıstıcs \\
\hline & Field notes & Holıstic coding \\
\hline $\begin{array}{l}\text { 1 c) Teacher versus student } \\
\text { director }\end{array}$ & Classroom observation & Descriptıve Statistics \\
\hline $\begin{array}{l}2 \text { a) Student engagement } \\
\text { levels }\end{array}$ & Classroom observation & Descriptıve Statıstıcs \\
\hline \multirow{3}{*}{$\begin{array}{l}\text { 2 b) Classroom management } \\
\text { strategies }\end{array}$} & Classroom observation & Descriptive Statıstıcs \\
\hline & Field notes & Holıstic codıng \\
\hline & Interview & Grounded theory \\
\hline \multirow[t]{3}{*}{3 a) Reflection on practices } & Interview & Grounded theory \\
\hline & Field notes & Holistic coding \\
\hline & Artıfacts & Holıstıc coding \\
\hline $\begin{array}{l}3 \mathrm{~b} \text { ) Perceived reasons for } \\
\text { winnıng awards }\end{array}$ & Interview & Grounded theory \\
\hline
\end{tabular}

\section{Demographic Information}

The partıcıpants were 12 teachers in 3rd Grade to 11 th Grade in China, and 13 teachers in Kindergarten to 11 th Grade in the United States Among the China teachers, 6 were female and 6 were male, and among the U.S teachers, 3 were male, and 10 were female All the participants taught in school for more than 5 years, with 11 China teachers and $8 \mathrm{U} \mathrm{S}$ teachers having more than ten years of teaching experience. Among the China teachers, 4 taught Math, 3 taught Science, and 5 taught Language (either Chinese or English) The US teachers consisted of 5 Math teachers, 1 Science teachers, 5 Language teachers, 1 music teacher, and 1 social science teacher Six China teachers taught at elementary schools, and 6 taught at secondary schools Eight U S teachers taught elementary grades and 5 taught 
secondary ones. These 25 teachers came from 25 different school districts which were located in different geographic areas. For the China teachers, 3 were from suburban schools, 4 from rural schools, and 5 from urban schools. Eight U.S. teachers taught in suburban schools, 1 in rural schools, and 4 in urban schools. Table 7 presents demographic information of the participants by frequency and percentage.

Table 7. Participant Background Information

\begin{tabular}{llccc}
\hline Item & Category & $\begin{array}{c}\text { China } \\
\text { Frequency } \\
\text { (Percentage) } \\
\mathrm{N}=12\end{array}$ & $\begin{array}{c}\text { United States } \\
\text { Frequency } \\
\text { (Percentage) } \\
\mathrm{N}=13\end{array}$ & $\begin{array}{c}\text { Total } \\
\text { Frequency } \\
\text { (Percentage) } \\
\mathrm{N}=25\end{array}$ \\
\hline Gender & Male & $6(50 \%)$ & $3(23 \%)$ & $9(36 \%)$ \\
& Female & $6(50 \%)$ & $10(77 \%)$ & $16(64 \%)$ \\
\hline Teaching & $<5$ & $0(0 \%)$ & $0(0 \%)$ & $0(0 \%)$ \\
& $5-10$ & $1(8 \%)$ & $5(38 \%)$ & $6(23 \%)$ \\
\hline Subject & Math & $11(92 \%)$ & $8(62 \%)$ & $19(76 \%)$ \\
& Science & $4(33 \%)$ & $5(38 \%)$ & $9(25 \%)$ \\
& Language & $3(25 \%)$ & $1(8 \%)$ & $4(16 \%)$ \\
& Social Studies & $5(42 \%)$ & $5(38 \%)$ & $10(40 \%)$ \\
& Music & $0(0 \%)$ & $1(8 \%)$ & $1(4 \%)$ \\
Grade level & Elementary school & $0(0 \%)$ & $1(8 \%)$ & $1(4 \%)$ \\
& Secondary school & $6(50 \%)$ & $8(62 \%)$ & $14(56 \%)$ \\
\hline School & Suburban & $3(25 \%)$ & $8(62 \%)$ & $11(44 \%)$ \\
& Rural & $4(33 \%)$ & $1(8 \%)$ & $5(20 \%)$ \\
& Urban & $5(43 \%)$ & $4(31 \%)$ & $9(36 \%)$ \\
\hline
\end{tabular}

\section{Findings for Research Question 1:}

\section{What Are the Similarities and Differences Between Selected Award-Winning United}

\section{States and China Teachers in Their Instructional Practices?}

The Differentiated Classroom Observation Scale (DCOS) yielded data regarding the nature and number of instructional activities, student engagement, and teacher-directed versus student-directed learning. The research findings of each measure are presented in descriptive statistics, i.e., in means and percentages. The findings that derived from interview data 
regarding instructional practices are also presented here to provide more illustration about what the participants look on at these practices. In addition, the researcher took field notes during the process of observation to keep more details regarding how each data point in DCOS was actualized by the teachers. Three sub-questions of Research Question 1 were respectively answered by a combination of these three sources of data.

a) What Types of Instructional Activities Are Used by Selected Award-Winning U.S. and China Teachers?

Number of instructional activities

All instructional activities were recorded in 5-minute segments using codes established by the DCOS. A total of 109 segments were observed in U.S. classrooms, and a total of 89 segments were observed in China classrooms. The length of the observations were comparable between China teachers and U.S. teachers, with the mean length of Chinese classroom observations being 7.4 segments (52 minutes) and the U.S. classroom observations being 8.4 segments ( 59 minutes). According to the data shown in Table 8 , the China teachers used, on average, 9.5 different instructional activities during an entire observation. United States teachers used, on average, 9.3 different instructional activities during an entire observation. Thus, there were only very minor differences noted in the number of activities per lesson between the teachers in the two countries.

Table 8. Results from the Differentiated Observation Scale, Number of Instruction Activities, by Country

$M \frac{\text { China Teachers }}{\text { Range }} \frac{\text { United States Teachers }}{M}$

Number of instructional

$\begin{array}{lllll}\text { activities per classroom } & 9.50 & 7-12 & 9.30\end{array}$
observation 
Table 9 shows the instructional activities most used by China teachers, with a comparison of how frequently those activities were used in United States teachers' classrooms, as shown by 1) the percentage of teachers who used the instructional activity and 2) the percentage of overall observation segments in which the instructional activity was used. The later were analyzed by determining the average use of the instructional strategies across all observed 5-minute observation segments. As indicated in Table 9, Figures 2 and 3, China teachers most often used questioning, student responding, lecture, technology use (by the teacher), lecture with discussion, and students working individually. Comparatively, United States teachers also used these instructional strategies but to a smaller degree.

Table 9. Most Used Instructional Activities by China Teachers, Compared with United States Teachers

\begin{tabular}{lcccc}
\hline \multicolumn{1}{c}{$\begin{array}{c}\text { Instructional } \\
\text { Activity }\end{array}$} & $\begin{array}{c}\text { Percentage of } \\
\text { teachers }\end{array}$ & $\begin{array}{c}\text { Percentage of } \\
\text { observation } \\
\text { segments }\end{array}$ & $\begin{array}{c}\text { Percentage of } \\
\text { teachers }\end{array}$ & $\begin{array}{c}\text { Percentage of } \\
\text { observation } \\
\text { segments }\end{array}$ \\
\hline Questioning & $100 \%$ & $84 \%$ & $100 \%$ & $62 \%$ \\
\hline Student Responding & $100 \%$ & $83 \%$ & $100 \%$ & $64 \%$ \\
\hline Lecture & $100 \%$ & $82 \%$ & $54 \%$ & $17 \%$ \\
\hline $\begin{array}{l}\text { Technology Use- } \\
\text { Teacher }\end{array}$ & $58 \%$ & $40 \%$ & $46 \%$ & $17 \%$ \\
\hline $\begin{array}{l}\text { Lecture with } \\
\text { Discussion }\end{array}$ & $58 \%$ & $30 \%$ & $46 \%$ & $11 \%$ \\
\hline $\begin{array}{l}\text { Student Working } \\
\text { Individually }\end{array}$ & $83 \%$ & $29 \%$ & $54 \%$ & $16 \%$ \\
\hline
\end{tabular}


Figure 2. Most Used Instructional Activities by China Teachers, Compared with United States Teachers: Percentage of Teachers

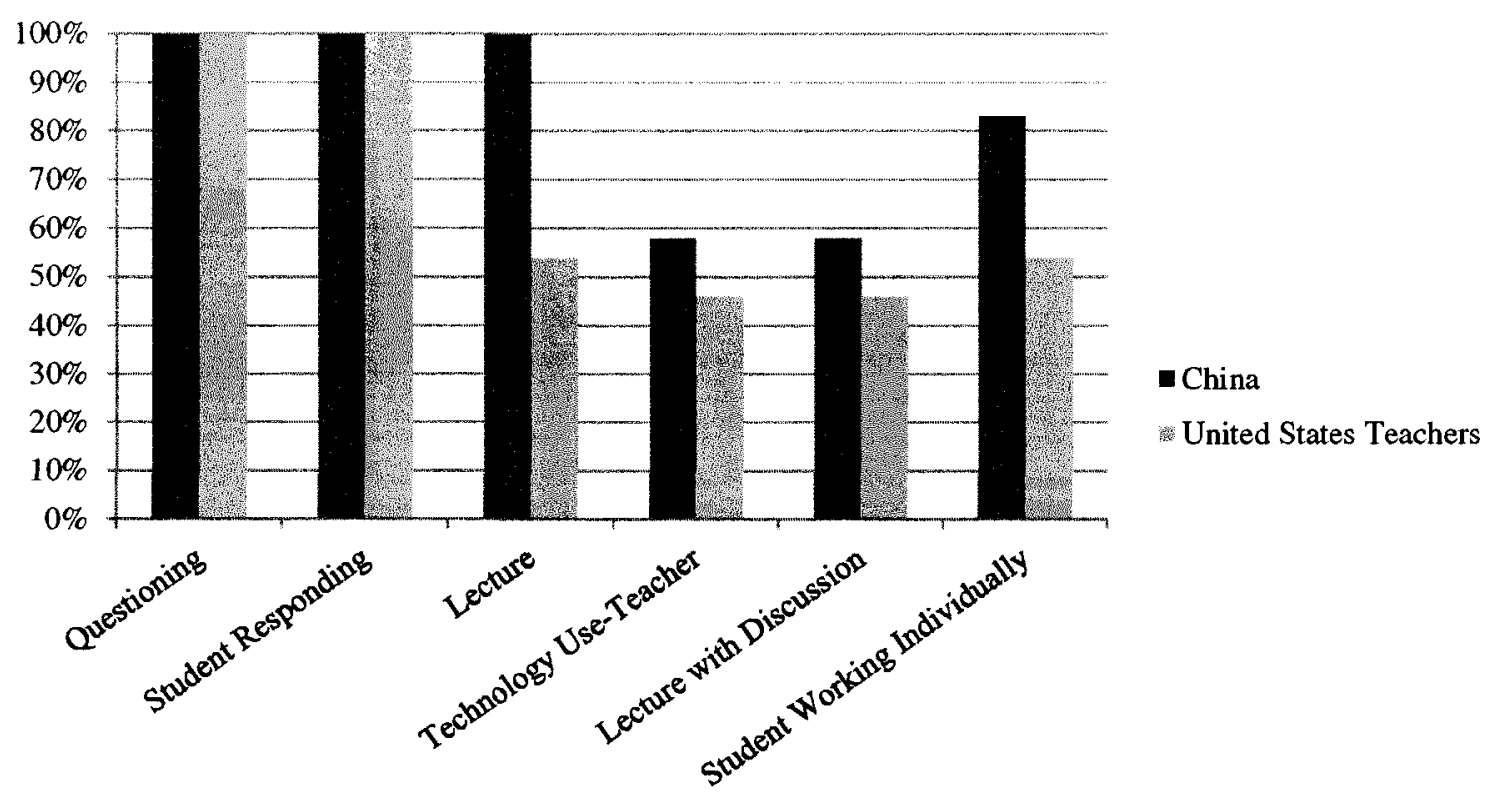

Figure 3. Most Used Instructional Activities by China Teachers, Compared with United States Teachers: Percentage of Observation Segments

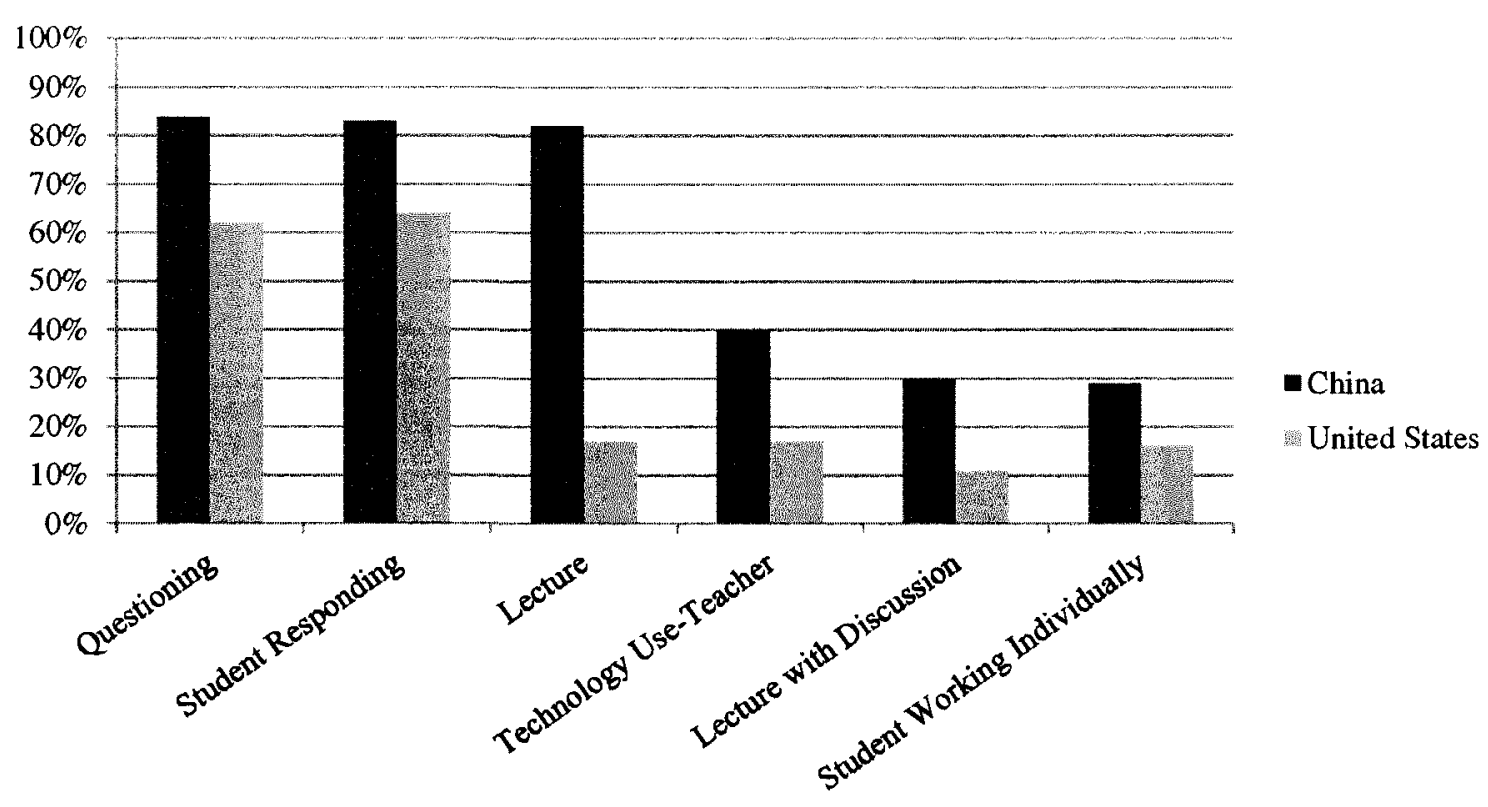

Table 10, Figure 4 and Figure 5 present the instructional activities most used by

United States teachers, with a comparison of China teachers' classroom. The United States 
teachers most frequently used student responding, questioning, teacher interacting with student and group, technology use (by the teacher), and lecture.

Table 10. Most Used Instructional Activities by United States Teachers, Compared with China Teachers

\begin{tabular}{lcccc}
\hline \multicolumn{1}{c}{$\begin{array}{c}\text { Unstructional } \\
\text { Activity }\end{array}$} & $\begin{array}{c}\text { Percentage of } \\
\text { teachers }\end{array}$ & $\begin{array}{c}\text { Percentage of } \\
\text { observation } \\
\text { segments }\end{array}$ & $\begin{array}{c}\text { China Teachers } \\
\text { teachers }\end{array}$ & $\begin{array}{c}\text { Percentage } \\
\text { of } \\
\text { observation } \\
\text { segments }\end{array}$ \\
\hline Student Responding & $100 \%$ & $64 \%$ & $100 \%$ & $83 \%$ \\
\hline Questioning & $100 \%$ & $62 \%$ & $100 \%$ & $84 \%$ \\
\hline $\begin{array}{l}\text { Teacher Interacting } \\
\text { with Individual }\end{array}$ & $69 \%$ & $24 \%$ & $50 \%$ & $8 \%$ \\
Student & $62 \%$ & $24 \%$ & $25 \%$ & $4 \%$ \\
\hline $\begin{array}{l}\text { Teacher Interacting } \\
\text { with Small Group }\end{array}$ & $46 \%$ & $17 \%$ & $58 \%$ & $40 \%$ \\
\hline $\begin{array}{l}\text { Technology Use- } \\
\text { Teacher }\end{array}$ & $54 \%$ & $17 \%$ & $100 \%$ & $82 \%$ \\
\hline Lecture & & & & \\
\hline
\end{tabular}

Figure 4. Most Used Instructional Activities by United States Teachers, Compared with China Teachers: Percentage of Teachers

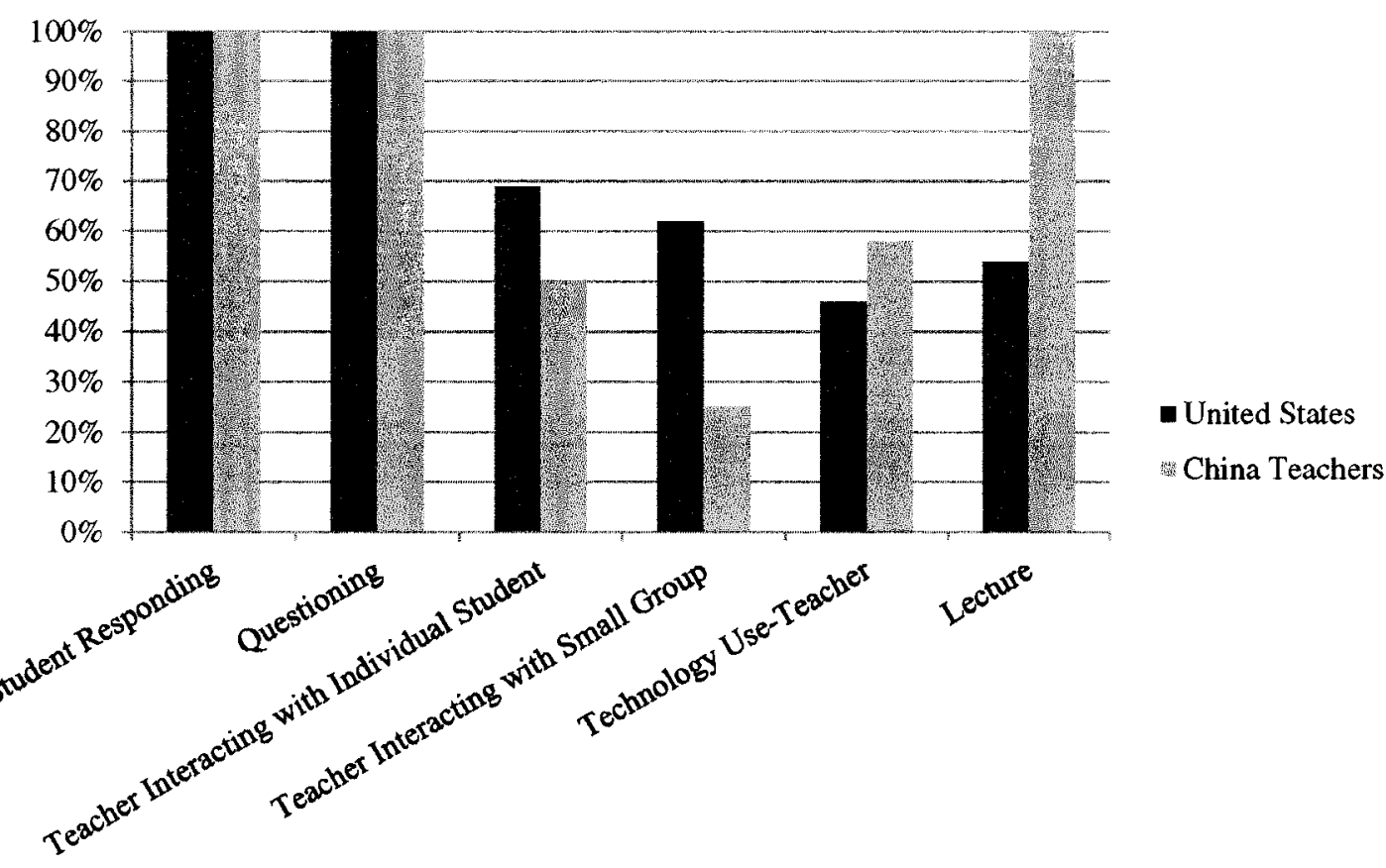


Figure 5. Most Used Instructional Activities by United States Teachers, Compared with China Teachers: Percentage of Observation Segments

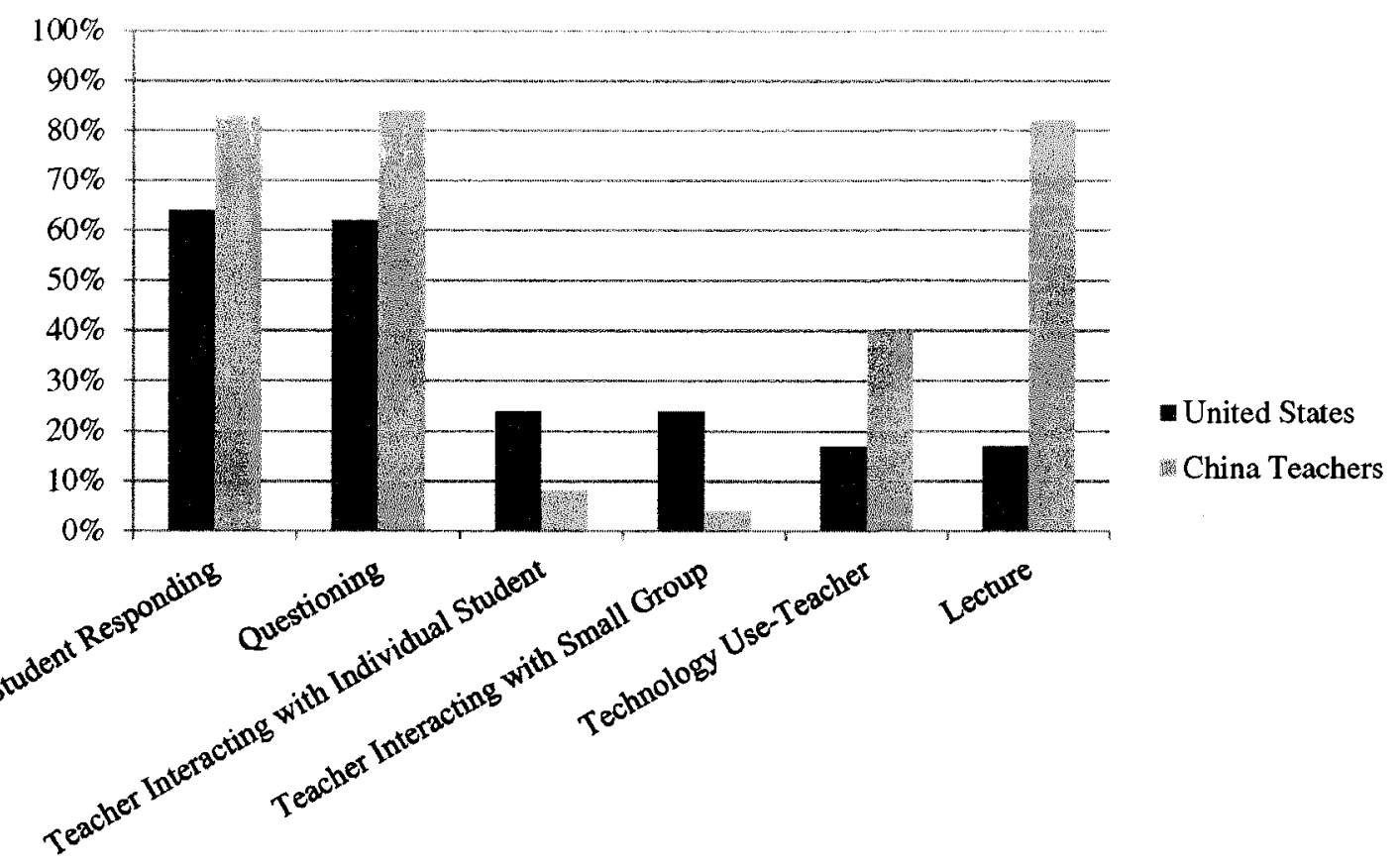

Questioning and Student Responding. All of the observed teachers, both in the United States and in China, asked appropriate questions at appropriate times to solicit responses from the students throughout their lessons. The China teachers used questioning and student responses in about $80 \%$ of their observed segments, and the U.S. teachers used them in $60 \%$ of their instruction. These teachers used questioning to stimulate student thinking and assess how well students have mastered the basic facts, concepts, or skills in their lessons. Questioning was an important strategy used by the teachers to stimulate students' learning motivation and increase their participation. Furthermore, in most of the cases student responding provided important input for the teachers to make instructional modifications. These observed teachers, in both China and the U.S. were adept at posing questions of different level of complexity, as a means of scaffolding to increase student participation, 
guide student thinking, verify and clarify student understanding. This finding was supported

by China teachers' comments during interviews:

"Most of my questions in class emphasize on the main and difficult points of my teaching goal. The questions function as a key drive to stimulate students' thinking."

"For the lesson I taught today, I didn't designed many questions. I just had a few major questions in my mind. When in the class, the rich responses from the students inspired me to ask more follow-up questions which were even more thoughtprovoking, which I've never thought about before the lesson."

"I prepare my questions before my classes. I think that what's essential to questioning is that it has to be related to the learning objectives. The sequence of questions should be in the order of from easier to more complicated. I think it's also important to ask the questions to students who can answer it, so that they can experience the success of learning. Since in some cases it's hard to predict students' responses, one should remain flexible for necessary change or ask opportunistic follow-up questions."

Some comments by U.S. teachers that would support this finding are:

"I'm aware of the levels of questioning skills. I try not to use too many yesino questions obviously. I try to ask speculative questions. I try to ask questions for which there is not a single answer so they can think. I try to whenever possible to elicit different points of view... Let the kids have time to think about it rather than go forward. Rather than we jumping in and being anxious to move them forward than giving them enough time. There's a fine line here because you can lose them too.You can wait for too much time. You've got to keep the tempo going, especially with teenagers... With 16 year olds and 17 years old you'd better keep things move kind of quickly. So there's probably a fine line."

"Questioning is so important, because otherwise you could have them not thinking. And the whole response to questions, if you just let the same people respond, half of them are never ever thinking, and it's not just that they're not responding, they haven't even engaged in your question, and that's deeply important, I'm sure, because otherwise you're not checking up on whether they're listening, you know. I mean I often know, when someone's asleep, I'll ask them a question and say what did they just say, and then others are alerted to the fact that I'm aware. And then hopefully the next time there's a question they might respond. I think questioning is hugely important, because you don't want yes or no, you want to se what else is there, because I mean some of these kids, they know so much, and you're never going to know." 
Lecture. China teachers were observed using lecture during $82 \%$ of the observed segments while United States teachers used lecture only in $17 \%$ of the segments.

Additionally, all of the $12(100 \%)$ China teachers used lecture while only 7 of $13(54 \%)$ of the United States teachers used lecture. Lecture was used by the China teachers for the purposes of: reviewing prior knowledge; clarifying learning objectives and specifying student expectations; presenting new learning content; and explaining with examples. Lecture was used only briefly the U.S. teachers to present learning objectives and key concepts.

Lecture with Discussion. Seven of $12(58 \%)$ China teachers used periodic student discussion within their teacher-led lecture. It was observed during $30 \%$ of the segments. Six of $13(46 \%)$ U.S. teachers adopted this strategy, and it was observed only in $11 \%$ of the segments. The observed teachers usually started the discussion by posing an open-ended, thought-provoking question related to the learning content to the whole class. Although the discussion lasted for a short of period of time within teacher-led lectures, the process of discussion was found to provide opportunities for the students to analytically read the text, verbally present their perspectives, or support their arguments with evidence. The students also listened carefully and critically, and disagree respectfully. Compared with lecture with discussion, another type of discussion - classroom discussion, whereby students are the primary discussants - was observed to occur on a smaller scale. Only 2 China teachers and 3 U.S. teachers used it, and it occurred in only 5 percent of the segments.

Small Group Discussion. Six China teachers (50\%) and 5 U.S. teachers (38\%) organized small group discussion. It occurred in 11 percent of the observed segments in both China classrooms and U.S. classrooms. The teachers usually established clear goals for each 
group discussion The transition between whole-class teacher and small group collaboration was smooth and efficient

Student Presentatıon Ten of 12 (83 percent) Chına teachers asked students to present information to the class, while only three out of 13 (25 percent) U S teachers used this actıvity Student presentation was observed in 22 percent of the segments in China classrooms, and 8 percent in U S classrooms

Learnıng Center(s) Two U S teachers organızed students to work at learning centers in small groups or indıvidually, and they used the learning centers intensıvely during the observed lessons None of the twelve China teachers used learning centers As a matter of fact, there were no learnıng centers in the classrooms in China Due to the large class size (with a range from 38 to 62 students, and a mean of 52 per classroom in this study), it may not be possible to set asıde enough space for a self-contained section in the classroom where students can engage in independent or small group study

Seat Work-Individual China teachers (83\%) were more likely to engage their students on indıvidual seatwork than the U S teacher (54\%) Student indıvidual seatwork was observed in $29 \%$ of the segments in China classrooms, while $16 \%$ in U S classrooms Seat Work-Group Based Seven out of $12(58 \%)$ Chna teachers used group seatwork, and 5 out of $13(38 \%)$ U S teachers used this activity Group based seatwork was observed in $8 \%$ of the segments in China classrooms and $16 \%$ of the segments in U S classrooms Teacher Interactıng with Individual Students and Small Group Although the China teachers had more student seatwork in their instruction compared with the US teachers, they were less likely to interact with indıvidual students or groups durıng the seatwork The Chına 
teachers tended to interact with the students as a whole group while United States teachers were observed more frequently interact with students individually or in small groups. Six of $12(50 \%)$ China teacher was observed interacting with individual students and 3 of them (25\%) was observed interacting with groups. Interaction with individual students occurred in $8 \%$ of the segments, and interaction with small group occurred in only $4 \%$ of the segments. In comparison, 9 out of $13(69 \%)$ U.S. teachers interacted with individual students, and 8 of them $(62 \%)$ interacted with small groups. Collectively, the U.S. teachers interacted with individual students and small groups in 24 percent of the segments. It was noted above that although the China teachers were more likely to use student seatwork in their classrooms than the U.S. teachers, they had less interaction with the students, either individually or on group basis. One possible reason for this difference is different student questioning behaviors in these two cultures. During student seatwork, the China teachers walked around the classroom, similarly to the U.S. teachers. However, the U.S. students were more likely to approach their teachers to ask for help and clarification.

Technology Use by Student and Technology Use by Teacher. China teachers (58\% of the teachers, and $40 \%$ of the segments) used more technology for presenting instructional content than the U.S. teachers ( $46 \%$ of the teachers, and $17.4 \%$ of the segments). Most of the technology use in the China classrooms was in the form of PowerPoint slides. On the other hand, U.S. teachers encouraged more student use of technology than China teachers, with 38\% of U.S. teachers involving their students in technology use in $11 \%$ of the segments. None of the China teachers was observed to have students use technology on related learning activities, however. Again, this is due to lack of resources. 
Cooperative Learning. Cooperative learning was not commonly used by the observed teachers in China or the U.S. Only $3(25 \%)$ China teachers and $3(23 \%)$ U.S. teachers used a planned cooperative structure to complete a task. Cooperative learning was observed in less than $4 \%$ of the segments both in China and U.S. classrooms.

\section{b) How Are Cognitive Levels, Based on Bloom's Revised Taxonomy (Anderson \&} Krathwohl, 2001), Represented in these Teachers' Classrooms?

Cognitive levels of instructional activities during each observation segment were analyzed. Specifically, during each 5-minute observation segment the researcher noted whether each cognitive level of the revised Bloom's Taxonomy was (1) not evident, (2) evident, or (3) well-represented. Table 11 and Figure 6 demonstrate the mean representation of each cognitive level across observations for both China teachers and U.S. teachers. The cognitive levels of Knowledge, Comprehension, Application, and Analysis all were documented as evident and well-represented for both China and United States teachers.

Evaluation and Creation were found to be between not evident and evident, indicating that in some instances students were engaged at the higher levels of thinking, but not on a consistent basis, at least not at the level of the lower cognitive levels. The cognitive level best represented, in both U.S. teachers' and China teachers' classrooms, was Comprehension. In addition, observed teachers in the United States tended to engage their students in Analysis at an equivalent level as their counterparts in China. However, more complex tasks of Evaluation and Creation were slightly more evident in the U.S. classrooms. 
Table 11. Cognitive Levels of Instructional Activities, by Country

\begin{tabular}{lcc}
\hline \multicolumn{1}{c}{ Cognitive Level } & China Teachers & United States Teachers \\
\cline { 2 - 3 } & $\mathrm{M}$ & $\mathrm{M}$ \\
\hline Knowledge & 2.28 & 2.45 \\
\hline Comprehension & 2.70 & 2.50 \\
\hline Application & 2.27 & 2.44 \\
\hline Analysis & 2.22 & 2.21 \\
\hline Evaluation & 1.33 & 1.64 \\
\hline Creation & 1.27 & 1.43 \\
\hline
\end{tabular}

Note. During each observation segment, cognitive levels were noted as being (1) not evident, (2) evident, or (3) highly evident.

Figure 6. Cognitive Levels of Instructional Activities, by Country

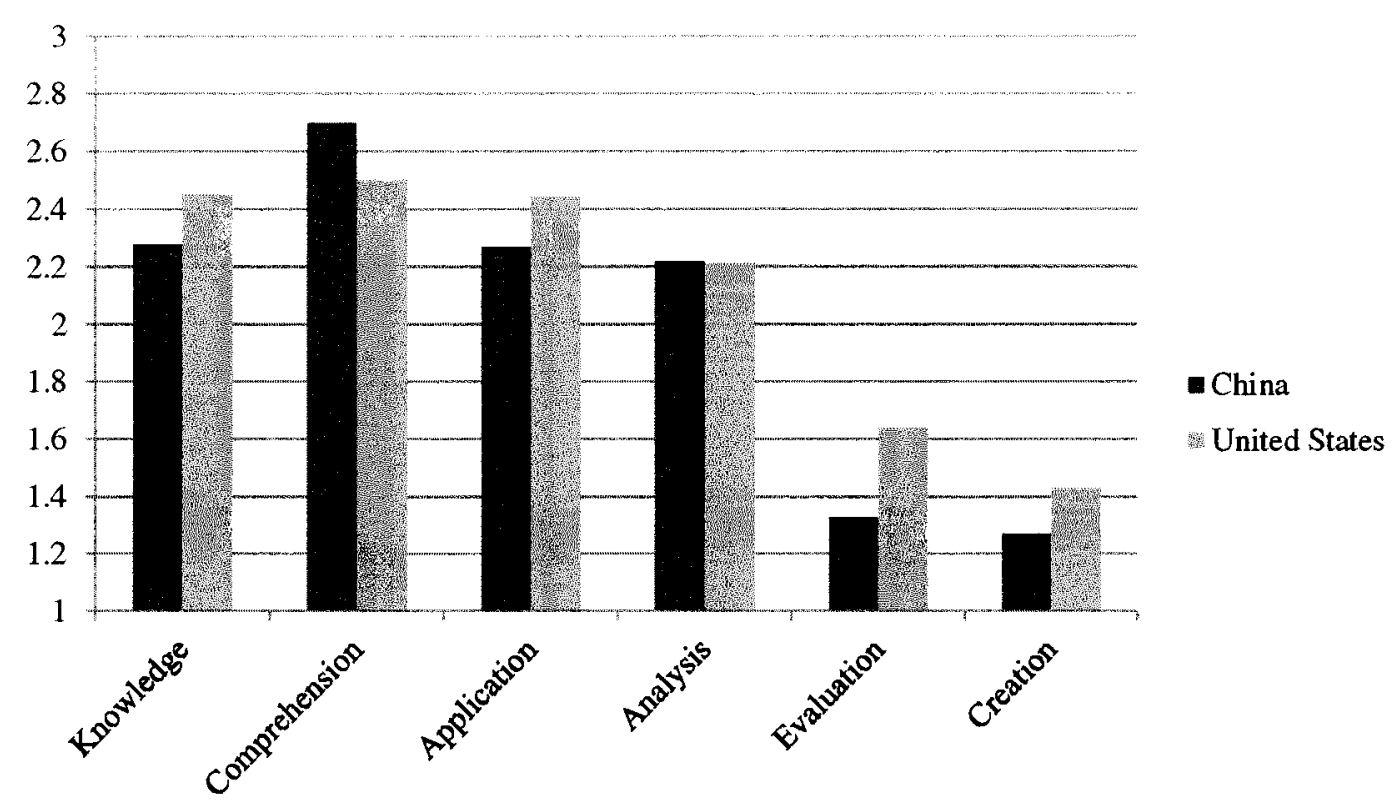

c) To What Degree is Learning Teacher-Directed in the Classrooms of Selected Award-

Winning U.S. Teachers and China Teachers?

The researcher noted the degree of teacher directiveness in the classroom, based on a continuum of (1) to (5). A (1) indicated that the teacher directs all learning and (5) indicated that students direct all the learning; ratings of 2,3 , and 4 indicated gradations of a shared direction of learning. The observational data revealed that China teachers and United States 
teachers, to a large extent, directed the learning, with an average of 1.46 in China teachers' classrooms and an average of 1.70 in United States teachers' classrooms as shown in Table 12.

Table 12. Teacher vs. Student Director of Learning, by Country

\begin{tabular}{lcc}
\hline & $\frac{\text { China Teaches }}{\mathrm{M}}$ & $\frac{\text { United States Teachers }}{\mathrm{M}}$ \\
\hline $\begin{array}{l}\text { Teacher vs. Student Director } \\
\text { of Learning }\end{array}$ & 1.46 & 1.70 \\
\hline $\begin{array}{l}\text { Note. Teacher versus student director of learning was rated on a 5-point Likert scale on a } \\
\text { continuum of (1) the teacher directs all learning to (5) the student directs all learning. }\end{array}$
\end{tabular}

\section{Findings for Research Question 2:}

How are selected national award-winning United States and China teachers' classroom practices - other than instructional activities — similar and different (such as their classroom management strategies)?

The level of student engagement in each observational segment was also recorded based on the observation protocol. Descriptive statistics will be used to present the findings. The researchers also conducted informally observation and took field notes to examine the classroom management strategies used by the teachers. These data along with interview data will be used to illustrate the participants' patterns of classroom management.

a) What Are the Student Engagement Levels in the Classrooms of Selected AwardWinning U.S. Teachers and China Teachers?

To record student engagement, the observer scanned the room at certain point of time within each 5-minute segment and recorded whether engagement was low (1), medium (2), or high (3). Based on the established protocol and operational definitions, (1) low engagement refers to $20 \%$ of fewer of students engaged in learning); (2) moderate engagement means that 
$21-79 \%$ of students were engaged in learning); and (3) high engagement identifies that $80 \%$ or more students were engaged in learning. For both China and United States teachers, student engagement was high as shown in Table 13. Students in the China teachers' classrooms were engaged in lessons with a mean of 2.85 across teachers. In the United States, student engagement level has a mean of 2.69 across teachers. Among the observed 89 fiveminute segments, low engagement was observed in only one segment ( $1 \%$ of overall observational time), medium engagement was observed in 12 segments (13\%), and high engagement occurred in ( $85 \%$ ). In comparison, among the 109 segments that were observed in the U.S. classrooms, low engagement was also observed in one segment (1\%), medium engagement occurred in 32 segments (29\%), and high engagement occurred in 76 segments $(70 \%)$

Table 13. Student Engagement in Classroom Learning, By Country

$\frac{\text { China Teachers }}{M} \quad \frac{\text { United States Teachers }}{M}$

Student Engagement 2.85 2.69

Note. Student engagement was rated as (1) low engagement, (2) moderate engagement, and (3) high engagement

\section{b) What Classroom Management Strategies Are Implemented by Selected Award-Winning}

\section{U.S. Teachers and China Teachers?}

The observational data indicated that the classroom management by teachers, both in China and the U.S., was characterized by: consistent monitoring of student behavior, efficient pacing of class activities, smooth transition between activities, and well-established classroom routines and procedures for daily tasks. The teachers were observed to use proximity or movement around the classrooms for nearness to possible trouble spots and to 
encourage attention (McLeod, Fisher, \& Hoover, 2003). It was observed that these awardwinning teachers had a high level of "with-it-ness"-an alternative term for effective classroom management, which refers an heightened awareness of the surroundings, all actions and activities in the classroom, the student's particular learning situation and needs, and the history of the student's behavior (LePage et al,, 2005; Wang et al., 1993). Some U.S. teacher's comments exemplify this:

"I do try to maintain eye contact as much as possible. I don't forus on straight ahead. I turn my body. I want them to know 'I'm looking at you too.' And I think they know that by now. And just walking around and checking on their work. Because they are working. So I have to go around and make sure I am there for help. There's no sitting at my desk grading papers anymore. When the kids are there I'm on. And that really helps a lot with keeping kids on-task. And when I sense that they are done with something, and the kids know this too, we move on."

"I also pay attention to the psyches of teenagers. I'm all about making it as hard as it needs to be. It needs to be rigorous and challenging for sure. And so I'm always pushing and pushing it. But I'm also paying attention to where like we're at a saturation point. I pay close attention not only in my class but in others and when everybody's feeling filled with angst and I can feel I can just feel them draining. Then I'll design some ridiculously easy assignment that we're going to do in class and everybody's going to do well and all of a sudden everybody is smart again and they are feeling happy again. So it's a lot of it is understanding who kids are, paying attention to who they are. Constantly adjusting what you're doing."

Teachers also commented that they realize when student engagement is low, there is

usually a need for more than behavior management to address it, because off-task behavior often is a result of poorly planned activities, inadequate scaffolding, modeling or explanations which leave students unaware of what to do (LePage et al., 2005). In addition, insufficient awareness of the norms and participation routines in the classroom can also lead student to be off task. For instance, one China teacher commented that when her students start to show offtask behaviors, she would immediately reflect upon her instruction. When she identified that it is her instruction that inadvertently contributed to student off-task behavior, instead of 
using classroom management strategies, she would modify her instructional strategies to

represent her explanations of the subject content differently. She said,

"When students start to daydream, I would immediately critique and modify my teaching. I have to do something different to maintain students' attention. In some cases, I would present fragmentary or contradictory information about the subject, and ask the students to use their available knowledge to make hypotheses. When they found that their predictions are wrong, they would have stronger eagerness to learn. In other cases, when my explanations don't make sense to some students, I would ask one student, who understood what I am talking about, to rephrase and reteach for me. Peer explanations are usually effective and can improve students' motivations to learn."

\section{Findings for Research Question 3:}

\section{What are the Similarities and Differences in Professional Thinking Between Teachers in}

\section{the U.S. and China?}

Grounded theory analysis of interview data generated seven major themes. These themes were further classified into three major categories. Furthermore, subthemes emerged within several of the major themes. The data generated through artifact collection and field notes, and analyzed by holistic coding, were included as a means of triangulation to increase the confirmability of these themes and also to provide a richer description of the themes by using complementary data collected from different vantage points. The categories and key themes are listed in Table 14. 
Table 14. Major Categories and Themes in Professional Thinking

\begin{tabular}{ll}
\hline \multicolumn{1}{c}{ Categories } & \multicolumn{1}{c}{ Themes } \\
\hline Practices and Habits of & Planning based the curriculum, textbooks, and \\
Mind in Teaching & student learning needs \\
& Variation and flexibility in planning and \\
instruction & Differentiation and Attention to Group and \\
Individual Differences & Maintaining a classroom environment that is safe, \\
& fun, and intellectually stimulating \\
& - Assessing student learning and self-evaluate the \\
& success of teaching \\
\hline Development as a & Personal and Professional Growth and Change \\
Professional & Use of Reflection \\
\hline Relationships & Relationships with Students and Parents \\
\hline
\end{tabular}

The category of "Practices and Habits of Mind in Teaching" captures the greatest portion of the teachers' interview responses. Five themes emerged under this category:

1) teachers spoke of a strong emphasis on planning;

2) teachers discussed the attention to variation and flexibility in planning and implementing varied instructional activities with students;

3) teachers shared how they differentiate their instruction based on group and individual difference;

4) teachers' comments focused on student engagement through environmental and instructional elements in the classroom;

5) teachers shared how they monitor student learning through assessment, homework, and other strategies.

The category of "Development as a Professional" represents teachers' perceptions of their professional growth across years. It contains two major themes: first, teacher's personal and 
professional growth and change through teacher preparation program, in-service professional development, scholarly study and professional reading; second, teachers use reflection to scrutiny their own beliefs and knowledge, and to analyze and improve their teaching. The last category, "relationships," captures teachers' perceptions of their relationships with their students and the parents.

a) How Do These Teachers Reflect on Their Practices, Particularly About Their

Relationships with Students, Classroom Environment, Instructional Planning, Instructional Strategies, Differentiation, and Assessment and Evaluation of students' learning?

Planning Based on the Curriculum, Textbooks, and Student Learning Needs

Each of the United States and China teachers spoke in detail about their instructional planning. Most of the teachers commented that they start their planning with in-depth studying of curriculum standards while keeping their planning adaptable to student needs. Both United States teachers and China teachers seemed to agree that effective student learning requires a progressive and coherent set of learning objectives. They referred to state/provincial/national standards and school district curriculum to identify the generic domains of subject content to be covered. Furthermore, they were aware that it is their responsibility to delineate the intended outcomes of each lesson and describe the behaviors or actions that students should be able to perform after participating in the learning activities.

This theme was supported by the comments of China teachers:

"I will ask myself what's the aim, what kind of goal I want to get and how I can get there. I also ask myself questions like: What issues do I want to clarify? What problems will the students have? How do I organize the activities, etc.?" 
"Quality planning is a prerequisite of a successful lesson. For me planning means two levels of lesson preparation. The first is to analyze the curriculum and clarify what should be taught. Effective teaching requires that there is a progressive and coherent set of learning objectives. The second, even more important, is that planning is not just about the curriculum or the textbooks. It is about the students. Are they cognitively ready to learn to new content? What are their interests? How that they learn best?"

To further illustrate, a U.S. teachers stated:

"I have rough ideas of where I'm going...There are units that they would like for us to cover, like there's an architecture unit in fourth grade they would like us to cover, but we have free reign of how we do that. They would like us to segue way into bridges for fifth grade architecture, so my fifth graders are in the middle of building bridges right now. But other than that it's pretty much up to us what we do. At the beginning of last year I had a really hard time. People would say, 'Oh, the sky's the limit!' and I'd say, 'Oh, the sky is really big, and where do we go?'"

Mental Planning Process. When deciding what should be taught, these exemplary teachers stated that they often unpacked prescribed standards and frequently had a blue print in their minds that continues to be formed and re-formed over time. Most of them commented that because of their lengthy experience with their current grade level or content area, and their expertise gained over time through a constant process of planning-reflection-refining. They no longer write meticulous, formalized plans for every lesson. Rather, they relied on a combination of plans from earlier years and a mental planning process that linked familiar instruction from the past with the current class and context. To illustrate, two U.S. teachers stated:

"If I'm starting something new'... I would develop a day-by-day, almost word-byword lesson plan, unit, that would say anticipatory set I'm going to say this, this, this, and this. In the introduction I'm going to say this, this, this... I'm very detail-oriented when it comes to that. Then after I've done it two years in a row, I'll have in my mind what questions are that I think are appropriate, and what extensions I can do to that, so then I'll just be more generic in my daily lesson plan." 
"I don't plan! [Laughs.] Let me start from square one. I've done this for so many years that I'm kind of an expert at third grade curriculum. But I have fully developed units that have the goals and objectives established, and my lesson plan format is truly Madeline Hunter, to a T. I'm always very cognizant of what my anticipatory set will be, how I'm going to have closure, what I'm going to do for a quick evaluation, whether it be a thumbs up thumbs down... I didn't have to write lesson plans that day. But I had it all laid out, on what they were going to do. So that's how I plan."

Similarly, the China teachers stated:

"Not too much in detail. But I have a goal, main points, the difficulties the students may have, and the procedures I will follow."

"I have been teaching for about 13 years. At the first few years, my lesson plans were extremely detailed. I even wrote down what I was going to say during the transition between activities, trying to make sure the flow of the lesson is smooth and the connections between artivities are meaningful. If I didn't write it down, I was afraid that I would be at lost about what to say due to nervousness or other reasons. However, for the last few years, I noticed that I changed my approach to lesson planning. I am much more familiar with the flow of my lesson, so I can spend more time on thinking about the students, rather than just the textbook. Now, my lesson plan is not detailed to the degree that I have to put down every sentence I am going to say. I feel more comfortable about improvising. I think that's a progress for me, because I can communicate with the kids more naturally, instead of putting on a scripted performance like I used to do."

Teachers' comments indicated that the level of detail in lesson planning is contingent upon these teachers' years of experience and the development of expertise. Relating back to the observational results of these teachers, the activities in their classrooms were well structured, and the routines were obviously institutionalized in the classroom activities. While these routines are almost automated actions, the teachers could direct their attention and judgment to more important matters, such as to present the information in a varied manner or check students' understanding.

Incorporate Assessment into Planning. The U.S. teachers were found more likely to comment that they have assessment in mind while planning instruction. Formal and informal 
assessment data influenced planning for instruction across those teachers. Several of them shared that their use of assessment in this way, as well as their purposefulness in planning and linkage of objectives and assessment, had developed over time as a skill area they had carefully honed. Two U.S. teachers shared:

"I've recently become more interested in backwards planning...It's a lot easier to just have the essential questions in your mind at this level, and then those are the things that eventually the kids would be able to answer... I have sort of forcibly changed my own lesson planning in the last two years, once I started reading Understanding by Design and thinking a lot more about it. I always have loved planning - it's possibly my favorite part. But I think now the planning's better, and the lessons are better, because I always, always now develop the assessment first."

"So what I do is to deconstruct the test. I go back and I see the latest version of the SAT. The latest version has the new part of the written. I look to see what kinds of things would be measured on that and I develop lessons that I'm positive and there's specific grammar lessons that I'm positive on those kinds of standardized test questions that they are likely to encounter."

Anticipate Students' Misconceptions. In contrast, the expert China teachers commented more about anticipating the difficulties students might encounter while learning new content. They also shared that they would consider students' thinking in order to evaluate the viability of the lesson plan and then modify their instruction promptly. All of the China teachers mentioned that they would visualize standing in the position of their students and predicting the learning problems they would have while learning new subject content, and accordingly plan for that. For instance, two China teachers stated:

"What is my goal and purpose? What kind of difficulties and problems that the students are likely to encounter? What kind of questions the students would ask? I make a prediction based on the students' prior knowledge and basis. What kind of teaching methods would I use?"

"Usually the night before each lesson, I would rehearse my lesson script in my mind like I am playing a movie. I would predict what would be the obstacles for students' 
success in learning, or what would make them interested. In this process, I can reveal what's my potential blind side and address that in my teaching next day."

Frame Lesson Plans around Key Terms. In addition, in China teachers' comments on planning, three terms continuously appeared: "knowledge points" (zhishi dian), "key points" (zhong dian), and "difficult points" (nan dian) (Tusi \& Wong, 2009). One fundamental task of their lesson planning is to identify and describe these elements. "Knowledge points" refer to all the facts, ideas, concepts, skills, or procedures that are covered by a specific lesson, but not all of them are "key points." Some of them may already have been taught before and will be briefly reviewed, and some of them may be too challenging for students to tackle with at this time being, but will be lightly touched upon as an early exposure can be helpful for future learning. "Key points" are the primary learning objectives that will be taught and mastered explicitly. If "key points" are identified through unpacking the curriculum, then "difficult points" have to be identified from an understanding of the students' prior knowledge of the subject matter and their learning habits. The lesson plan artifacts that were collected revealed that all China teachers included descriptions for at least "key points" and "difficult points" in their lesson plans. That means the China teachers need to 1) develop a systematic understanding about the scope and depth of the learning standards in the curriculum;2) explicitly spell out the aspects of the topic or concepts that will be learnt in each lesson; and 3) predict where the students are likely to stumble upon based on knowledge of their prior learning.

Autonomy and Creativity versus Following Textbooks in Planning. The comments on planning also revealed that U.S. teachers have more autonomy in deciding what they are 
going to teach and how they will teach. One U.S. teacher commented on the creativity with regard to her lesson planning:

"Now it's like I need those outcomes, the indicators, whatever, however you guys call it, essential questions, whatever. But that's what I need to start with in order to be creative, you know, so I need to know what they need to know and be able to do. I have my little guides over there, that basically just give me the objectives - they give me lessons, too, but I don't like to use the lessons in the guide. Some of them are good, and I start there, but I find out what my kids enjoy, what speaks to them, what speaks to me, ..., and I create my lessons."

However, all the China teachers mentioned that they would follow the textbook and the teacher reference book closely, both of which were developed by the Ministry of Education. A considerable amount of their planning time was spent on studying the text and teachers' manual, either individually or collaboratively with colleagues. In addition, all of the China teachers were in a certain type of collaborative team, which engaged in a recursive cycle of studying curriculum, textbook, and teacher reference book, planning a lesson, implementing the lesson, and discussing and revising the plan and instruction. They all agreed that team planning is an effective way to share resources, increase their understanding of the framework of the curriculum and textbook, cut down the workload, build stronger collegial networks, and improve the quality of lesson plan. Furthermore, since all of the interviews with the China teachers were conducted in their offices, the researcher had the opportunity to observe that, in each of the schools that were visited, teachers who teach the same subject, in some cases the same grade level too, were arranged in the same office to facilitate collaboration. Tables 15 and 16 compare the percentage of China teacher and United States teachers who reflected these above-mentioned subthemes, thereby highlighting the similarities and differences regarding instructional planning between these two nations. 
Table 15. Instructional Planning Similarities, by Subthemes

\begin{tabular}{lcc}
\hline \multicolumn{1}{|c}{ Instructional Planning Strategies } & $\begin{array}{c}\text { Percentage of China } \\
\text { Teachers } \\
(\mathbf{N = 1 2})\end{array}$ & $\begin{array}{c}\text { Percentage of U.S. } \\
\text { Teachers } \\
(\mathbf{N = 1 3 )}\end{array}$ \\
\hline $\begin{array}{l}\text { Planning based on the curriculum, } \\
\text { textbooks, and student learning needs }\end{array}$ & $100 \%$ & $100 \%$ \\
\hline Using mental planning process & $100 \%$ & $100 \%$ \\
\hline $\begin{array}{l}\text { Allowing lessons to follow a different } \\
\text { path (illustrated in next subtheme } \\
\text { "Variation and Flexibility in Planning } \\
\text { and Instruction") }\end{array}$ & $67 \%$ & $77 \%$ \\
\end{tabular}

Table 16. Instructional Planning Differences, by Subthemes

\begin{tabular}{lcc}
\hline \multicolumn{1}{c}{ Instructional Planning Strategies } & $\begin{array}{c}\text { Percentage of China } \\
\text { Teachers } \\
(\mathbf{N = 1 2 )}\end{array}$ & $\begin{array}{c}\text { Percentage of U.S. } \\
\text { Teachers } \\
(\mathbf{N = 1 3 )}\end{array}$ \\
\hline Anticipate students' misconceptions & $100 \%$ & $15 \%$ \\
\hline $\begin{array}{l}\text { Follow the textbook and teacher } \\
\text { reference book closely }\end{array}$ & $83 \%$ & $0 \%$ \\
\hline $\begin{array}{l}\text { Frame lesson plans around three key } \\
\text { terms: "knowledge points," "key } \\
\text { points," and "difficult points" }\end{array}$ & $75 \%$ & $0 \%$ \\
\hline Autonomy and creativity in planning & $0 \%$ & $61 \%$ \\
\hline Incorporate assessment into planning & $0 \%$ & $46 \%$ \\
\hline
\end{tabular}

\section{Variation and Flexibility in Planning and Instruction}

Both U.S. teachers and their China peers emphasized that they keep their planning open to changes and continuously adjust their implementation of the plan based on student needs. The classroom is full of ebbs and flows. Correspondingly, these exemplary teachers tapped into their pedagogical and content resources in a fluid and flexible manner in order to maximize students' learning. Several of the teachers commented specifically that with more 
years of teaching experience, they become more comfortable with allowing lessons to follow

a different path than the one originally planned, because of the teachers' own confidence with

the structure of the lesson and the possible variation within it. To illustrate, some

representative statements made by the teachers were:

"I try to make sure that I have a linear way of planning so you can follow through and each day's building on the next. But I also try to take the opportunities when they arise, if something crops up to link the outside in, so flexible but structured as well."(U.S.)

".... I'll put things in front of them and we may take a different path than what I had anticipated. .... Because I've been teaching the same grade for so long, I understand what I'm supposed to teach, and I'm not afraid to let the kids take me off topic and go down a different path, .... So my role, I think, is facilitator, guider." (U.S.)

"The standards are written, I follow the standards, I try to organize projects that force the kids to learn those standards or at least part of those standards, but I'm known far and wide - as far and wide as this little school can be - of being the guy who, if something comes up in class that's a learning opportunity, but it doesn't have anything to do with the Compromise of 1850, then you know what, we're going to take this opportunity and we're going to learn it." (U.S.)

"I know my students' learning fairly well. My teaching is flexible and what I am doing is totally contingent upon the students. For instance, if my students' mastery is not solid enough to move forward to the next step, I would change my original plan. In most cases, I would immediately generate associations with knowledge learnt earlier and help students solve their problems. I always enjoy changing tracks and incorporating my students' learning pace and characteristics while implementing a lesson plan." (China)

Both the classroom observations and interviews indicated these award-winning teachers had

fast and accurate pattern recognition capabilities (Berliner, 1986). They had the skills to

recognize the schema or pattern in student learning, and making inferences about the situation,

for instance instantly identifying what difficulties the students are having and making

adjustment to the instruction. In addition, they were good at anticipating challenges and

difficulties that students were likely to encounter. Thereby, they were able to make 
contingency plans based on those possibilities. These teachers were opportunistic, in the sense that they welcomed changes and used the opportunities that occurred along the way to guide their teaching.

The observations indicated that these teachers used questioning to continuously assess how students have mastered the targeted learning content. Student responses provided important input for teachers to make instructional accommodations, to be flexible with original plans, and to exploit chances offered by the immediate circumstances. This was also supported by teachers' comments during interviews. Two teachers shared:

"I think that everyone can always grow, but I think sometimes I have to step back and think what can I ask them to make them think through the answer... sometimes with planning those might be things that I write down, just to keep it focused, but I think that over the time I've learned to try to have a variety of questions in the different ranges of thinking that students need, and - I don't know, I guess I try to think about... what am I trying to get them to show me that they know, so trying to gear the questions sort of that way. So that I'm not giving them the answer when I ask the question, but asking them sort of a series of questions to get to aha, you do know it, so now what should you do?"(U.S.)

"I use questioning to push my students forward in their learning. My students" responses are often insightful and sometime shed light on something I never thought about. I could actively take advantage of those opportunities to lead my students to explore more." (China)

\section{Differentiation and Attention to Group and Individual Differences}

About 80 percent of the teachers offered specific comments about the ways in which

they blended "content and pedagogy into an understanding of how particular topics, problems, or issues are organized, represented, and adapted to the diverse interests and abilities of learners, and presented for instruction" (Shulman, 1987, p.8). Within their comments around content pedagogical knowledge, both U.S. and China teachers commented on the importance of using varied methods of instruction and engagement to involve students in learning. In 
addition to this, the teachers commented more directly on their understanding of the needs of particular students or groups of students, and the types of modifications that need to be made to their plans and practices to support differentiation. Teachers commented on the importance of knowing specific student characteristics, including learning preferences and modalities, the speed and format in which different students best learn, and the background knowledge students bring to each lesson and each year. The teachers' comments on differentiation also included how they pre-assessed student learning needs and how they accommodated those differences. Several teachers made reference to multiple intelligences and learning styles. Several of the teachers also commented on their efforts to get to know student interests and to design lessons so as to engage those interests, in a way that responded to the changing interests of students of a given age in general. Some illustrative comments by U.S. teachers are:

"I try to, not necessarily target specific learning styles but to acknowledge the strengths in each child and rather than teach to their strength, to bring up the other learning styles to be of an equal strength because basically when they get to high school there are certain learning styles that they need to have in place and not all kids are born with that so I try to help fill in the gaps. I try to make things as childcentered as possible so that they have relevance to the children in their everyday lives."

"I try to hit as many learning styles as possible, the multiple modalities, give them choices, I try to have as many things here for scaffolding and support as possible. If they need manipulatives, for my visual learners, if it's there for my auditory, you know, being able to use the computer and hearing some things that are generated. They're very kinesthetic, so trying to get their bodies moving to engage them... and I go back into my reteaching and pull those kids, and the kids who already know it, compact and push them forward, but you know, give them choices, but I try to give everybody choices."

"I try to vary it by having different displays and things around to tailor it to different children's needs. We've got quite a few visual learners in here so I try to have visual options for them." 
"And that's (differentiation) been a real challenge, because they really are different even third to fifth grade, what they want to be doing, and what they care about. So every year I have to shift the units a little bit to get closer and closer to what they care about at that age level."

"What I did 20 years ago wouldn't work all that well...my contemporary examples have to change.... So when I'm planning for poetry I force myself to listen to rap music; I'll do teenage movies because when we're talking about story ideas for example and short story in creative writing I want to give them examples they can relate to."

Correspondingly, two China teachers stated:

"I would regard different students with special respect or new views according to the students' needs. To students who learn slower I give more instruction, spend more time, give them more chances to express themselves in class, and different homework. To the students who learn faster I give them more difficult homework, challenge them to do better according to their merit points."

"I usually respond to student differences in three ways. One is to give different tasks to the students. For those who learn better through hands-on activities, I will ask them to do something. For those who are good at language, I will ask them to write. The second is that sometimes I will ask students to do some things that are their areas of weakness. The third ways is to give the students different homework."

Some U.S. teachers also commented on collaborating with resource teachers for special education and gifted education to meet the needs of identified students. For instance, one teacher spoke "so whether that child be a student who is identified for special services, through special education or through gifted and talented, I try to make that program individual for every child across that spectrum." Since there are no special education or gifted education programs established in the public school systems, no China teachers made similar comments.

Although most China teachers reported that they used a variety of strategies and methods to deliver instruction, the observation data indicated an over-representation of 
whole-group lecture in China teachers' actual classroom practices. (China teachers were observed using lecture during 82 percent of the observation segments.) Plausible reasons that explain the gap between China teachers' self-reported belief that they extensively use a variety of instructional strategies for differentiation and their observed lecture-dominating instruction may be three-fold:

1) One reason is that lecture is the most efficient method available that can cover large amounts of content in a limited period of time.

2) Another possible reason is the pressure from local and national examinations. Some China teachers acknowledged the challenges of ongoing differentiation, commenting on the difficulties of managing individual differences within a large group and the obstacles to developing effective differentiation within the time constraints.

3) Finally, the China teachers' classes were substantially larger than their U.S. counterparts, with China classes often containing 50 to 70 students.

Some China teachers shared:

"Because of the exams. We have a lot to teach. I don't have as much time to let the students discuss. I spent more time on catching up with the schedule."

"You cannot use stereotype methods. You should use different methods according to the students' characteristics, to use authentic examples. But sometimes I am not free to use what I think is the best method because of the examination baton."

"I feel it is difficult to give consideration to students" differences in classroom teaching. There are more than 50 students in my class. They differ greatly."

Although limited differentiation in terms of varied learning activities was observed in Chinese classrooms, China teachers stated that they did differentiate the pace of learning for 
one specific learning activity in accordance to the students' individual needs. Many China teachers also mentioned that they differentiated the cognitive level of questioning and used questioning to involve students of all ability levels and build their self-esteem. They also differentiated the product of learning for students, such as designing different types of homework and examinations for students of different levels. Another important method that China teachers used to actualize differentiation is variation, i.e., representing their explanatory frameworks (which organize and connect ideas) in different ways, so that students could be exposed to the content in different forms and were able to develop a deeper understanding (Feiman-Nemser, 2001). This variation was observed to be prevalent in the classroom of these award-winning teachers who had solid knowledge of central facts, concepts, and procedures of the subject they taught. For instance, in a math lesson where the students were learning that the sum of the length of any two sides of a triangle is always greater than the third side, the teacher observed used alternative explanations, examples, and procedures to represent core concepts and processes.

The limited presence of differentiation in China teachers' classrooms also may relate to their Confucian belief that effort overpowers ability in determining a student's academic achievement. When discussing the learning differences among the students, the China teachers commented that there were few formative or benchmark assessments available in their school systems to diagnose students' special needs. In terms of assessment of students with disabilities, China schools, on the whole, simply do not acknowledge special education as it is addressed in the United States. 
Six China teachers shared that they believed that all their students have the ability to succeed in learning, and some students underachieve because they had not put in enough effort or they used inappropriate learning strategies. China teachers were liable to attribute student learning success and failure to non-intellectual factors, such as effort, learning strategies, rather than to student innate ability. Such pattern of attribution and a strong belief in student effort may keep China teachers from differentiating their instruction based on different student learning abilities. Some comments reflecting this belief are:

"I believe that all my students have the ability to succeed in their learning, but there is a fairly large amount of variety in their achievement, as indicated by their test scores. I think there might be two reasons to account for that. One is some students don't have good learning habits or attitudes. They don't work hard enough. In some cases, some students work hard but are still unable to perform well, and the reason for that is they haven't found the learning strategies that work best for them. Also sometimes students have poor performance because they come from a disruptive family environment."

"I am teaching 8th-grade English to two classes, but these two classes have drastically different performance. That doesn't mean the students in the class of lower achievement have lower learning ability. These two classes are parallel, as indicated by their entrance exam scores. Sometimes, I would invite some students from the higher-achieving class to give a performance in English for the students in the other class. I think that stimulate the lower-achieving class to think why both of the classes received the same instruction from the same teacher but have different outcomes. That comparison would encourage them to spend more time learning English."

\section{Maintaining a Classroom Environment That Is Safe, Fun, and Intellectually Stimulating}

Both U.S. and China teachers discussed shared how they build an engaging, stimulating, and enriching learning environment for their students to grow and thrive. They stated that they established and communicated guidelines for expected behavior, monitored student behavior, kept students on task, and infused humor, joy, care, and respect into the classroom interactions, so as to develop a climate that is conducive to student learning. They 
also commented that they stimulated student enthusiasm through modeling and careful calibration of the learning experience to students' level of development. Overall, their classrooms were characterized by a positive climate that encouraged student growth in cognitive, motivational, emotional, and behavioral domains. These teachers used different methods and tactics to stimulate and sustain student enthusiasm for learning. For instance, a U.S teacher shared:

"Praise from a student for me would be that I've made their learning interesting and their day fun, rather than just we had to sit down and do all these things. They could actually verbalize for me the reason why they're doing it and the value for them out of it.

Similarly a China teacher commented,

"Student motivation is the most important for their success in learning. Many of my lessons are scheduled in the afternoons, and the students are often tired at that time, therefore I have to have a variety of tools at my disposal to stimulate their interest in the subject matter. First of all I need to make my presentations energetic and enticing. That enthusiasm is contagious."

These teachers also spoke of the learning environment in their classroom as being supportive, safe, challenging, and academically robust. These attributes defined why the learning climate in their classroom was conducive to student success. Their classroom teaching was challenging but all its goals were attainable when students are cognitively engaged. Some supporting statements are:

"Just like the student earlier, who I was saying he will say I can't do it I don't know how to do it, and it's like well you're not going to do it because you're setting yourself up to not do it by saying that you're not going to. And so just - I would want them to come back and say thanks for telling me that I could do it - they're all smart, and they all know how to do things and learn and get better at what they're doing, but I think that would probably be the most memorable." 
'I've had a couple students say to me, 'You made me want to do better,' and to me that's pretty cool. I've taken them beyond what they thought they could do, and they end up doing more. They pushed their boundaries, they pushed their limits."

"I outlawed 'I can't.",

"I look to see, am I making it rigorous, am I making it hard for them, because I tell students throughout the building my job is to make their brains hurt, because if your brain isn't struggling it's not growing."

Related to the high cognitive demand, many teachers spoke of how they build a

tolerance for failure when the students are engaged in effort-demanding tasks. A China teacher perceived that students made mistakes because they were making meaningful processing attempts to integrate new information with existing knowledge to form a richer, more coherent mental representation, and these mistakes were great opportunities to maximize student learning. These teachers concentrated on building a learning environment that allowed students to accept mistakes and encouraged risk taking. For instance, a U.S. teacher shared:

"I want it to be a classroom where they feel welcome and so I have to create that welcoming environment and to create that atmosphere where they feel relaxed where they are not afraid to say something silly where I reward them. They know I'm going to reward them for what they do well rather than be punitive so that they are not afraid to take a chance. That's my whole philosophy. Reward you for what you do well it's all about positives. And then we'll build on those and then along the way maybe diminish the shortcomings. But so how do I create environment? To make it a place where they are anxious to come and also to pay attention to the psyches of teenagers but I really do have to do this. I'm all about making it as hard as it needs to be. It needs to be rigorous and challenging for sure. And so I'm always pushing and pushing it. ..., always keeping the standards right there in the front, always making it rigorous, always making it challenging."

When discussing the teaching strategies they use in their classrooms, U.S. teachers emphasized more on designing authentic learning experiences for their students within a specific content area. For example, one secondary English teacher emphasized that she made 
a habit of "show[ing] them how good writers do use all of this stuff and give them examples

of why it's important." She commented that in developing assessment situations, she strived for authenticity in both the language skills to be used and the simulated circumstances that formed the context for language use. This emphasis on authenticity also fit within a focus on U.S. teachers' own content knowledge, acknowledged by many teachers to be a critical part of their work and their credibility in the eyes of students.

U.S. teachers also made references to the importance of learning community. Their comments suggested that a successful learning community should provide the students with a feeling that members matter to each other and to the whole group. There was a shared belief that each individual should be respected and the members have a joint commitment to work together for learning and development (Bransford, et al., 2005). A U. S teacher said:

"You know we have some basic rules. We don't pick on each other. I don't pick on you, you don't pick on me, you don't pick on the guy next to you. We try and be respectful of thoughts and ideas, so if I'm thinking something and it sounds really strange, we let me think that and we even let me think that aloud and we don't pick on me about it. We're just friendly and we try and be a community. We know we have work to do we try hard to get it done. And in response to that I know that kids have outside work to do that they need support with. So as long and they're working hard for me, I'll work hard for them."

"And I love the fact that today there were three different opinions about what the thesis statement was and they each was able to, and one girl didn't back down because it's safe to be the only one in the room. I work hard. There is no making fun because someone disagrees. Sometimes I have them line up on opposites sides of the room and allow them to convince each other and allow people to swap places if they like. We are here to explore ideas. The kids today were not looking for what the right answer is from the teachers. That's the environment that I want - that it's safe to explore ideas and it's safe to change your mind and so I think that's part of what we do there because we are supportive of the kids."

The U.S. teachers and China teachers differed to a great extent in their reflection on their use of the physical space in the classroom. The comments by the U.S. teachers indicated 
that they had greater flexibility in making an efficient classroom organization and

arrangement to facilitate different learning activities and purposes. Some examples of the

comments are:

"I try to make it as kid-friendly as I can. I put kid work out in the hall, but in the classroom I try to put up learning poster kind of stuff, but it's still very kid-oriented. I play music all the time. We - I use a lot of rewards, whether it be verbal or foodoriented. We chew gum during math because I read somewhere that chewing gum makes you do math better, something stupid like that. And I have the kids - oh, you don't know this - at the beginning of the year, there's nothing set up in my classroom. All the desks are pushed against the wall, the chairs are all set up on top of each other, and the floor is empty, and there are no posters up, there's no bulletin board background, there's nothing, it's just a blank room. And the kids walk in and they see a clipboard on the floor with a floor plan and a pencil. And the lockers in the hall are covered up with "do not enter" tape, and those flashing street lines and cones, and so the theme is "under construction." And so that first day of school, they design where they want me to sit, and how they're going to have their desks, and then I have them go down and get books from the library, and we put bulletin board material that they've made for that day or for the beginning of the year. And so they create the room themselves. And then throughout the year we redo it, and then at the end of the year they take it all down, they stack it up exactly the way it was, and there's nothing on the wall, there's nothing in the lockers, and so there's closure to their third grade year."

"I think the most important thing is small group instruction. I set up the classroom so the kids have a space to work. I also set up the class so the kids know where to get materials they need for learning. I want kids to be able to get what they need. Every person has a job so the classroom runs smoothly. I want them to be independent and functioning."

"It's very fluid because my desks - well even in my regular class when I was a classroom teacher I was constantly moving things out of the way so that I could use the floor space. The kids knew just because it's here now doesn't mean it's going to be here tomorrow. This afternoon the tables will be all around the circle so that we can continue with our circle class. I like working in groups, I very rarely work independently, it's always collaborative, so when I need smaller groups the tables get separated. So when I got to move in here I kind of shanghaied a couple extra tables because there weren't as many in here, just so there were different spaces so we could move to wherever we were comfortable, wherever we felt a good space. Sometimes we play games, if there're just a few of us, sometimes we'll be at this table." 
In reflecting upon their flexibility with the physical environment, the U.S. teachers also

made reference to teacher proximity. One teacher highlighted that:

"The classroom arrangement is so that students look at each other and you can't hide. You can't hid in my classroom anywhere. You are visible all the time by the teacher. I see all those kids. And the other thing is during the class is proximity. Although I do begin my instruction standing at the front of the room if you watch I do circulate... We are always with all the kids. And if you notice as we walk by kids feel very free to ask for help because we create a very safe environment."

None of the China teachers commented on using different classroom arrangements to facilitate different kinds of teaching, except one said she occasionally reorganized seating for cooperative learning. Many China teachers shared that they felt that the physical space in the classroom was limited due to large class sizes, although they did not comment that a limited flexibility regarding the physical layout could negatively impact on their teaching. A China teacher commented:

"In my classroom, I use posters to display inspiring sayings and quotes. For example, to seek the ways for success, and not to seek excuses for failures. I display all the certificates of merit we got in the classroom. Because my classroom is small and we have little space, I sometime rearrange the desks and chairs for different types of learning activities, but not often, because it's very time-consuming."

The physical environment of the classroom determines the role of the teacher and the students, and influences power relations among the students and between the teacher and students (LePage et al., 2005). Since the school was set up in China's early history, the student chairs are arranged in rows and teachers teach on a podium in the front of the classroom. This power relationship was also reflected in China teachers' comments on classroom control:

"I am a rigorous teacher. I had class rules." 
"My students pay more attention to learning when I exert more control. It's better for me to control the class. The students obey to my management, my classes are more effective."

"During the teaching, I use eye contact to drop a hint to individual student who misbehave. After class, I talk to students who misbehave and sometimes I criticize a student in the presence of the whole class."

In comparison, the power within the classrooms of the U.S. teachers was more shared and

decentralized. The students had a wider range of choices, as long as they stayed within the

boundaries of pre-set rules:

"The other thing about that is that I respect my students as people and individuals, and I value their choices and give them choices and say we can do this, we can do this, try that, and really let them know that I'm trusting them with the information, like today with the fourth graders I could have said, 'This is how you do it, now go do it.' But I said, 'You could do it this way, you could try this way, you could do this, you could do that.' They all chose their own player, they all decided which statistics they wanted to do, so I kind of honed in on learning about statistics, but 'you can do it this way or this way or this way.' So giving them the choices but letting them know, 'You have to have the graph before the end of the day so I know you know how to make the graph. You had to have the statistics in beforehand, you had to have the player, you need to update these."

"I don't have many rules. The one rule that I try very hard to stick to is, as long as what you're doing is not distracting someone else, then it's on you... But I try to stick to that rule, and I've been known to, as they say, fly off the handle, when that gets crossed, when I become aware that somebody else is hurting someone who's trying to learn. I just try to make a really hard boundary, and inside that, you know, we make it up as we go along."

Many of the teachers made reference to happiness and fun while reflecting on learning

environment. For instance, two U.S. teachers said:

"Since becoming a teacher - that's always what I wanted to do - I've played in my classroom for years, and I've always told my students that we're going to have a good time because I don't do boring, I don't know how to do boring, and I want them to enjoy themselves and really want to be in my classroom."

"I think for kids at this level if they think it was interesting or fun and that they learned a lot. I think that's what I like to hear most... I want to be, they need to like 
school to get into it. I try to make things engaging and also have them learn, so it's not just fun."

Also, China teacher's control and strictness in classroom did not prevent them from making students experience pleasure during learning. Five China teachers said an important criterion that they used to evaluate their teaching is if the students were happy in the classroom and had fun with learning.

\section{Assessing Student Learning and Self-Evaluating the Success of Teaching}

Many of the U.S. teachers and China teachers mentioned they use multiple types of assessment to self-evaluate instruction and monitor student learning outcomes, such as observation, homework, student feedback, and student achievement scores. When answering the question of "What praise would you most value from students?" The responses of most teachers surrounded upon their students' positive feedback on their classroom teaching. For instance:

"I like it when at the end of a lesson that I've conceived as - I thought was good in my mind - when they say something - they won't say 'that was a great lesson' - they just don't say that. But they'll say 'I love Japanese!' And it's when they say it that tells you what it was from. And that I value, ..., and I don't think - kids might get used to it, even, and occasionally you'll get it to the point where they love it enough to tell you that. Or sometimes if they're cheering, or if they're actively engaged. Like yesterday a special ed teacher came in and she said one of the kids was hanging over his desk to see what the result was going to be of this activity we were doing, and she said, 'wow, that's engaged.' And so I would see him hanging over a desk as a compliment. So to me the ultimate compliment would be that they loved it because they were so engaged and felt so successful in the learning. "(U.S.)

"The biggest compliment for my teaching that students come up to me and say that they like to come my class and enjoy my lessons." (China)

When discussing what assessment strategies they use to monitor student progress, there was a great amount of variability among the teachers' responses. Some highlighted informal classroom observation of student learning: 
"On a day to day basis, just how the child is functioning as part of the class and how they're functioning within lessons, the amount of success that they have earned. The expression on their face can tell you a lot."(U.S.)

Some referred to formative assessment strategies such as quiz: homework, and project product;

"The questions that kids ask me. The product they develop - whether it be their written questions to a book that they're asking a peer, or a poster that they've developed outside at home, or a poster they've developed in class, or a poem, or a story, or the moon report that they're writing - a physical product."(U.S.)

"I look at test results, especially when I was in the general ed classroom. We look at our local assessments and our state assessments and see how we did. We have the students in the general ed class do a quality folder where they keep track of scores on different things and they can chart their progress throughout the course of the year."(U.S.)

"Currently I am teaching the ninth grader and we are preparing for the high school entrance examinations. The students have tests every three weeks for each subject area. I would ask each student to make a graph that represents their progress over time, not just their raw scores but the gap between their scores and the average score. In that way, they self-evaluate their learning."(China)

And some emphasized high-stakes standardized tests:

"Oh Yes, well certainly standardized test scores, It's one valid measure of how you're doing. .... I look standardized test scores as one measure. "(U.S.)

"I think the end-of-year standardized exams are the fairest and most reliable measures of student learning. I am aware that there is a lot criticism about standardized tests, but I think they are often closely aligned with the curriculum. They test what students are supposed to know. Most of the test items demand student thinking of high cognitive levels, such as comprehension, analysis, and evaluation. I think they are worthy of teaching to. And I don't pay much attention to school or teacher-developed tests. (China)

But in most cases, the teachers use a combination of these three:

"I look at their work, I observe them at their play, during their play, to see if they're bringing into their play things that we're doing - that's always so cool - things that we're doing instructionally. I have specific assessments that I'm supposed to give. You know, I do the pre-assessments and then ongoing observations so that I can see where I need to go in my teaching. Then I do the post-assessments-some of them are 
real specific, sometimes it's just observing the work and looking at the rubric and matching it to what the expectations are. I talk to the kids and find out how are they feeling about the work that they're doing - what is their understanding? So interviews, I guess, with the kids."(U.S.)

"I look at, I guess - I mean they say you're not - I don't wholly, but test scores, and you've got to look at those, because that's what everyone else is looking at - in class, observing, looking at student work, looking at classwork, homework, as well as assessments that I do individually with them, running records or the DIBELS fluenry test and things like that. Math, when they have independent work, or quizzes, or the end of the unit reviews, those are things that I sort of look at to see what kinds of things are they picking up, is there a pattern here? So it would be just the - daily classroom observation of what's going on, and then more the individual things that they do on their own. Because then I get to sort of see a picture of what everyone knows individually. I think that's probably, those are the two core anchor things. Because even standardized testing, I can look at it to get an overall picture, but usually by the time I get it, it's onto a different year, it's over. "(U.S.)

"Well, the success of my teaching - part of it is the usual, data from the sort of formative mini-assessments that you're doing along the way, part of it is the data from the final assessment that you do in each unit... Then, though, it's other things, less tangible things, like how much the students seem to be enjoying the class, how many hands are up, how much participation, comments I get from the parents at open house, how many parents we get attending events that we hold - we hold some big events each year, some festival-like events, then we also hold parent visitation week, so we get a lot of interaction with parents that way, we can hear what kids have to say."(U.S.)

"I use student engagement in my classroom evaluate my own teaching, for example, how many of them raised their hands to answer my questions, did they preview the textbook, and if their facial expression tell me they are pay attention. I keep track of the students' on-going performance on homework. At last, my students' scores on end-of-year examination and their performance at the High School Entrance examination were key standards I use to self-evaluate." (China)

All of the China teachers commented that they used homework to re-expose students to subject matter, increase the retention of the concepts taught, and assess their learning. They connected homework assignments to classroom learning and clearly communicated the purpose of the assignment. They used homework to provide non-punitive feedback. They also 
addressed student mistakes in the beginning of some classes and used students' errors as re-

teaching opportunities. Some examples of China teacher's comments are:

"I pay a lot attention to student homework. Their mistakes give rich information of their learning and my teaching as well. I spend a lot time correcting homework. In addition, I address student errors at beginning of each lesson. This kind of further explanations is an effective way to review students' prior knowledge and modify their misconception timely so that they can move on."

"Homework is a wonderful opportunity to re-expose students to the learning materials. I carefully select homework assignment and mark each student's homework everyday."

In contrast, two U.S. teachers stated they "do not care about homework" and they do grade

homework. Only one out of the 13 U.S. teachers voluntarily elaborated on homework, but

also negatively. Her comments suggested that she regarded homework as an ineffective

strategy for formative assessment, and she preferred other assessment methods that are more

authentic in examining student learning, such as discussion:

"I didn't really look at homework too often, but sometimes. That's something about evolving. I used to rely a lot on homework to decide how to group and those sorts of things. Through taking more courses and now differentiation, homework is not a really adequate way to look at students because some students have help, some students have no help, some students don't do it but they know it. It's not even, and it's not a fair way to look at students, so in my Challenge classroom I've done a lot more of what can we do in class, and you have to be prepared for the next class, like you need to be able to tell me your vitamin and your mineral because that's going to be part of our next class, so that is their own learning, that's not a written assignment or things like that. I try to get as much of that done in class and assess them that way. .... It's just homework, it doesn't need to be graded, you know, to see the progress that the kids are making. So I have definitely evolved that way and about what the students need to do to show me that they've understood something or that they've mastered a concept."

\section{Personal and Professional Growth and Change}

When commenting upon the professional growth and change over the years, the

teachers discussed key influences on their practice, specific aspects of their teaching that had changed over the years, and the impact of their involvement in the field beyond the 
classroom. They participated in various forms of professional development activities, such as mentoring, peer coaching, supervising practicing teachers or interns, attending conferences or workshops, taking course work, pursuing higher degree, and serving professional organization. Several of the teachers identified specific instructors of their own who had influenced either their desire to become a teacher or their practices of teaching, and each teacher commented on some structured educational opportunity that had been influential; however, only a few of the teachers specifically credited a teacher preparation program with much influence on their success. Key professional development experiences among the U.S. teachers included:

- the National Board Certification process, which was mentioned by three teachers: "It made me much more analytical and reflective about what I do."

- coursework in a child development program, which one teacher specifically noted to be separate from and more valuable than educational coursework: "There we really honed in on theory and the workings of a child and we got to begin to explore what makes a child tick, what kind of activities can you do."

- opportunities to work as a demonstration teacher in a professional development institute and to attend an annual conference: "I could choose the sessions I needed at the time, and as every year, as I got better at what I was doing or I knew what I wanted to learn, then I could sort of step up what I was choosing to something different, and so it was absolutely tailored to my needs."

All of the China teachers mentioned that they were part of "lesson research" (keyan) (Tusi \& Wong, 2009) at their school, which includes collective lesson preparation, lesson 
observation, and post-observation conferencing, particularly for teacher who teach the same subject matter. Another format of in-service professional development activity they found helpful was “open lessons" (gongkaike) (Tusi \& Wong, 2009), which are exemplary demonstration lesson given by expert teacher either from local district or beyond that. One China teacher commented,

"In this office, as you can see, the desks next to mine are owned by teachers who teach the same subject and grade level as me. Each Tuesday afternoon, we would sit down together and talk with others about our teaching and our students' learning. What went well and didn't go well. We analyze our students' work and compare our students' progress over time. When I ran into challenges, we consult others for problem-solving strategies. At the beginning of each semester, we study the curriculum and the textbook. We also share materials and give other emotional support."

Each teacher spoke of ways in which developing experience had changed his or her work, frequently with reference to the beginning teacher's concern with "survival" versus the more experienced teacher's focus on finer details of professional practice. The teachers spoke of becoming more systematic in their planning, better at managing the flow of their instruction, and in cumulatively building a repertoire of lessons and activities from year to year. Several of the teachers commented on specific resources, programs, or ideas that had caused them to change their professional practice in some way as well.

Each of the teachers spoke of involvement in professional activities beyond the classroom and how those activities had influenced their teaching. For example, a teacher described how several years working in her district office on various grants had helped her learn new skills and develop a greater appreciation for the role of assessment in planning. Another teacher commented that her work as a demonstration teacher and organizer of a professional development institute helped her to make connections in her field and to become 
more reflective in her own practice. One teacher discussed a lesson study program in his school that supports teacher collaboration and instructional planning based on student achievement data. All of the teachers commented on active involvement in activities beyond their own schools, speaking of service at the local and state levels and beyond, and viewed these activities as a part of their professional role and key influences on professional growth. Another aspect of professional growth that teachers often referred to is collaboration. For instance, one U.S. teacher commented:

"..... The other thing I think in terms of preparing myself in service and the like is working collaboratively with other teachers and never being in isolation. At the high school where I worked for 24 years I had a partnership with the media specialist there and we were able to infuse technology in I thought in a really meaningful way like having kids go and look at primary source documents. Together we would get gloves for them to wear and magnifying glasses so that everything was sort of engaging and they got excited about and I would have never been able to do that on my own. It took two people and it took another voice too. I like the idea that kids saw it from not just my voice but another point of view. So that's worked really well."

An important character of these award-winning teachers is a commitment to continuous improvement and perpetual learning. They have an eagerness to learn and expand their knowledge and skills about teaching. Most of these participants reported that there are instructional leaders. They contributed to the teaching profession by being a mentor to novice teachers. They engaged in various types of study, inquiry and even experimentations to develop personal best practices. In their schools, they served resources to enrich the professional knowledge base about academic standards, curriculum, pedagogy, and assessment. Several China teachers were prolific scholars and researchers on teaching their subject areas and were well-known in their fields. Some of them even gave presentations and demonstration lessons around the nation. 


\section{Use of Reflection}

Teachers spoke of how they used reflection as a key part of planning and of growing as a professional. The theme of reflection included emphasis on reviewing lessons for ways to improve, using self-evaluation and feedback, and selecting areas for improvement.

Each teacher commented on the practice of systematically looking back over lessons they had conducted for purposes of informing further planning, whether it was for future implementation of the same lessons or for subsequent lessons. One teacher spoke of a combination of daily reflection for ongoing planning with time spent on weekends to reflect more broadly. An example would be: "I step back and say 'am I going through this too slowly, or do I need to pick things up a little bit to still cover the things that are important, or is this really worth focusing on, should I adjust my long term plan..."” Another teacher shared that her reflection was one of the habits she changed and refined over time: "It [used to be J just $O K$, I did a good job, I got through today, and now it's much more than that. Did I do a good enough job today? Did I explain it well enough? Did I make the right choices?"

The teachers commented on the value of both self-evaluation and feedback and of their own efforts to get feedback on their own practice and to use experiences with other teachers as ways of promoting self-evaluation. A U.S. teacher said, "I am happy to have more feedback... I would like more and more critical feedback." Another said, "I never pass up an opportunity to go look at another teacher, to go be in another teacher's classroom, because I think having a window into another teacher's classroom-I always have something to learn." One teacher said that she found the videotaping and self-evaluation portion of the National Board Certification Process to be "one of the most exhilarating things I ever did. I 
loved it! I loved looking at what I was doing and objectively and honestly." Similarly, a

China teacher also stated she could record her teaching and self-critique after class.

Another component of reflection evident in the teachers' comments was a focus on areas for improvement and growth. They noted specific areas within their practice that they were targeting for improvement at the time or wanted to improve in the future. In several cases, those areas for growth were personal habits and characteristics, such as organization, rather than pedagogical skills. In other cases, teachers did highlight teaching practices or content emphases for improvement, such as building more differentiation into questioning or improving wait time. One U.S. teacher described an effort he made over a period of several years to improve his reading instruction, developing and working toward specific goals, reading reference materials to support his work, and carefully evaluating his progress; he commented that he is currently working to make similar improvement in his mathematics teaching. Another captured the overall reflective emphasis with the comment that "one of the good things about teaching is that you begin again every year.... Some years things just click and you go higher and higher and other years you don't. But each year, that's one of the best things about teaching is that you begin again... you get to re-examine what you did."

Four China teachers said they kept a journal for reflection on their teaching. They commented in their journals what worked in that day's teaching, for instance the interesting dialogues that occurred in that class, the good examples the teacher used, the thoughtprovoking questions asked, the fun hands-on activities, and the technology. They also wrote down what did not work, such as what made their explanations unclear and if they were blind to the learning needs of some students. 


\section{Relationships with Students and Parents}

The caring and positive relationships with students permeated the teaching of the observed teachers in both countries. Many of their comments during the interview also focused on their relationships with students. In many cases, the participants viewed their relationships with students were the foundation for successful teaching and learning. These teachers portrayed their relationships with their students as warm, friendly, and caring. They demonstrated their care, either for the academic aspect or the nonacademic aspect of the students' growth, in such as way that their students are aware of it. One teacher said, "I try to have meaningful connections with them. You know, I try to know them as people and to meet their individual needs and have an understanding of what's going on at home." The teachers also highlighted developing relationships and connecting with students on an emotional or personal level. One teacher commented:

"I think where I've been successful in the classroom is that just about every single student in there knows that I like them. They know it and I always try to find something important about them and I try to personalize them. I try to use their names. I try to pay attention to what they care about and make sure that I say 'Nice new piercing you got there' ... or 'Hey, you got some blue hair going on."'

All of these teachers commented not only on developing relationships, in general, but also on how teacher-student relationships were important in achieving desired results with students, in encouraging students to engage with the learning process, and to behave appropriately in school. A teacher commented, "I think knowing your students and making sure that they know that you care about them goes a thousand percent to getting results from them." Another said, "I think that we have a deep sense of trust. My kids know that I believe in them and so they 're willing to take risks." Many China teachers, who teach her students 
over a period of years, spoke of their understanding of the student behavior: "I feel such a bond with them because I have them for so long.... [H]aving them three years, by that point you get so close to them that you feel like if they do something wrong, it's out of their character in the relationship with you."

These award-winning teachers regarded the ethic of care and respect as a vital foundation for students' best learning and a prerequisite for effective teaching. They are able to find a balance among respect for students as human beings, for student individuality, for discipline, and for academic success. Many of the teachers mentioned they help students with schoolwork, and many China teachers mentioned they stayed in the classroom after school to provide one-to-one tutoring to students who are at risk of failing. In addition, they go the extra miles to help students with their personal problems and provide guidance.

Teachers in both China and the U.S. commented that their purpose is not only to teach knowledge but also to educate the students as a whole person. One U.S. teacher commented "It's not just about the content and the curriculum. It's about them [the students] as a whole person, and we want what is absolutely best for every single child that's in here." Another U.S. teacher wished to influence students with "just the kinds of things that don't have any thing to do with necessarily the content but have to do with the idea that learning can be joyful, that learning makes us human and it gives us tools to be real people and enjoy our lives." Comparably, one China teacher stated "the responsibilities of a teacher are not only to transmit the knowledge of subject matter, but also to nourish the students as a whole person." 
In particular, 8 of 12 Chinese teachers shared that they needed to be the role models

for their students, not just for their academic learning, but also for their moral development.

For instance, one teacher shared,

"Because I am the head teacher (ban zhu ren), I spend a lot of time with my students after class and I monitor their moral development. I think it's important for these teenagers to have moral guidance. They spend most of their time in this school and in this classroom, so it's of great significance for me to be a role model. I noticed that most of the children and youth nowadays are not grateful and take everything for granted, especially those coming from the only-child families. I often share with them that they need to appreciate what their parents and the society have done for them."

The U.S. teachers who highlighted relationships with students most thoroughly were

also the ones who made the most comments about relationships with parents. One teacher

mentioned the necessity of strong home-school connections and understanding what is

happening at home. Another teacher, in particular, spoke extensively of working in

partnership with parents from an initial meeting to ongoing discussions throughout the year:

"Continual conversation with parents throughout the year. Once you get that base developed of a relationship with a parent, you're not as hesitant, vou're not as afraid, you're not concerned about calling them up and saying look, you know what your child did today? and how are we going to help him not do that again? ... I'm not afraid to do that. Because they know what my intent is. And when you've not had conversations, and you've not developed a relationship with parents, they don't know where you're coming from."

U.S. teachers spoke of their relationships with parents and with the students beyond the classroom with a broad sense of the community. One teacher commented: "My relationship with the child is community based. It's not just I'm teaching you between 9 and 3, but it's my whole life, because that's my vocation."

In comparison, the China teachers' relationships with parents were more personal than the U.S. teachers. Five teachers used the word of "friendship" to describe their relationships 
with the parents. Furthermore, when describing their relationships with the students, 8 out of

12 China teachers used terms of family relationships. For instance, one younger female teacher said her students treated her like an elder sister, and one middle-aged male teacher commented his relationship with the students was similar to relationships between a father and sons. Some examples to illustrate would be:

"I keep close relationship with my students, and we never keep a distance from each other. At the same time, they respect me. I pay close attention to the changes that happen to their life, likewise, they care about the changes that happen in me too."

"When I teach, I make my authority present and stick to my strict rules, but after class, I mingle with my students and we do a lot of fun things together. I invite them to my home. We chat. We go on outings regularly. We do physical exercises together every morning on campus. I also cheer for them when they participate in sports events on campus."

"I treat my students as I were their father. I am authoritarian and strict when I need to be, but the students know that I love them and care about them."

"I am going use a quote of my students. They said our classroom is like a family, and each one is a member."

\section{Metaphors of Teaching}

In this study, the researcher also asked the participants to generate a metaphor that

describes what they think about teaching. Their metaphors turned out to be creative and insightful. Despite their differences across the domains of planning, instructional delivery, and professional development, both China and U.S. teachers in this study exhibited their commitment and enthusiasm to their students' learning and growth. Some of the metaphors created by the teachers themselves can best testify to this claim:

"Teaching is like fostering (planting) a piece of seed. You must have a correct values like nutrition, correct view of knowledge like sunshine, correct methods like the farmers' work." (China) 
"Teaching is like a roller coaster. There are incredible highs and incredible lows but eventually you reach your destination if you just hang on. If you don't mind being on a roller coaster it's the thrill of a lifetime." (U.S.)

"Flowers. Teaching is similar to a process of watching flowers come into blossom. Teaching is to appreciate the beauty of growing lives. "(China)

"Teaching is like cooking. In a kitchen you have an arsenal of tools and ingredients. Put together they can create every dish imaginable. There are recipe books you can follow, and anyone can be a cook by following the directions. But a chef understands the nuances and special character of each food and which tools and technique will bring about the best flavors without consulting the cookbook." (U.S.)

"The optimal education that a student can receive should be traceless and markless. It's all natural without any artificial twists. So I think teaching is like the spring rain in South China. Just as it is described in the famous poem by Du Fu: it knows when to come; it follows the wind secretly into the night, and moistens all things gently, without sound; it is gone at dawn, but flower buds are starting to show up at the tips of plants. "(China)

"I'd like to think of teaching kind of as you are building a castle but you can only build the castle one brick at a time. .... But you have to start at the foundation and sometimes that means you can't do the fun stuff-you can't put the spires on at the top. You get to do all the dirty work... Teaching is a lot of hard work and sometimes you are the guy digging the ditch and just getting your hands all mucky and dirty and it's not glamorous work." (U.S.)

The metaphors demonstrate patterns of these awarding-winning teachers' thinking about teaching: professionalism, passion for teaching, steady work of improvement, and creativity in their reflection. Additionally teaching is viewed by the teachers as a complex experience that involves feelings of hope, doubt, exhilaration, ambiguity, victory, and weariness.

\section{b) What Are the Selected Teachers' Perceptions of Why Their Practice Merited}

\section{Recognition With A National Award?}

When the award-winning teachers, themselves, were asked why they thought they were selected for their honor, three themes to their responses emerged: 1) relationships with students and others, along with dedication to teaching; 2) achievement, particularly of their 
students, and their contributions to their fields; and 3) humility. Table 17 is illustrative of the

teachers' responses.

Table 17. Self-identified Reasons by Teachers for Receiving Awards

\begin{tabular}{|c|c|}
\hline Theme & Illustrations \\
\hline $\begin{array}{l}\text { Relationships/ } \\
\text { Personal } \\
\text { Dedication }\end{array}$ & $\begin{array}{l}\text { China Teacher Illustration } \\
\text { - 'Because my teaching is appreciated by the students. That is why I } \\
\text { got the award. My colleagues also recognize me. ... I think a good } \\
\text { relationship played a role in my being awarded nationally. I always } \\
\text { have a good relationship with my students... so this gives me a good } \\
\text { reputation." } \\
\text { - "My perseverance and determination. I hang in there until the end } \\
\text { despite all the obstacles along the way. Staying steadfast for one day } \\
\text { or two days may not be impossible, but staying firm to your faith for } \\
\text { more than ten years is really something. I am proud of that." } \\
\text { United States Teacher Illustration } \\
\text { - "I would say it's my enthusiasm. I love my students, and I love } \\
\text { coming to school, and I love working with the teachers that I work } \\
\text { with. I'm very creative, and I have a very supportive administration } \\
\text { that has let me do pretty much anything I wanted in my classroom, } \\
\text { and a couple of years ago I was stunned when a parent told me they } \\
\text { had requested me for their child for fifth-grade teacher. I said, } \\
\text { 'Really? Why?' It was just one of those things. And she goes, 'Oh, } \\
\text { you know, the neighborhoods talk.' And I'm like, 'Oh my gosh, } \\
\text { they're talking about me in the neighborhood!'" }\end{array}$ \\
\hline $\begin{array}{c}\text { Student } \\
\text { Achievement/ } \\
\text { Professional } \\
\text { Contribution }\end{array}$ & $\begin{array}{l}\text { China Teacher Illustration } \\
\text { - "The continuous outstanding performance of my students on } \\
\text { standardized tests. Each year, I provided demonstration lessons in at } \\
\text { the levels of my school, school district, province, and even other } \\
\text { provinces. I also publish one monograph and a dozen journal articles } \\
\text { about teaching Math to elementary students." } \\
\text { - "The students' achievement. My students rank very high within the } \\
\text { district. I am also a grade director and a banzhuren (i.e., head } \\
\text { teacher), and my class has been awarded } 5 \text { times in the district." } \\
\text { United States Teacher Illustration } \\
\text { - "I think dedication and enthusiasm for this job. My principal said I'm } \\
\text { a maximizer. I write grants, and I'm willing to try new things. And } \\
\text { it's constantly in the back of my mind, 'what can I do to improve.", }\end{array}$ \\
\hline Humility & $\begin{array}{l}\text { China Teacher Illustration } \\
\text { - "By accident. ... We have many teachers who are better than me or } \\
\text { just as good as me ... So, I said it is by chance that I was chosen." } \\
\text { - "There are many teachers deserving this award. I was picked because } \\
\text { my colleagues want show their encouragement for me to keep up } \\
\text { with the good work." } \\
\text { United States Teacher Illustration } \\
\text { - "Milken is interesting because I think Milken - Milken has an } \\
\text { emphasis on leadership in the field, too, so part of me wants to think }\end{array}$ \\
\hline
\end{tabular}


... it was because I' $m$ a great teacher ..., but there are millions of great teachers. ... I certainly worked a lot, but I think that there are lots of really great teachers who aren't being recognized, and probably are doing as much work as well..."

- "The National Teachers Hall of Fame - umm gosh. It's hard talking about awards because I tell you what. ... you realize that you have gotten recognition but you know so many incredibly excellent teachers who should have the awards too, you know, and so you feel kind of ill at ease talking about it." 


\section{CHAPTER 5 \\ SUMMARY, DISCUSSION, AND IMPLICATIONS}

\section{Summary of Findings}

This cross-cultural comparative study explored patterns of teaching and reflections of teachers who received national-level award for teaching in the United States and China.

Research of the process of teaching is crucial to understanding what effective teachers do in the classroom. The teachers involved in this study demonstrated high levels of competence related to the qualities of effective teachers identified in Stronge's (2007) framework, as well as frameworks offered by Bai (2000) and Cui and Wang (2005). The U.S. and China teacher cases in this study shared several similarities.

Use of a Wide Variety of Instructional Activities across Different Cognitive Levels.

The teachers from both China and the U.S. used a wide variety of instructional strategies which spanned lower to higher cognitive levels. There were no significant differences noted in the numbers of activities per lesson used by the teachers in the two countries. Knowledge and comprehension were the most evident cognitive level of learning for teacher in both countries.

Teacher Direction of Learning. In most of the classes observed, there was a high degree of teacher direction. The majority of learning activities were directed by the teacher. The classrooms in both countries were characterized by strong academic focus. Clear, understandable, and attainable goals were communicated to the students.

High Student Engagement. The students were highly engaged in learning in both Chin and U.S. classrooms. The students exhibited concentration, interest, and enjoyment about the 
subject matter. This high engagement level was achieved through the teachers' relevant teaching, enthusiasm, and the balance between challenge of the task and the students' ability.

Opportunistic. The teachers in both countries stayed opportunistic and quickly changed tracks of instruction based on situations of student learning. They planned contentspecific pedagogy, and improvised as required by the classroom circumstances to maximize meaningful learning opportunities.

Assessment. In both countries, the teachers used a variety of assessment strategies to monitoring student progress. They included both formative assessment, such as whole-class discussion, homework assignments, student opinion, project products, and summative assessment. These teachers continuously used student performance to evaluate the effectiveness of their reaching and adjust their instruction

Creation of Optimal Learning Environment. The observed teachers in both countries were proficient at creating and maintaining a learning environment that is safe, fun, and intellectually stimulating. They implemented effective classroom management to establish order and engage students. The classrooms were organized with efficient routines and procedures for tasks. No disruptive student behaviors were observed.

Reflection. The teachers, in both China and the U.S., continuously practiced selfevaluation and self-critique for professional growth. They perceived themselves as students, who need to growth the students they teach. They constantly strove to improve their instruction and take risks to try new approaches in the classroom. They also kept up with what research says about best practices in their field, through scholarly reading and attending professional development activities. 
These similarities indicated that certain characteristics of exemplary teachers are shared by the cultures in both China and the United States. For instance, one shared key behavior of these effective teachers was instructional variety. The teachers in both China and the United States used a variety of instructional activities to engage students and stimulate their thinking. Classroom observations and interviews also revealed that the classroom practices and professional thinking of China and United States teachers were unique in various ways.

Planning. While planning instruction, both China teachers and U.S. teachers tended to emphasize the alignment between curriculum standards and instruction, while U.S. teachers went further to incorporate the assessment of learning in their planning process. China teachers stressed more that they developed and tested hypotheses about student learning difficulties, and they anticipated students' misconceptions while planning. In addition, they identified "key points" and "difficult points" in their planning process for each lesson. In contrast, U.S. teachers had more autonomy in planning, and they valued such selfgovernance. They had most flexibility in designing the units, lesson and assigning timelines based on the needs, strengths, and interests of the students.

Instructional Activities. Although the observation data revealed that both U.S. teachers and China teachers used various instructional activities in classroom, they presented different patterns regarding what specific teaching activities to use. The most frequently used activities of China teachers were questioning, student responding, lecture, technology use by teacher, lecture with discussion, and student working individually. Comparatively, the U.S. teacher most frequently used student responding, questioning, teacher interacting with 
individual student and group, technology use by teacher. Although questioning and student responding were the most frequently used strategies in both nations, they occurred in striking different patterns. In China classrooms, they were attached to lecture and mixed with lecture, while in U.S. classrooms, there was no such connection.

Instructional Delivery. It is noticeable that the instruction in China was more whole group teacher-centered. Lecture was the prevailing instructional strategy observed in China classrooms. China teachers' teaching was carefully scripted and structured. The observation of their instruction indicated that the strategy of lecture has the advantage of covering large amount of content within a limited amount of time. Every task or concept is taught and demonstrated by the teacher. The teachers maintained a central role during the instruction and minimized the amount of nonacademic task. The continuous scaffolding provided by the teacher gave the children a sense of accomplishment that motivated them to stage engaged and seek further knowledge (Joyce, Weil, \& Calhoun, 2004). Comparatively, the U.S. students provided student-centered learning opportunities for students to explore. They allowed more time for their students to observe and question phenomena, and pose or revise explanations by themselves, rather than feeding them with knowledge. By comparison, the U.S. teachers tended to use activities that allowed them to interact with students in small groups or individually. Additionally, during the interview, the U.S. teachers reflected more about how to involve students in authentic learning experiences within a specific content area, while none of the China teachers reflected on this issue. This finding was supported by an earlier study which found U.S. teachers perceive the goal of instruction is to teach students how to solve problems in the real world, and believe that teaching content in real life 
situations and connecting it to concrete models is an important instructional approach (An, Kulm, Wu, Ma, \& Wang, 2002). Contradictorily, China teachers may emphasize teaching students learning methods and the ability to transfer learning to the real world, while they seldom incorporate concrete models into their own teaching.

Differentiation. The China teachers and U.S. teachers differed in their practices of differentiation. China teachers found it more challenging to differentiate their teaching due to large class size, pressure from an examination-driven education system, and limited instructional time. The observation data further supported this finding by indicating their instruction primarily involved whole-group instruction. By comparison, the U.S. teachers involved students in different activities individually or in groups at different paces. Compared with the China teachers, they also interacted more with students in small groups or individually to provide guidance and feedback.

Classroom Management. The teachers in China and U.S. were observed use the physical space in their classroom differently. The physical arrangements in U.S. teachers' classroom changed from day to day to day or week to week depending on what kinds of activities students were engaged in and what the teachers were trying to accomplish. The teachers in China had much less flexibility with classroom arrangements because of the large class size. In addition, the China teachers tended to reflect more on their demands for classroom discipline and teacher control during interviews.

Collaborative Professional Development. The study also found that the collaborative professional development was more institutionalized among China teachers. Most of the China teachers were in school-level Teacher Research Group and grade-level Lesson 
Preparation Groups. They engaged in collaborative study of teaching materials, collaborative instructional planning, and frequent classroom observation. These teachers also indicated positive attitudes toward the collegial, collaborative working environment.

Relationship with Students and Parents. The researcher found that China teachers had more personal and family-like relationships with students and parents, while the relationships between the U.S. teachers and students/parents are more professional and community-based.

This study highlighted the cross-system similarities and differences in carrying out and reflecting high-quality classroom instructional valued in the U.S. and China. This findings of the study indicated that they are certain practices and beliefs formed similarly across different cultures, and some distinctive teaching practices are shaped and nurtured in specific cultures and educational systems.

\section{Discussion}

The study revealed several prominent themes related to teacher practices and beliefs in China and the United States. In particular, the themes, where these two groups varied, may be worth further discussion, including: instructional planning; instructional delivery; classroom management; differentiation; relationships with students and parents; and professional development. Each of these themes will be explored, in turn.

\section{Instructional Planning}

The findings of this study found that the teachers in China and the United States use curriculum materials differently to plan for classroom teaching. In China, textbooks and teachers' manuals play an essential role in teachers' work and serve as a primary source of subject matter and pedagogical knowledge (Fan \& Gurcharn, 2000). These materials, 
carefully developed by the Ministry of Education, not only prescribed the learning standards and curriculum, but also prescribed lessons. This confirmed what Fang and Gopinathan (2009) noticed - most East Asian countries rooted in Confucian heritage culture attach great important to texts. One of the advantages of such top-down mandates is to make the alignment among curriculum, instruction, and assessment more feasible. Furthermore, as mentioned earlier, all the China teachers were in a certain collaborative group, the pressure to keep up with the pacing of peer classrooms seem to deprive the teachers of their flexibility and autonomy. Such a strict pacing mandated a fixed amount of time each day in which formal instruction of certain lesson or concepts may occur. In comparison, the teachers in the United States enjoyed more flexibility and autonomy regarding pacing, learning materials selection, content goals, as long as they are in alignment with overall curriculum and standards. However, it was found that the selected award-winning teachers were thriving within their constraints-they were adept at not only meeting the requirements for the coverage of content and the prescriptive pacing, but also using curriculum guidance to scaffold based on student ability and progress. The textbooks and reference books seemed to free up more time for these teachers to look more attentively at their student learning and consider how to deliver each lesson more effectively.

It was noted that the China teachers' lesson plan were organized around "knowledge points," "key points," and "difficult points." Identifying each of these areas for each lesson required the teachers to be knowledgeable about the framework of learning objectives and be sensitive to student learning and difficulty of the content. The observation of this study confirmed that China teachers used frequent questioning as a strategy of scaffolding to 
diagnose student learning needs on specific learning areas and adapt their teaching strategies so as to conform to the evolving learning level of the students. In comparison, the observed teachers in the United States valued their autonomy in making decisions about teaching materials. The state-mandated curricula in the United States usually do not specify the lessons that take place in the classroom, therefore the teachers has more freedom to sequence units and lessons in their own ways, and to develop appropriate timelines for the completion of these plans. They also have more choices and flexibility in selecting instructional materials and resources. The literature in the United States elaborated that autonomy is crucial for teaching be identified as a profession and teachers be regarded as professionals. In addition it is a critical component for teacher growth and career satisfaction (Conley, Muncy, You, 2005; Johnson, 1990; Mangin, 2005). Alexander (2002) argued that U.S. teachers value independence and individualism and their decision-making autonomy over schedule, curriculum and classroom management (Alexander, 2002).

Team planning was another important subtheme emerged in the findings regarding China teachers. Teachers who taught the same subject and the same grade level usually grouped together to study the curriculum, textbooks, and teacher reference books. Such collaboration allowed them to see the curriculum in its entirety and avoid over-emphasizing one area of content at the expense of others (Chan \& Rao, 2010). Stigler and Stevenson (1991) has long before observed that teachers in China have a tradition of planning together and observing each other's lessons, fostered by a culture that value collegiality over individualism. Such a culture and habit of collaboration has enabled teachers to pull together teaching ideas and resources. Literature also noted that China teachers have relatively lighter 
work load than their U.S. peers, due to large class sizes and different scheduling method, thereby having more time for collaborative or individual planning. As mentioned earlier the teachers in China are usually assign to school office rooms by subject matter and grade level, and often their office desks are grouped together to organize a group workplace. This physical proximity facilitates collective learning and promotes teachers' engagement in conversations of their daily practices (Fang, Hooghart, Song, \& Choi, 2003). This workplace culture allows teachers to refine their craft of teaching together and engage in continuous improvement of planning and teaching (Fang \& Gopinathan, 2009; Paine, 1990).

Another difference in instructional planning was related to the structural differences between the educational systems in China and the U.S. One of the tradeoffs of large class sizes in China is less workload in terms of number of courses taught per week by teachers, thereby generating more time for planning or collaborative planning. The schedule of schools in China established that the lessons are of short sessions (45-50 minutes each session) and each teacher teaches only one subject area, but multiple times to multiple classes. The typical teacher in China teaches 12-16 lessons each week. However, in the U.S., the typical teacher contract requires teachers to spend up to 32 hours per week at school or a little over 6 hours per day (Drago, et al., 1999). Of that time, teachers typically allocate 1 hour to planning and the remaining 5 hours for classroom instruction (Kennedy, 2010). The ratio of planning time to instructional time is around $1: 6$. In other words, there are around 10 minutes available to plan for an hour's instruction. The U.S. teacher planning time is sparse, particularly at the elementary level where classroom teachers usually teach multiple subjects-reading, mathematics, science and social studies. Moreover, this " 1 hour" is also the only official time 
for classroom teachers to correct student work, diagnose students' learning process, communicate with parents or special education teachers or school counselors, and complete paperwork which may or may not be related with classroom instruction. In China, the ratio of planning time to instructional time would be 2:1 typically (Kennedy, 2010). In addition, the centralized curriculum and the philosophy of collectivism in Chinese culture provide favorable conditions for collaboration in instructional planning.

\section{Instructional Delivery}

It was found that questioning and student responding were the most frequently used instructional strategies in both China and U.S. classrooms, with China teachers using them in about 80 percent of the overall observational time and the U.S. teachers using them in 60 percent of the observational time. These teachers used questions and student responses to elicit and interpret students' ideas and to understand what students find confusing or difficult. They promptly provided alternative explanations, models, and procedures to represent core concepts. In this dynamic interaction, the teachers created a responsive and flexible instruction through bring together their knowledge of the explanatory frameworks that organize and connect idea, and their knowledge of their students to make adjustments in accordance to what happens. This skill of listening to what students say and constructing appropriate adaptive responses on a moment to moment basis is exemplary demonstration of teaching expertise (Feiman-Nemer, 2001).

The lectures that occurred in the China teachers' classrooms often were mixed with questioning, students responding, and scaffolding. The lectures also were attached to many other major instructional strategies used by the observed teachers, such as technology use 
(i.e., use PowerPoint slides to present textbook content) and engaging students in seat-work (i.e., student study textbooks individually or in small groups). However, no such connection was observed in the U.S. classrooms. In the U.S. classrooms, learning activities were much more student-centered, with the teachers acting as facilitators and students actively participating in individual or group work that fosters problem-solving. The individualism in Western culture suggests that learning is optimal when student self-expression is exploited and when students are engaged in exploration themselves.

The different roles played by textbook-based lecture in the instruction of China and U.S. classrooms can be explained, at least partially, by the different beliefs of learning held by the teachers in these two nations. In the West, educators believe in learning through exploring. Learners learn best when they start with exploring first, then move to the understanding of concepts and development of skills Educators in China believe in understanding the content first and then in creative exploration of the learnt concepts (Biggs, 1996). In China classrooms, teacher lecture not only involved conveying information to students, but also stimulated higher-order thinking skills. The representation of comprehension, application, and analysis during China teachers' instruction was not significant lower than that of the U.S. teachers' whose instruction was more student-centered. Within whole group instruction, the students in China seemed to learn through memorization or structured practices, thus engaging in lower-order cognitive learning. However, the students' learning was scaffolded to learn the underlying concepts and apply them to various new examples. 
The findings of the study support earlier studies that examined instructional practices in mathematics in Mainland China, Hong Kong, U.S., and other high-achieving educational systems (Hiebert et al., 2003; Huang \& Leung, 2004). These studies also found the salient features of classrooms in Confucian culture is the dominance of the teacher in the teaching and learning process; however, high quality teaching and learning and active student engagement still take place in a teacher-controlled classroom, even where the class size is large. The overrepresentation of whole class direct instruction or lecture in the China's exemplary classrooms seems to be counterintuitive based on Western mainstream thinking of quality instruction. Critics of lecture believe lecture rests on the assumption that students are passive receivers in the process of learning and it is associated with learning at low cognitive levels based on Bloom's taxonomy. Nevertheless, the empirical research has consistently indicated that direct instruction is one of the most effective strategies in producing high student learning outcomes across subject areas (Kroesbergan \& Van Luit, 2004; Rosenshine, 1995; Schwerdt \& Wuppemann, 2009; Stevens, Slavin, \& Farnish, 1991), across grade levels (Darch, Gersten, \& Taylor, 1987; Schwerdt \& Wuppemann, 2009; Upadhyay \& DeFranco, 2008), across students with different learning abilities, (Algozzine \& Maheady, 1986; Rosenshine \& Stevens, 1986), and across students with different socioeconomic backgrounds (Rosenshine, 2002).

The instruction of China teachers was found to be more structured than U.S. teachers. The sequences of instruction of China teachers are uniform across classes (also across subject areas and grade levels), while the sequences in U.S. teachers' instruction vary from classroom to classroom. China teachers usually start their lesson with a review of the content of last 
lesson, then present new learning content. Then they would present more variations of key concept and have students engaged in structured practices. At the end of lesson, they assign homework to reinforce student learning. Each lesson was about 45-50 minutes. As earlier research found, the instruction in China classrooms is characterized by density and fast pacing. A well-known international study by Steven and Stigler (1992) reviewed more than 800 hours of classroom observations in Asia, including some China areas. The researchers reported that they were struck by the structured and interconnected activities used by the teachers there toward specific learning objectives from lesson to lesson. They stated that the lessons were marked by "coherence" and "a consistent theme" (p. 177). In contrast, the teachers in the U.S. often cover multiple topics in their instruction and integrate them or shift between them.

Literature has well documented the so-called East Asian learner paradox: lecture and seemingly surface learning lead to high academic achievement. Observers of East Asian classrooms share a common impression - large class size with students sitting in rows of desks facing the teacher and the teacher leading nearly all the classroom activities and doing most of the talking to reticent students (Fang \& Gopinathan, 2009; Huang \& Leung, 2004; Paine, 1990; Park, 2006). Whole class instruction is the prevailing strategy to teach, and the teacher is perceived as the "purveyor of authoritarian information" (Stevenson \& Stigler, 1992, p. 18) transmitting knowledge to students, who act as passive recipients, through repetitive and rote memorization. These characteristics of the China classrooms are in sharp contrast to what is found to be conducive to student learning in Western academics. Yet in large-scale international tests, students from this type of learning environment performed 
consistently better than students in most Western countries (OECD, 2010; Steven \& Stigler, 1992). Various researchers have observed that apparently teacher-centered classrooms and large classes may not necessarily translate into passive learning or learning of low cognitive levels (Chan \& Rao, 2010). Chinese learners may be not as expressive as Western learners, but they actively listen and respond to teacher's instruction (Cortazzie \& Jin, 2001). The findings of this study confirmed that the teacher control and lecture in China classrooms are not without virtues; actually, they had some laudable advantages.

\section{Differentiation}

The findings of this study revealed that China teachers and U.S. teachers presented different patterns of differentiation. The observations indicated that the students in the U.S. were often grouped to work on different tasks at different paces. During the interviews, the U.S. teachers also commented intensively about how they developed multiple paths of instruction so that students of varying abilities, interests, and learning needs can experience equally appropriate ways to learn. This finding was particularly indicated in the differentiated learning materials and differentiated learning activities used in the teachers' instruction. In contrast, differentiation in China teachers' classroom was limited to tiered questioning and homework. The rich differentiation observed in the U.S. classrooms is aligned with the emphases on heterogeneity, inclusion, and cultural diversity in U.S. school reform. Throughout the literature about school reform, classroom instruction, and teacher professional development in the U.S., there is a call for teachers to adjust curriculum, materials, and activities to ensure each student has an equal and appropriate education. These cultural beliefs, directions of school reform movement, and the philosophy of individualism, 
which believes the welfare of the whole society is contingent on the fulfillment of individual needs, make differentiation and serving academically diverse learners in regular classrooms crucial parts of a teacher's role (Tomlinson et al., 2003). The lesser presence of differentiation in China teachers' instruction may be a result of large class size and limited instructional time. It also may relate to their Confucian belief that effort overpowers ability in determining a student's academic achievement.

Because cultures provide different tools, habits, and assumptions that significantly influence human thought and behavior (Tweed \& Lehman, 2002), Western and Chinese theories about the dichotomy of nature versus nurture are different. Generally, Chinese culture credits nurture over nature in human learning and achievement. Confucian philosophy on learning and achievement places primary emphasis on non-intelligence factors, such as personality traits (e.g., motivation, perseverance, and effort) and environmental factors (e.g., parental and familial support, and teacher and school instruction), rather than natural ability, as the most important prerequisites for desired performance (Chen \& Stevenson, 1995; Chen, 1996; Rosenthal \& Feldman, 1991; Shi \& Zha, 2000). Confucius's lasting influence in history resides in his concept of "Ren," which is "a lifelong striving for any human being to become the most genuine, sincere, and humane person he or she can become" (Li, 2003, p. 146). According to Confucius, the process of actualizing Ren is a process of self-cultivation and self-perfection. He taught that the goal for the individual is the development of personality until the ideal of a perfect man, a true gentleman, a sage is reached ( $\mathrm{Li}, 2003)$. Confucius believes that, within this developmental process, one's single-minded effort and consistent practice are more important than his/her innate ability in achieving success (Tweed \& 
Lehman, 2002). Ultimately, ideal status of Ren is achievable by anyone striving for it. The China teachers influenced by Confucian thinking tend to regard the possibility to overachieve or underachieve is under individual control rather than be predestined by their natural ability. Research also revealed that Chinese culture and Western cultures have different attribution patterns and locus of control (Hau \& Salili, 1991; Salili \& Hau, 1994; Stevenson \& Lee, 1990; Walberg, 1992). People from Chinese culture tend to attribute success to effort and failure to lack of effort, whereas Westerners tend to attribute success and failure to ability or lack of ability. Gardner (1995) made the following comment regarding the phenomenon that East Asian students outscored American students on IQ tests:

"Genetics, heredity, and measured intelligence play no role here. East Asian students learn more and score better on just about every kind of measure because they attend school for more days, work harder in school and at home after school, and have better-prepared teachers and more deeply engaged parents who encourage and coach them each day and night. Put succinctly, Americans believe (like Herrnstein and Murray) that if you do not do well, it is because they lack talent or ability; Asians believe it is because they do not work hard enough" (p. 31).

\section{Classroom Management}

Every observed teacher created and maintained a classroom learning environment that is safe, respectful, and conducive to student optimal learning. Their classroom management covered a wide range of practice from setting up the physical environment (especially the U.S. teachers in this aspect) and establishing routines, preventing disruptions, and supporting intellectual risk-taking. Through effective classroom management, these teachers rarely had 
disruptive student behavior, thereby increasing student engagement in academic tasks.

Disruptive behaviors are particularly problematic for classrooms in that they can interfere with learning, compete with instruction, create an unsafe learning environment, and make it less likely that students will achieve academic objectives (Luiselli, Putnam, \& Sunderland, 2002). When these teachers' high expectations were communicated and received, their students made more psychological investment in learning and use more self-regulation strategies like memorization, task planning, and self-monitoring (Shernoff, Csikszenthmihalyi, Schneider, \& Shernoff, 2003). Differences were also found between China teachers and U.S. teachers with respect to the teacher power and control. During the interview, China teachers used the word of "control", "power", and "authoritarian" to describe their presence in the classroom, however at the same time, they were student sensitive too.

\section{Relationships with Students and Parents}

This study also revealed that teachers in China had more personal relationships with the students and their parents. They tended to project family relationships to their relationships with students. China teachers also emphasized their responsibility of being a role model of moral perfection. These beliefs about their moral guidance and parental role may explain their authoritarian and teacher-dominated instructional style. Earlier research observed that some distinguishing traits of Chinese culture promote such overlap between school/classroom and family, including children are expected to be submissive to their parents, stronger interdependence among family members, and children are raised with the belief that their school performance reflects on the family's honor (in turn impacting on the 
"face" of the classroom teachers and schools) (Blair \& Qian, 1998). In comparison, the relationships between U.S. teachers and students are more professional and communitybased. Earlier research found that Western teachers tend to view their involvement in students' learning within the framework of professional responsibilities as defined by the job description, while China teachers in many cases may go beyond the professional duties to get personally involved with their students' learning (Ho, 2001).

Researchers also noticed that China parents have high expectations for their children's educational success and that their children are more likely to equate academic achievement with parental satisfaction (Chen, 2001; Pearce \& Lin, 2005; Schneider \& Lee, 1990). Studies found that Chinese parents and Western parents have differential expectations and different expressiveness of their expectations about their children's learning and success. Schneider and Lee (1990) conducted in-depth interviews to illustrate how student learning is linked to children's perception of what makes their parents happy. They found that Western parents, on average, express satisfaction with their children if they are successful in one of the many realms of youths' lives (school, sports, music, or other hobbies), but Chinese parents express satisfaction only when their children have good academic performance (i.e., high test scores). Research also found that Chinese students exert more effort to fulfill their parents' and families' expectations (Dandy \& Nettlebeck, 2002; Phillipson, 2006).

Furthermore, similar to the China teachers who mirror the parent-child relationships in their classrooms, the parents in China also mirror teacher-student relationships at home when it comes to student learning. Research found that Chinese parents dedicate more time supervising their child's after-school activities, monitoring the completion of homework, 
assigning extra learning materials or assign additional homework (Schneider \& Lee, 1990).

All these similarities between classroom and home explain why teachers would build a "friendship" with the parents and engage in a joint endeavor to promote student learning.

\section{Professional Development}

When reflecting on their growth as a professional, the participants reflected that they learned from their daily practices as a site for inquiry (Ball \& Cohen, 1999). Many of them shared the frustration they experienced when they were novice teachers. Some China teachers also shared how the national curriculum reform disrupt their old experience and paradigm regarding teaching and learning, and how they raised up to the challenges and rode with the waves of external reforms. Their professional growth was an ongoing-process of experimenting something new and studying the effects, and generating new approaches to extend their repertoire of instructional experiences. Such self-initiated and autonomic growth required skills of observation and reflection, and dispositions to persevere, seek evidence, take risks, and remain open-minded to changes (Feiman-Nemser, 2001). The teachers also shared that their improvement of teaching was not accomplished alone. They are involved with various forms of professional development activities, such as mentoring, peer coaching, supervising practicing teachers or interns, attending conferences or workshops, pursuing course work and higher degree, and serving professional organization. Earlier studies (e.g., Wang \& Paine, 2003) also found the two typical approaches for the teacher development of China teachers are: 1) careful individual or collaborative study of mandated curriculum materials that are consistently structured; and 2) continuous and substantial participation in 
the lesson research, which includes the components of collaborative observations, reflection, and lesson debriefing based on a shared curriculum and language.

With regard to collaborative professional development activities, the study found that one striking difference between the teachers in China and the United States: the China teachers improve their teaching through "lesson research," which is cycles of activities in which teachers group by subject and grade level to design, implement, and critique together lessons. In China, team work is institutionalized, mostly in the form of school-level Teacher Research Groups and grade-level Lesson Preparation Groups (Fang \& Gopinnathan, 2009). Paine (1990) noted that these collaborative opportunities socialized teachers into "a community that shares a common body of knowledge and speaks a common language" ( $p$. 75). Table 18 summarizes the major similarities and differences found in this study between the China award-winning teachers and U.S. award-winning teachers, and interpretations for the differences. 
Table 18. A Summary of Similarities and Differences Between China and U.S. Award-Winning Teachers, and Relevant Interpretations

\begin{tabular}{|c|c|c|c|}
\hline Themes & $\begin{array}{l}\text { Similarities Between China } \\
\text { and U.S. Teachers }\end{array}$ & Differences Between China and U.S. Teachers & Explanations for such Differences \\
\hline $\begin{array}{l}\text { Instructional } \\
\text { planning }\end{array}$ & $\begin{array}{l}\text { - Planning based on the } \\
\text { curriculum, textbooks, and } \\
\text { student learning needs } \\
\text { - Using mental planning } \\
\text { process } \\
\text { - Allowing lessons to follow } \\
\text { a different path }\end{array}$ & $\begin{array}{l}\text { China teachers: } \\
\text { - Anticipate students' misconceptions while } \\
\text { planning } \\
\text { - Follow the textbook and the teacher } \\
\text { reference book closely, both of which were } \\
\text { developed by the Ministry of Education } \\
\text { - Frame lesson plans around three key terms } \\
\text { - More time for planning and collaborative } \\
\text { planning } \\
\text { U.S. teachers } \\
\text { - More autonomy and creativity in } \\
\text { instructional planning } \\
\text { - Incorporate assessment of student learning in } \\
\text { planning (backward planning) }\end{array}$ & $\begin{array}{l}\text { - Training emphasis on understanding } \\
\text { student learning (including student } \\
\text { misconceptions) in China } \\
\text { - Structural differences (i.e., trade-off } \\
\text { of large class size-less work load } \\
\text { and more time for planning in } \\
\text { China) } \\
\text { - Philosophy of U.S. and China } \\
\text { educational culture (individualism } \\
\text { versus collectivism; the tradition of } \\
\text { focusing on textbook in China } \\
\text { education history) }\end{array}$ \\
\hline $\begin{array}{l}\text { Variation and } \\
\text { flexibility in } \\
\text { planning and } \\
\text { instruction }\end{array}$ & $\begin{array}{l}\text { - Opportunistic } \\
\text { - Pattern recognition } \\
\text { capabilities }\end{array}$ & N/A & N/A \\
\hline Differentiation & $\begin{array}{l}\text { Referring to student learning } \\
\text { preferences and modalities }\end{array}$ & $\begin{array}{l}\text { U.S. teachers developed multiple paths of } \\
\text { instruction (i.e., differentiated curriculum, } \\
\text { learning materials, and learning activities), } \\
\text { while the differentiation was limited to tiered } \\
\text { questioning and homework in China } \\
\text { classrooms } \\
\text { Whole-group lecture was the dominant } \\
\text { instructional strategy used by China teachers. }\end{array}$ & $\begin{array}{l}\text { - Structural difference (e.g., different } \\
\text { class size) } \\
\text { - High density of curriculum content } \\
\text { in China educational system } \\
\text { - Perceived belief that students are } \\
\text { similar in ability among China } \\
\text { teachers } \\
\text { - Philosophy of U.S. and China } \\
\text { educational culture (individualism }\end{array}$ \\
\hline
\end{tabular}


versus collectivism)

- Different training emphasis in China and U.S. educational systems

\section{Classroom}

learning

environment
Maintaining a classroom environment that is safe, fun, and intellectually stimulating
- U.S. teachers had more flexibility in using the physical space in their classrooms to

serve instructional purposes

- China teachers placed more stress on control power, and authority

- China teachers valued more homework through addressing student error to whole class and using homework as re-teaching opportunities

- U.S. teachers emphasized more authentic assessment

Personal and Professional

Growth and

Change

Use of reflection

Pattern of professional
growth (from novice to
expert)
growth (from novice to

Collaborative professional development was more institutionalized in China (school-level Teacher Research Group and grade-level Lesson Preparation Groups)

Continuously practicing self- N/A evaluation and self-critique for professional growth

Relationships Caring, warm, and positive
with Students and relationships with students Parents
China teachers had more personal and familylike relationships with students and parents, while the relationships between the U.S. teachers and students/parents were more professional and community-based.
- Structural difference (e.g., different class size, different tradition in classroom arrangement)

- Cultural beliefs (transfer of filial piety in Chinese Confucian culture to classroom)

Different beliefs about homework
- Philosophy of U.S. and China educational culture (e.g., individualism versus collectivism)

- Different training emphasis N/A
- Philosophy of U.S. and China educational culture (e.g., teachers are moral models in China)

- High social status of teachers in China and high parental involvement in and commitment to the education of children 


\section{Implications for Practice}

The findings of this study demonstrated that there are common aspects of practices among the award-winning teachers in both China and the United States. These aspects include: using a variety of instructional strategies to encourage student involvement in activities and lessons; planning, yet remaining flexible and spontaneous; understanding students' learning; thinking about and reflecting on teaching; monitoring and assessing student progress; and creating a positive classroom learning climate. The difference between teachers in China and United States teachers in their practices and beliefs illuminated what they can learn from each other:

China

-Anticipate students' misconceptions while planning

-More whole group instructional activities used

-Lecture is the prevailing instructional strategy

-More challenges with differentiation

-More challenges with authentic learning

\section{United States}

-More autonomy in instructional planning

-Mixture of whole group and teacher-student interaction

-Provide student-centered learning opportunities for students to explore -Incorporate assessment of student learning in planning and instruction

The U.S. teachers can grow through collaborative professional development models like their China peers use. Currently, the United States educational community is attempting to 
improve the long-standing problem by engaging teachers in collaborative planning and studying student work as part of school reform initiatives (Cobb, McClain, Lamberg, \& Dean, 2003; Elmore \& Burney, 1999). The Instruction Preparation Group and Lesson Research Group used by the China teachers may offer two optional models.

On the other hand, the China teachers can learn from their U.S. peers about providing students with more opportunities to explore and develop their own views. Research found that Chinese learners are not passive and teacher-dependent rote-learners. Within pertinent learning environments, they embrace and welcome new pedagogical goals and approaches. They were also found to value and cherish learning experiences that involved constructivist elements such as authentic learning, problem-based learning, discourse involving diverse viewpoints, and collaborative inquiry (Chan \& Rao, 2010). The traditional education system in China is often criticized for its emphasis on conformity, being highly examinationoriented, discouraging students' creativity development, authoritarian teachers for whom the rigid and centralized curriculum is a more important agenda than catering to individual differences among students (Cheng, 2004). Preus (2006) observed that national education reform in China since 2001 is moving its educational system toward decentralization of elementary and secondary education. China is striving to establish a "quality-oriented" rather than a "test-oriented" system (Preus, 2007, p. 115).

Chinese educational reforms at national, provincial, and local levels are attempting to decrease the density of curriculum, encourage teachers to adopt more student-centered inquiry and problem-solving activities, and empower teachers with more autonomy and encourage teachers to be more innovative and flexible about curriculum to better meet the 
needs of the students Contrastingly, the reform in the United States is driving its educational system toward centralization of elementary and secondary education It is increasingly more test-onented Furthermore, professional development is marked by non-collaborative organizational structures Similarly, Fang and Gopinathan (2009) also noted that educational reformers in the West are oriented toward better structured subject content, while the East is lookıng at how to involve students more actıvely in learnıng and how to relate learnıng to real work and students' real life These opposite trends of educatıonal reform policies and practıces highlighted that the expenence in China and U S educatıonal systems can be a potent source of learning for each other As an UNESCO report artıculated, different countries can come together to explore best practices and "the problems others face, the objectives they seek, the routes they try, the results they arrive at and the unintended results they produce are worth analysis" (Schwille, Dembele, \& Schubert, 2007, p 10)

\section{Implications for Research}

This cross-cultural comparatıve study explored patterns of teaching and reflection of teachers who receıved natıonal-level award for teachıng in the Unıted States and Chına There is abundant and compellıng research evidence supportıng that teacher eftectıveness matters and there is a large variation among teachers in terms of their effectiveness However, what is more useful for educational policy and practice is to find out what factors related to teachers actually cause those effects Thıs study used quantıtatıve classroom observation data to identıfy the practıces of great teachers, and qualitatıve interview data to reveal the perceptions and 1deations of highly effective teachers as they reflected on their experience of teachıng That makes thıs study different from the research lıne of value-added studies that 
use readily avallable data on teacher characteristıcs (e $g$, degree, certıfication status, years of teaching experience) to portray effective teachers Although it is premature to make a definıte conclusion on what makes an effective teacher just based on the findings of one limited study, nonetheless, the researcher trusts the findings do contribute to our understanding of this vital issue - teacher effectiveness

The observation protocol and interview questions that were used in this study focused on the process of teaching, rather than the products, or outcomes, of teaching Effective teaching also can be viewed in terms of outcomes -that is -are students makıng learnıng gains as a result of being a student in the teacher's classroom (Mendro, 1998, Nye, Konstantopolous, \& Hedges, 2004, Palardy \& Rumberger, 2008, Sanders \& Horn, 1994, Wright, Horn, \& Sanders, 1997) However, the process of teaching is the focus of this study as a group of researchers stated, " How can processes be improved by inspectıng only theır outcomes (Hiebert, et al , 2005, p 112)?" Research of the process of teaching is crucial to understandıng what effectıve teachers do in the classroom Through observıng and talkıng with effective teachers, the researcher solicited information as to their practices and beliefs that make them effective in the classroom These practices and beliefs can then be grounded In the existing literature, beginnıng to build a composite sketch of the elusive concept of teacher effectiveness

Thus, as reflected in this study, the researcher contended that research on the processes of teaching is crucial to better understand what effective teachers in different countries and cultures do in the classroom For future research, the researcher antıcıpates that as more teachers from varyıng teaching levels and subjects from high-achieving classrooms 
will be observed and interviewed, the understanding of the work of these great teachers will be illuminated. The researcher suggests that in the future effort to understand the difference between effective and less than effective teachers, researchers should look beyond the characteristics of teachers themselves to contextual factors, such as the amount of planning time available, the collegiality in school, schedule, leadership in school, teachers' resources, the impact of educational policies and reforms at various levels of school, district, state or whole nationwide (Kennedy, 2010). For instance, the researcher found that China teachers tended to have more planning time and were more likely to have team planning. One reason might be that they taught larger class sizes thereby teaching fewer lessons. The researcher also noticed that China teachers had fewer resources than their United States peers, such as computer and physical space within the classroom, and that influenced the instructional strategies they used. However, no specific questions regarding these contextual factors were developed at the beginning of the study, thus the data collected was fragmentary. Researchers in the field are encouraged to explore the important influences that these situational factors have on instructional practices and student learning in classroom. Furthermore, more finegrained analysis on classroom discourse and culturally-relevant lenses (e.g., social power, individualism/collectivism) are needed to make meaning of what happens in the classrooms of different cultures. The findings of this study confirmed that effective teaching involves a dynamic interplay among subject matter, teachers' pedagogy, characteristics of learners, and the contexts in which the learning occurs (Schalock, Schalock, Cowart, \& Myton, 1993). The researcher recommends future research in the field to explore deeper into the nuances, subplots, settings, complexities, and interdependencies of teacher teaching in natural 
classrooms. Although at this stage it is not possible to conclude what makes a teacher effective based on the findings of one study, I trust the findings of this study will contribute to a richer understanding of teacher effectiveness, especially in different cultural settings. 


\section{References}

Aaronson, D., Barrow, L., \& Sander, W. (2007). Teachers and student achievement in the Chicago public high schools. Journal of Labor Economics, 25(1), 95-135.

Akiba, M., LeTendre, G. K., \& Scribner, J. P. (2007). Teacher quality, opportunity gap, and national achievement in 46 countries. Educational Researcher, 36(7), 369-387.

Allington, R. L., \& Johnston, P. H. (2000). What do we know about effective fourth-grade teachers and their classrooms? Albany, NY: The National Research Center on English Leaning \& Achievement, State University of New York.

An, S., Kulm, G., Wu, Z., Ma, F., \& Wang L. (2002). The Impact of Cultural Differences on Middle School Mathematics Teachers' Beliefs in the U.S. and China. In: Preconference Proceedings (Supplement) of the ICMI Comparative Study Conference, 20th-25th October, 2002, Hong Kong. Hong Kong: The University of Hong Kong, Faculty of Education

Anderson, L., \& Krathwohl, D. (2001). Taxonomy of learning, teaching and assessing: A revision of Bloom's taxonomy of educational objectives. New York: Longman.

Bai, Y. (2000). Practices and characteristics of highly effective teachers. Educational Research and Experiment, 4, 31-37.

Ball, D. L., \& Cohen, D. K. (1999). Developing practice, developing practitioners: Toward a practice-based theory of professional education. In G. Skyes \& L. Darling-Hammond (Eds.), Teaching as the learning profession: Handbook of Policy and Practice (pp. 332). San Francisco: Jossey-Bass.

Bandura, A. (1997). Self-efficacy: The exercise of control. New York: W. H. Freeman. 
Barber, M., \& Mourshed, M. (2007). How the world's best-performing school systems come out on top. London: McKinsey \& Company. Retrieved November 7, 2008, from http:/www.mckinsey.com/locations/ukireland/publications/pdf/Education report.pdf.

Beaman, R., Wheldall, K., \& Kemp, C. (2007). Recent research on troublesome classroom behavior: A review. Australasian Journal of Special Education, 31, 45-60.

Bembry, K. L., Jordan, H. R., Gomez, E., Anderson, M. C., \& Mendro, R. L. (1998, April). Policy implications of long-term teacher effects on student achievement. Paper presented at the 1998 Annual Meeting of the American Educational Research Association, San Diego, CA.

Berliner, D. C. (1986). In pursuit of the expert pedagogue. Educational Researcher, 15(7), 513.

Berliner, D. C. (2004). Describing the behavior and documenting the accomplishments of expert teacher. Bulletin of Science, Technology and Society, 24, 200-212.

Betebenner, D. (2009). Norm- and criterion-referenced student growth. Educational Measurement: Issues and Practice, 28(4), 42-51.

Bettencourt, E. M., Gillett, M. H., Gall, M. D., \& Hull, R. E (1983). Effects of teacher enthusiasm training on student on-task behavior and achievement. American Educational Research Journal, 20(3), 435-450.

Biggs, J. (1996). Western misperceptions of the Confucian-heritage learning culture. In D. A. Watkins and J. B. Biggs (Eds.), The Chinese learner: Cultural, psychological, and contextual influences (pp. 46-67). Hong Kong: Comparative Education Research Center. 
Black, P. J. \& Wiliam, D. (1998) Assessment and classroom learning. Assessment in Education: Principles, Policy \& Practice, 5(1), 7-73.

Blair, S. L., \& Qian, Z. (1998). Family and Asian students' educational performance. Journal of Family Issues, 19(40), 65-72.

Bo, H. (2008). A preliminary study on effective instruction of high school mathematics within the settings of implementing new curriculum. Unpublished master's thesis, Shandong Normal University, Qingdao, Shandong, China.

Borko, H., \& Livingston, C. (1989). Cognition and improvisation: Differences in mathematics instruction by expert and novice teachers. American Educational Research Journal, 26(4), 473-498.

Borman, G. D., \& Kimball, S. M. (2005). Teacher quality and educational equality: Do teachers with higher standards-based evaluation ratings close student achievement gaps? The Elementary School Journal, 106(1), 3-20.

Boyd, D., Lankford, H., Loeb, S., \& Wyckoff, J. (2005). Explaining the short careers of highachieving teachers in schools with low-performing students. American Economic Review, 95(2), 166-171.

Bransford, J., Derry, S., Berliner, D., Hammerness, K., \& Beckett, K. L. (2005). Theories of learning and their roles in teaching. In L. Darling-Hammond and J. Bransford (Eds.), Preparing teachers for a changing world: What teachers should learn and be able to do (pp. 40-87). San Francisco, CA: Jossey-Bass.

Buttram, J. L., \& Waters, J. T. (1997). Improving America's schools through standards-based education. Bulletin, 81 (590), 1-5. 
Carlson, E., Lee, H, \& Schroll, K. (2004). Identifying attributes of high quality special education teachers. Teacher Education and Special Education, 27, 350-359.

Campbell, J., Kyriakides, L., Muijs, D., \& Robinson, W. (2004). Assessing teacher effectiveness: Developing a differential model. New York: RoutledgeFalmer.

Cameron, C. E., Connor, C. M., Morrison, F. J., Jewkes, A. M. (2008). Effects of classroom organization on letter-word reading in first grade. Journal of School Psychology, 46, 173-192.

Carter, P. J. (2003). A review of highly effective teachers in Hamilton County: Analysis of current trends and implications for improvement. Chattanooga, TN: Public Education Foundation. Retrieved November 7, 2008, from http://pef.ddngroup.com/.

Cassady, J. C., Speirs Neumeister, K. L., Adams, C. M., Cross, T. L., Dixon, F. A., \& Pierce, R. L. (2004). The Differentiated Classroom Observation Scale. Roeper Review, 26(3), 139-147.

Cassidy, W., \& Bates, A. (2005). "Drop-outs" and "push-outs": Finding hope at a school that actualized the ethic of care. American Journal of Education, 112, 66-102.

Cawelti, G. (Ed.). (2004). Handbook of research on improving student achievement (3rd ed.). Arlington, VA: Educational Research Service.

Chan, C. K. K., \& Rao, N. (2010). The paradoxes revisited: The Chinese learner in changing educational contexts. In C. K. K. Chan and N. Rao (Eds.), Revisiting the Chinese learner: Changing contexts, changing education (pp. 315-349). Hong Kong: Comparative Education Research Centre/Springer Academic Publishers. 
Charmaz, K. (2008). Grounded theory in the $21^{\text {st }}$ century: Applications for advancing social justice studies. In N. K. Denzin and Y. S. Lincoln (Eds), Strategies of qualitative inquiry (3rd ed.), pp. 203-242. Thousand Oaks, CA: Sage.

Chaskin, R. J., \& Rauner, D. M. (1995). Youth and caring: An introduction. Phi Delta Kappan, 76(9), 667-674.

Chen, H. B. (2001). Parents' attitudes and expectations regarding science education: Comparisons among American, Chinese-American, and Chinese families. Adolescence, 36, 305-314.

Chen, C., \& Stevenson, H. W. (1995). Motivation and mathematics achievement: A comparative study of Asian-American, Caucasian-American, and East Asian high school students. Child Development, 66, 1215-1234.

Cheng, V. M. Y. (2004). Progress from traditional to creativity education in Chinese societies. In S. Lau, A. H. H., Hui. And G. Y, C., Ng (Eds.). Creativity: When east meets west (pp. 137-168), River Edge, NJ: World Scientific Publications.

Cloud, J. (2008, February 2). The science of experience. Time. Retrieved June 11, 2008, from http://www.time.com/time/health/article/0,8599,1717927-2,00.html.

Cobb, P., McClain, K., Lamberg, T., \& Dean, C. (2003). Situating teachers' instructional practices in the institutional setting of the school and district. Educational Researcher, $32(6), 13-24$

Cohen, D. K., Raudenbush, S. W., \& Ball, D. L. (2003). Resources, instruction, and research. Educational Evaluation and Policy Analysis, 25(2), 119-142. 
Collinson, V., Killeavy, M., \& Stephenson, H. J. (1998). Exemplary teachers: Practicing an ethic of care in England, Ireland, and the United States. Paper presented at the Annual Meeting of the American Educational Research Association, San Diego, CA, April 13-17.

Comedena, M.E., Hunt, S.K., \& Simonds, C.J. (2007). The effects of teacher clarity, nonverbal immediacy, and caring on student motivation, affective and cognitive learning. Communication Research Reports, 24(3), 241-248.

Conley, S., Muncy, D.E., \& You, S. (2005). Standards-based evaluation and teacher career satisfaction: A structural equation modeling analysis. Journal of Personnel Evaluation in Education, 18, 39-65.

Corbett, D., Wilson, B., \& Williams, B. (2002). Effort and excellence in urban classrooms: Expecting and getting success with all students. New York: Teacher College Press.

Cortazzie, M., \& Jin, L. (1996). Cultures of learning: Language classrooms in China. In H. Coleman (Ed.), Society and the language classroom (pp. 169-206). Cambridge: CambridgeUniversity Press.

Cortazzi, M., \& Jin, L. (2001). Large classes in China: "Good" teachers and interaction. In D. A. Watkins and J. B. Biggs (Eds.), Teaching the Chinese learner: Psychological and pedagogical perspectives (pp. 115-134). Hong Kong: Comparative Education Research Center,

Cotton, K. (2000). The schooling practices that matter most. Portland, OR: Northwest Regional Educational Laboratory; and Alexandria, VA: Association for Supervision and Curriculum Development. 
Craig, J. \& Cairo, L. (2005, December). Assessing the relationship between questioning and understanding to improve learning and thinking (QUILT) and student achievement in mathematics: A pilot study. Charleston, WV: Appalachia Educational Laboratory, Inc.

Crossley, M., \& Waston, K. (2003). Comparative and international research in education:

Globalization, context, and difference. New York: RoutledgeFalmer.

Cruickshank, D. R., \& Haefele, D. (2001). Good teachers, plural. Educational Leadership, $58(5), 26-30$.

Cui, Y, \& Wang, S. (2005). Conceptualizing and constructing effective instruction. Curriculum and Instruction in Elementary and Secondary Education, 182, 5-7.

Dandy, J., \& Nettelbeck, T. (2002). The relationship between IQ, homework, aspirations and academic achievement for Chinese, Vietnamese and Anglo-Celtic Australian school children. Educational Psychology, 22, 267-275.

Darling-Hammond, L. (1996). What matters most: A competent teacher for every child. Phi Delta Kappan, 78, 193-200.

Darling-Hammond, L. (2000). Teacher quality and student achievement: A review of state policy evidence. Education Policy Analysis Archives, 8(1). Retrieved January 22, 2004 from http://olam.ed.asu.edu/epaa/v8n1/.

Darling-Hammond, L., Holtzman, D. J., Gatlin, S. J., \& Heilig, J. V. (2005). Does teacher preparation matter? Evidence about teacher certification, Teach for America, and teacher effectiveness. Educational Policy Analysis Archives, 13(42). Retrieved April 2, 2009, from http://epaa.asu.edu/epaa/v13n+2/v13n+2.pdf. 
Denzin, N. K. (1989). The research act: A theoretical introduction to sociological methods. ( $3^{\text {rd }}$ ed.). Englewood Cliffs, NJ: Prentice Hall.

Ding, M., Li, Y., Li, X., \& Kulm, G. (2008). Chinese teachers' perceptions of students' classroom misbehavior. Educational Psychology, 28(3), 305-324.

Dolezal, S. E., Welsh, L. M., Pressley, M., \& Vincent, M. M. (2003). How third-grade teachers motivate student academic achievement. The Elementary School Journal, $103,239-267$.

Drago, R., Caplan, R., Costanza, D., Brubaker, T., Cloud, D., Harris, N., et al. (1999). New estimates of working time for elementary school teachers. Monthly Labor Review, $122(4), 31-40$.

$\mathrm{Du}, \mathrm{H},(2004)$. A discussion on effective teaching within the implementation of new curriculum. Journal of Southwest University for Nationalities, 25(7), 356-359.

Dunn, R., Honigsfeld, A., Shea Doolan, L., Bostrom, L., Russo, K., Schiering, M.S., et al. (2009). Impact of learning-style instructional strategies on students' achievement and attitudes: Perceptions of educators in diverse institutions. Clearing House: A Journal of Educational Strategies, Issues, and Ideas, 82(3), 135-140.

Eberts, R. W., \& Stone J. A. (1984). Unions and public schools: The effects of collective bargaining on American education. Lexington, MA: Heath.

Elmore, R., \& Burney, D. (1999). Investing in teacher learning: Staff development and instructional improvement. In L. Darling-Hammond \& G. Sykes (Eds.), Teaching as the learning profession: Handbook of policy and practice (pp. 263-291). San Fransisco: Jossey-Bass. 
Emmer, E. T., Evertson, C. M., \& Worsham, M. E. (2008). Classroom management for middle and high school teachers ( $8^{\text {th }}$ ed.). Boston: Allyn and Bacon.

Emmer, E. T., \& Stough, L. M. (2001). Classroom management: A critical part of educational psychology, with implications for teacher education. Educational Psychologist, 36(2), 103-112.

Erlandson, D. A., Harris, E. L., Skipper, B. L., \& Allen, S. D. (1993). Doing naturalistic inquiry. Newsbury Park, CA: Sage Publications.

Fan, L., \& Gurcharn, K. (2000). The influence of textbooks on teaching strategies: An empirical study. Mid-Western Educational Researcher, 13(4), 2-9.

Fang, Y., \& Gopinathan, S. (2009). Teachers and teaching in Eastern and Western schools: A critical review of cross-cultural comparative studies. In L. J. Saha and A. G. Dworkin (Eds.), International handbook of research on teachers and teaching (pp. 557-572). New York: Springer.

Fang, Y., Hooghart, A., Song, J., \& Choi, J. (2003). Roles in context-Examine staffrooms as sites for teacher learning in three cultures: China, Japan, and South Korea. Paper presented at Annual Meeting of the American Educational Research Association, Chicago.

Feiman-Nemser, S. (2001). From preparation to practice: Designing a continuum to strengthen and sustain teaching. Teacher College Record, 103(6), 1013-1055.

Fraser, B. J., \& Fisher, D. L. (1982). Predicting students' outcomes from their perceptions of classroom psycho-social environment. American Educational Research Journal, 19, 498-518. 
Fuchs, L. S., Deno, S. L., \& Mirkin, P. K. (1984). The effects of frequent curriculum-based measurement and evaluation on pedagogy, student achievement, and student awareness of learning. American Educational Research Journal, 21(2), 449-460.

Fuchs, L. S., \& Fuchs, D. (2003). What is scientifically-based research on progress monitoring? Washington, DC: National Center on Student Progress Monitoring.

Gall, M. D. (2001). Figuring out the importance of research results: Statistical significance versus practical significance. Retrieved August 24, 2009, from http://www.uoregon.edu/ mgall/statistical_significance_v.htm.

Gall, M. D., Gall, J. P., Borg, W. R. (2007). Educational research: An introduction ( $8^{\text {th }}$ ed.). Boston: Pearson.

Gallagher, H. A. (2004). Vaughn Elementary's innovative teacher evaluation system: Are teacher evaluation scores related to growth in student achievement? Peabody Journal of Education, 79(4), 79-107.

Gardner, H. (1995). Cracking open the IQ box. In S. Fraser (ed.), The bell curve war: Race, intelligence, and the future of America (pp. 23-35). New York: Basic Books.

Goddard, R. G., Hoy, W. K., \& Hoy, A. W. (2004). Collective efficacy: Theoretical development, empirical evidence, and future directions. Educational Researcher, $33(3), 3-13$.

Goddard, R. G., LoGerfo, L. \& Hoy, W. K. (2004). High school accountability: The role of collective efficacy. Educational Policy, 18, 403-425.

Goldhaber, D. (2002). The mystery of good teaching. Education Next, 2(1), 50-55. Retrieved December 7, 2008, from http://www.hoover.org/publications/ednext/3368021.html. 
Goldhaber, d. (2006, December). Teacher pay reforms: The political implications of recent research. Chicago: The Center for American Progress.

Goldhaber, D. D., \& Brewer, D. J. (1997a). Evaluating the effects of teacher degree level on educational performance. In W. J. Fowler (Ed.), Developments in school finance, 1996 (pp. 197-210). Washington, DC: National Center for Educational Statistics, U.S. Department of Education.

Goldhaber, D. D., \& Brewer, D. J. (1997b). Why don't schools and teachers seem to matter? Assessing the impact of unobservables on educational productivity. The Journal of Human Resources, 32(3), 502-523.

Goldhaber, D. D., \& Brewer, D. J. (2000). Does teacher certification matter? High school certification status and student achievement. Educational Evaluation and Policy Analysis, 22(2), 129-145.

Good, T. L., \& Brophy, J. E. (1973). Looking in classrooms (1st ed.). New York: Harper \& Row.

Good, T. L., \& Brophy, J. E. (2008). Looking in classrooms (10th ed.). Boston: Allyn \& Bacon,

Gordon, R., Kane, T. J., \& Staiger, D.O. (2006). Identifying effective teachers using performance on the job. Washington, DC: Brookings Institution.

Grant, L.W., Xu, X., Stronge, J. H., Little, C.A., \& Sun, Y. (2009). Beliefs and practices in the United States and China: A comparative analysis of effective teachers. Paper presented at the annual conference of the University Council of Educational Administration, November 11, Anaheim, CA. 
Greenwald, R., Hedges, L. V., \& Laine, R. D. (1996). The effect of school resources on student achievement. Review of Educational Research, 66(3), 361-396.

Gross, B., Booker, T. K., \& Goldhaber, D. (2009). Boosting student achievement: The effect of comprehensive school reform on student achievement. Educational Evaluation and Policy Analysis, 31(2), 111-126.

Gronlund, N. E. (2006). Assessment of student achievement $\left(8^{\text {th }}\right.$ ed.). Boston: Pearson.

Guba, E. G. (1981). Criteria for assessing the trustworthiness of naturalıstic inquiries. Educational communication and technology journal, 29, 75-91.

Guba, E. G., \& Lincoln, Y. S. (1994). Competing paradigm in qualitative research. In N.K. Denzin \& Y. S. Lincoln (Eds.), Handbook of qualitative research (pp. 10-117). Thousand Oaks, CA: Sage.

Guin, K. (2004, August 16). Chronic teacher turnover in urban elementary schools. Education Policy Analysis Archives, 12(42). Retrieved October 29, 2007 from hıtp://epaa asu_edu/cpaa/ 12 n $12 \%$.

Guo, S., Tsai, C., Chang, F. M., \& Huang, H. (2007). The study of questioning skills on teaching improvement. The International Journal of Learning, 14(8), 141-145.

Hamilton, L., \& Stecher, B. (2004). Responding effectively to test-based accountability. Phi Delta Kappan, 85(8), 578-583.

Hamre, B.K. \& Pianta, R.C. (2005). Can instruction and emotional support in the first-grade classroom make a difference for children at risk of school failure? Child Development, 76(5), 949-967. 
Hanushek, E. A. (1997), Assessing the effects of school resources on student performance: An update. Educational Evaluation and Policy Analysis, 19, 141-164.

Hanushek, E. A. (2008, May). Teacher deselection. Retrieved December 13, 2009, from http://www.stanfordalumni.org/leadingmatters/san francisco/documents/Teacher_Des election-Hanushek.pdf.

Hanushek, E. A., Kain, J. F., O’Brien, D. M., \& Rivkin, S. G. (2005). The market for teacher quality. Cambridge, MA: National Bureau of Economic Research. Retrieved December 6, 2008, from http:/www.nber.org/papers/w 11154.pdf.

Hanushek, E. A., Kain, J. F., \& Rivkin, S. G. (1998, August). Teachers, schools, and academic achievement. Cambridge, MA: National Bureau of Economic Research. Retrieved January 24, 2009, from htp.//ww w nber.org/papers/n6691.

Hanushek, E, Kain, J. F., \& Rivkins, S. G. (2004). Why public schools lose teachers. Journal of Human Resources, 39(2), 326-354.

Harris, D. N., \& Sass, T. R. (2007). Teacher training, teacher quality and student achievement. Washington, DC: National Center for Analysis of Longitudinal Data in Education Research. Retrieved April 4, 2009, from www.caldercenter.org/PDF/1001059_Teacher_Training.pdf

Hatch, J. A. (2002). Doing qualitative research in education setting. New York: Albany State University.

Hattie, J. (2003). Teachers make a difference: What is the research evidence? Retrieved December 12, 2008, from http://www.leadspace.govt.nz/leadership/pdf/john_hattie.pdf. 
Hattie, J. (2009). Visible learning: A synthesis of over 800 meta-analyses relating to student achievement. New York: Routledge.

Hau, K. T., \& Salili, F. (1991), Structure and semantic differential placement of specific causes: Academic causal attributions by Chinese students in Hong Kong. International Journal of Psychology, 26, 175-193.

Haycock, K., \& Crawford, C. (2008). Closing teacher quality gap. Educational Leadership, 65(7), 14-19.

Haynie, G. (2006, April). Effective Biology teaching: A value-added instructional improvement analysis model. Retrieved February 7, 2009, from http://www.wcpss.net/evaluation-research/reports/2006/0528biology.pdf.

Heistad, D. (1999, April). Teachers who beat the odds: Value-added reading instruction in Minneapolis 2nd grade. Paper presented at the Annual American Educational Research Association Conference, April, Montreal, Canada.

Heneman, H. G., Milanowski, A., Kimball, S. M., \& Odden, A. (2006). Standards-based teacher evaluation as a foundation for knowledge-and skill-based pay. Philadelphia: Consortium for Policy Research in Education. Retrieved November 24, 2010, from http://www.cpre.org/images/stories/cpre pdfs/RB45.pdf

Herbert, T. (2007). The impact of state-mandated, high-stakes testing on fifth grade science teachers' instructional practices. Paper presented at the Third International Congress of Qualitative Inquiry, University of Illinois Urbana Champaign, May 2-5, 2007.

Hiebert, J., Gallimore, R., Garnier, H., Givvin, K. B., Hollingsworth, H., Jacobs, J., Chui, A.M. Y., Wearne, D., Smith, M., Kersting, N., Manaster, A., Tseng, E., Etterbeek, W., 
Manaster, C., Gonzales, P., \& Stigler, J. (2003). Teaching mathematics in seven countries. Results from the TIMSS 1999 video study. Washington DC: National Center for Education Statistics.

Heibert, J., Stigler, J.W., Jacobs, J.K., Givvin, K.B., Garnier, H., Smith, M., Hollingsworth, H., Manaster, A., Wearne, D., \& Gallimore, R. (2005). Mathematics teaching in the United States today (and tomorrow): Results from the TIMSS 1999 Video Study. Educational Evaluation and Policy Analysis 27(2), $111-132$.

Hill, H. C., Rowan, B., \& Ball, D. L. (2005). Effects of teachers' mathematical knowledge for teaching on student achievement. American Educational Research Journal, 42, 371406.

Hindman, J. L., Grant, L. W., \& Stronge, J. H. (2010). The supportive learning environment: Effective teaching practice. Larchmont, NY: Eye On Education.

Ho, I. R. (2001). Are Chinese teachers authoritarian? In D. A. Watkins \& J. B. Biggs (Eds.), Teaching the Chinese learner: Psychological and pedagogical perspectives (pp. 99 114). Hong Kong: Comparative Education Research Center.

Hoepfl, M. C. (1997). Choosing qualitative research: A primer for technology education researchers. Journal of Technology Education, 9(1), 47-63.

Holtzapple, E. (2003). Criterion-related validity evidence for a standards-based teacher evaluation system. Journal of Personnel Evaluation in Education, 17(3), 207-2-9.

Hoy, W. K., Sweetland, P. A., \& Smith, P. A. (2002). Toward an organizational model of achievement in high schools: The significant of collective efficacy. Educational Administration Quarterly, 38, 77-93. 
Hoy, W., Tarter, J., \& Hoy. A. W. (2006). Academic optimism of schools: A force for student achievement. American Educational Research Journal, 43(3), 425-446.

Huang, R. \& Leung, F. K. S. (2004). Cracking the paradox of the Chinese learners - Looking into the mathematics classrooms in Hong Kong and Shanghai, In L. Fan, N. Wong, J. Cai, \& S. Li (Eds.), How Chinese learn mathematics: Perspectives from insiders. New Jersey: World Scientific.

Huang, F. L., \& Moon, T. R. (2009). Is experience the best teacher? A multilevel analysis of teacher characteristics and student achievement in low performing schools. Educational Assessment: Evaluation and Accountability, 21(3), 209-234.

Ingersoll, R. M. (2007, February). A comparative study of teacher preparation and qualifications in six nations. CPRE Policy Briefs, RB-47, pp. 1-15.

Jacob, B. A., \& Lefgren, L. (2008). Can principals identify effective teacher? Evidence on subjective performance evaluation in education. Journal of Labor Economics, 26(1), 101-135.

Jin, L., \& Cortazzi, M. (2006). Changing practices in Chinese cultures of learning. Language, Culture and Curriculum, 19(1), 5-20.

Johnson, B. L. (1997). An organizational analysis of multiple perspectives of effective teaching: Implications for teacher evaluation. Journal of Personnel Evaluation in Education, 11, 69-87.

Johnson, S.M. (1990). Teachers at work: Achieving success in our schools. New York: Basic Books. 
Jones, B. D., \& Egley, R. J. (2004). Voice from the frontlines: Teachers' perceptions of highstakes testing. Educational Policy Analysis Archives, 12(39). Retrieved November 17, 2007, from http://epaa asu.edu/epaa/ 1 a 12 n39.

Jones, G.., Jones, B. D., Hardin, B., Chapman, L., Yardrough, T, \& Davis, M. (1999). The impact of high-stakes testing on teachers and students in North Carolina. Phi Delta Kappan, 81(3), 199-203.

Joyce, B., Weil, M., \& Calhoun, E. (2004). Models of teaching (7th ed.). Boston: Allyn and Bacon.

Keller, B. (2008). Drive on to improve evaluation systems for teachers. Education Week, 27(19), 1-8.

Kennedy, M. M. (2010). Attribution error and the quest for teacher quality. Educational Researcher, 39(8), 591-598.

Kimball, S. M., White, B., Milanowski, A. T., \& Borman, G. (2004), Examining the relationship between teacher evaluation and student assessment results in Washoe County. Peabody Journal of Education, 79(4), 54-78.

Kunter, M., Baumert, J., \& Koller, P. (2007). Effective classroom management and the development of subject-related interest. Learning and Instruction, 17, 494-509.

Kunter, M., Tsai Y., Klusmann, U., Brunner, M., Krauss, S., \& Baumert, J. (2008). Students' and mathematics teachers' perceptions of teacher enthusiasm and instruction. Learning and Instruction, 18, 468-482.

Kvale, S. (1999). InterViews: An introduction to qualitative research interviewing. Thousand Oaks, CA: Sage. 
Lai, F. (2005). The impact of school quality and social interaction on student performance: Insights from middle school educational reform in Beijing's Eastern City district. Unpublished doctoral dissertation, University of California, Berkeley.

Lankford, H., Loeb, S., \& Wyckoff, J. (2002). Teaching sorting and the plight of urban schools: A descriptive analysis. Educational Evaluation and Policy Analysis, 24(1), $37-62$.

Le V., Lockwood, J. R., Stecher, B. M., Hamilton, L. S., \& Martinez, J. F. (2009). A longitudinal investigation of the relationship between teacher's self-reports of reformoriented instruction and mathematics and science achievement. Educational Evaluation and Policy Analysis, 31(3), 200-220.

Leigh, A. (2010). Estimating teacher effectiveness from twp-year changes in students' test scores. Economics of Education Review, 29, 480-488.

LePage, P., Darling-Hammond, L., Akar, H., Guitierrez, C., Jenkins-Gunn, E., \& Rosebrock, K. (2005). Classroom management. In L. Darling-Hammond and J. Bransford (Eds.), Preparing teachers for a changing world: What teachers should learn and be able to do (pp. 327-357). San Francisco, CA: Jossey-Bass.

Leung, F. K. S. (1995). The mathematics classroom in Beijing, Hong Kong and London. Educational Studies in Mathematics, 29, 297-325.

Li, J. (2003). US and Chinese cultural beliefs about learning. Journal of Educational Psychology, 95, 258-267. 
Li, Y., \& Shimizu, Y. (2009). Exemplary mathematics instruction and its development in selected education systems in East Asia. The International Journal on Mathematics Education, 41(3), 257-262.

Libresco, A. S. (2006). A case study of four forth grade teachers of social studies or how they stopped worrying and learned to love the state test...sort of. Unpublished Dissertation.

Lincoln, Y. S., \& Guba, E. G. (1985). Naturalistic inquiry. Beverly Hill, CA: Sage.

Liu, S. (2006). School effectiveness research in China. Unpublished dissertation, Louisiana State University, Baton Rouge.

Liu, S., \& Meng, L. (2008). Qualities of good Chinese teachers: Perspectives from teachers, students and parents. 2008 National Evaluation Institute Conference on Assessment, Evaluation, \& Professional Leaning Communities, Wilmington, NC, October 8-11.

Long, J. F., \& Hoy, A. W. (2006). Interested instructors: A composite portrait of individual differences and effectiveness. Teaching and Teacher Education, 22(3), 303-314.

Lovelace, M.K. (2005). Meta-analysis of experimental research based on the Dunn and Dunn model. Journal of Educational Research, 98(3), 176-183.

Ludtke, O., Robitzsch, A., Trautwein, U., \& Kunter, M. (2009). Assessing the impact of learning environments: How to use student ratings of classroom or school characteristics in multilevel modeling. Contemporary Educational Psychology, $34,120-131$. 
Luiselli, J. K., Putnam, R. F., \& Sunderland, M. (2002). Longitudinal evaluation of behavior support intervention in a public middle school. Journal of Positive Behavior Interventions, 4, 182-188.

Lumpkin, A. (2007). Caring teachers: The key to student learning. Kappa Delta Pi Record, 43(4), 158-160.

Marton, F., Dall'Alba, G. D., \& Kun, T. L. (1996). Memorizing and understanding the keys to the paradox? In D. A. Watkins and J. B. Biggs (Eds.), The Chinese learner: Cultural, psychological, and contextual influences (pp. 69-83). Hong Kong: Comparative Education Research Center.

Mangin, M.M. (2005). Distributed Leadership and the Culture of Schools: Teacher Leaders' Strategies for Gaining Access to Classrooms. Journal of School Leadership, 15, 4.

Marzano, R. J., Marzano, R. J., \& Pickering, D. J. (2003). Classroom management that works: Research-based strategies for every teacher. Alexandria, VA: Association for Supervision and Curriculum Development.

Mastin, V. (1963). Teacher enthusiasm. Journal of Educational Research, 56, 385-386.

McEwan, E. K. (2002). 10 traits of highly effective teachers: How to hire, coach, and mentor successful teachers. Thousand Oaks, CA: Corwin Press.

McLeod, J., Fisher, J., \& Hoover, G. (2003). The key elements of classroom management: Managing time and space, student behavior, and instructional strategies. Alexandria, VA: Association for Supervision and Curriculum Development.

Mendro, R. L. (1998). Student achievement and school and teacher accountability. Journal of Personnel Evaluation in Education, 12, 257-267. 
Mendro, R. L., Jordan, H. R., Gomez, E., Anderson, M. C., \& Bembry, K. L. (1998a, April). Longitudinal teacher effects on student achievement and their relation to school and project evaluation. Paper presented at the 1998 Annual Meeting of the American Educational Research Association, San Diego, CA.

Mendro, R. L., Jordan, H. R., Gomez, E., Anderson, M. C., \& Bembry, K. L. (1998b, April). An application of multiple linear regression in determining longitudinal teacher effectiveness. Paper presented at 1998 Annual Meeting of the American Educational Research Association, San Diego, CA.

Merriam, S. B. (1998). Qualitative research and case study applications ( $2^{\text {nd }}$ ed.). San Francisco: Jossey-Bass.

Midgley, D., Feldlaufer, H., \& Eccles, J. (1989). Change in teacher efficacy and student self and task-related beliefs in mathematics during the transition to junior high school. Journal of Educational Psychology, 81(2), 247-258.

Monk, D. H. (1994). Subject area preparation of secondary mathematics and science teachers and student achievement. Economics of Education Review, 13 (2), 125-145.

Milken Family Foundation. (n.d.). Milken Educator Awards: Criteria for selection. Retrieved December 14, 2009, from http://www.mfforg.

Ministry of Education of the People's Republic of China. (n.d.). Ministry of Education's memorandum on selecting and recognizing recipients for 2009 National Teachers/Educators Excellence Awards. Retrieved December 14, 2009, from http://www.moe.edu.cn/edoas/website 18/58/info1245807430939658.htm. 
Misulis, K. (1997). Content analysis: A useful tool for instructional planning. Contemporary Education, 69(1), 45-47.

Monk, D. H., \& King, J. (1994). Multilevel teacher resource of effects on pupil performance in secondary mathematics and science: The case of teacher subject-matter preparation. In R. Ehrenberg (Ed.), Contemporary policy issues: Choices and consequences in education (pp. 29-58). Ithaca, NY: ILR.

Muijs, D., \& Reynolds, D. (2003). Student background and teacher effects on achievement and attainment in Mathematics: A longitudinal study. Educational Research and Evaluation, 9(3), 289-314.

Munoz, M. A., \& Chang, F. C. (2007). The elusive relationship between teacher characteristics and student academic growth: A longitudinal multilevel model for change. Journal of Personnel Evaluation in Education, 20, 147-164.

National Academy of Education. (2008). Teacher quality: Education policy white paper. Washington, DC: The author. Retrieved December 14, 2009, from http://www.naeducation.org/Teacher_Quality_White_Paper.pdf.

National Board on Educational Testing and Public Policy. (2003).Perceived effects of statemandated testing programs on teaching and learning: Finding from a national survey of teachers. Boston: The author.

Noblit, G. W., Rogers, D. L., \& McCadden, B. M. (1995). In the meantime: The possibilities of caring. Phi Delta Kappan, 76(9), 680-685.

Noddings, N. (1992). The challenge to care in schools. New York: Teachers College Press. 
Nye, B., Konstantopoulos, S., \& Hedges, L. V. (2004). How large are teacher effects? Educational Evaluation and Policy Analysis, 26(3), 237-257.

Odden, A. (2004). Lessons learned about standards-based teacher evaluation systems. Peabody Journal of Education, 79(4), 126-137.

Odden, A., Borman, G., \& Fermanich, M. (2004). Assessing teacher, classroom, and school effects, including fiscal effects. Peabody Journal of Education, 79(4), 4-32.

On, L. W. (1996). The cultural context for Chinese learners: Conceptions of learning in the Confucian tradition. In D. A. Watkins and J. B. Biggs (Eds.), The Chinese learner: Cultural, psychological, and contextual influences (pp. 25-41). Hong Kong: Comparative Education Research Center.

OECD. (2010). Strong performers and successful reformers in education: Lessons from PISA for the United States. Retrieved from February 17, 2011 from http://dx.doi.org/10.1787/9789264096660-en.

Paine, L. W. (1990). The teacher as virtuoso: A Chinese model for teaching. Teachers College Record, 92(1), 49-81.

Paine, L. (2003). Making schools modern: Paradoxes of Educational Reform. Paper presented at the International Conference on Educational Reform in China, Teachers College, Columbia University, New York, NY.

Pajares, M. F. (1992). Teachers' beliefs and educational research: Cleaning up a messy construct. Review of Educational Research, 62(3), 307-332. 
Palardy, G. J., \& Rumberger, R. W. (2008). Teacher effectiveness in first grade: The importance of background qualifications, attitudes, and instructional practices for student learning. Educational Evaluation and Policy Analysis, 30(2), 111-140.

Panasuk, R., Stone, W., \& Todd, J. (2002). Lesson planning strategy for effective mathematics teaching. Education, 22 (2), 714, 808-827.

Park, A., \& Hannum, E. (2001). Do teachers affect learning in developing countries?: Evidence from matched student-teacher data from China. Paper presented at the Conference Rethinking Social Science Research on the Developing World in the $21^{\mathrm{st}}$ Century, Park City, UT, June 7-11.

Parke, C. S., Lane, S., \& Stone, C. A. (2006). Impact of a state performance assessment program in reading and writing. Educational Research and Evaluation, 12(3), 239269.

Park, A., Wen, L., \& Wang, S. (2003) School equity in rural China. Paper presented at the International Conference on Educational Reform in China, Teachers College, Columbia University, New York, NY. Retrieved June 16, 2009, from http://www.ssc.upenn.edu/china/gscf/documents/schequity.02.03.PDF.

Patrick, B. C., Hisley, J., Kempler, T., \& College, G. (2000). What's everybody so excited about? The effects of teacher enthusiasm on student intrinsic motivation and vitality. Journal of Experimental Education, 68(3), 217-236.

Patton, M. Q. (2002). Qualitative evaluation and research methods ( $3^{\text {rd }}$ ed.). Thousand Oaks, CA: Sage. 
Pearce, R., \& Lin, Z. (2005). Cultural capital and postsecondary educational attainment among White and Chinese Americans: An analysis of NELS 1988-2000. Asian American Policy Review, 4, 19-37.

Peart, N. A., \& Campbell, F. A. (1999). At-risk students' perceptions of teacher effectiveness. Journal for a Just and Caring Education, 5(3), 269-284.

Phillipson, S. (2006). Cultural variability in parent and child achievement attributions: A study from Hong Kong. Educational Psychology, 26, 625-642.

Pressley, M., Rapael, L. Gallagher, J.D., \& DiBella, J. (2004). Providence-St. Mel School: How a school that works for African Americans works. Journal of Educational Psychology, 96(2), 216-235.

Preus, B. (2007). Educational trends in China and the United States: Proverbial pendulum or potential for balance? Phi Delta Kappan, 89(2), 115-118.

Redfield, D. (2000). What makes effective teachers effective? (An unpublished document). Charleston, WV: Appalachian Educational Laboratory.

Rice, J. K. (2003). Teacher quality: Understanding the effectiveness of teacher attributes. Washington, DC: Economic Policy Institute.Rice, J. K. (2003). Teacher quality: Understanding the effectiveness of teacher attributes. Washington, DC: Economic Policy Institute.

Rosenthal, D., \& Feldman, S. (1991). The influence of perceived family and personal factors on self-reported school performance of Chinese and Western high school students. Journal of Research on Adolescence, 1, 135-154. 
Rowan, B., Chiang, F. S. \& Miller, R. J. (1997). Using research on employees' performance to study the effects of teachers on student achievement. Sociology of Education, 70, 256-284.

Rivkin, S. G., Hanushek, E. A., \& Kain, J. F. (2005). Teachers, schools, and academic achievement. Econometrica, 73(2), 417-458.

Rockoff, J. E. (2004). The impact of individual teachers on student achievement: Evidence from panel data. The American Economic Review, 94(2), 247-252.

Rockoff, J. E., Jacob, B. A., Kane, T. J., \& Staiger, D. O. (2008, November). Can you recognize an effective teacher when you recruit one? Cambridge, MA: National Bureau of Economic Research. Retrieved April 1, 2009, from http://www.nber.org/paper/w14485.

Rossman, G. B., \& Rallis, S. F. (2003). Learning in the field: An introduction to qualitative research $\left(2^{\text {nd }}\right.$ ed.). Thousand Oaks, CA: Sage Publications.

Rothman, R. (2008, Summer), Developing human capital. Voices in Urban Education, 20. Retrieved September 10, 2008, from http://www annenberginstitute org/VLE/summer/s/Rothman.php.

Rowan, B., Chiang, F.S., \& Miller, R. J. (1997). Using research in employees' performance to study the effects of teachers on student achievement. Sociology of Education. 70, 256-284.

Rowan, B., Correnti, R., \& Miller, R. J. (2002). What large-scale, survey research tells us about teacher effects on student achievement: Insights from the Prospects study of elementary schools. Teachers College Record, 104(8), 1525-1567. 
Safer, N., \& Fleischman, S. (2005). How student progress monitoring improves instruction. Educational Leadership, 62(5), 81-83.

Salili, F., \& Hau, K. T. (1994). The effect of teachers' evaluative feedback on Chinese students' perception of ability: A cultural and situational analysis. Educational Studies, 20(2), 223-236.

Sanders, W. L, \& Rivers, J. C. (1996, November). Cumulative and residual effects of teachers on future student academic achievement. Knoxville, TN: University of Tennessee Value-Added Research and Assessment Center.

Sargent, T. C. (2006). Institutionalizing educational ideologies: Curriculum reform and the transformation of teaching practice in rural China. Unpublished doctoral dissertation, University of Pennsylvania, Philadelphia.

Scafidi, B., Sjoquist, D. L., \& Stinebrickner, T. R. (2008). Race, poverty, and teacher mobility. Economics of Education Review, 26, 145-159.

Schacter, J., \& Thum, Y. M. (2004), Paying for high- and low-quality teaching. Economics of Education Review, 23, 411-430.

Schalock, H. D., Schalock, M. D., Cowart, B., \& Myton, D. (1993). Extending teacher assessment beyond knowledge and skills: An emerging focus on teacher accomplishments. Journal of Personnel Evaluation in Education, 7, 105-133.

Schneider, B., \& Lee, Y. (1990). A model for academic success: The school and home environment of East Asian students. Anthropology and Education Quarterly, 21, 358377. 
Schroeder, C.M., Scott, T.P., Tolson, H., Huang, T., \& Lee, Y. (2007). A Meta-analysis of national research: Effects of teaching strategies on student achievement in science in the United States. Journal of Research in Science Teaching, 44, 1436-1460.

Schwandt, T. A. (2007). Judging interpretation. New Directions for Evaluation, 1/4, 11-25.

Schwarzer, R., \& Hallum, S. (2008). Perceived teacher self-efficacy as a predictor of job stress and burnout: Mediation analyses. Applied Psychology: An International Review, 57, 152-171.

Schwille, J., Dembele, M., \& Schubert, J. (2007). Global perspectives on teacher learning: Improving policy and practice. Paris: United Nations Educational, Scientific and Cultural Organization.

Shahid, J., \& Thompson, D. (2001). Teacher efficacy: A research synthesis. Paper presented at the annual meeting of the American Educational Research Association, Seattle, WA, April 10-14. (ERIC Document Reproduction No. ED 453 170).

Shen, J., Zhang, N., Zhang, C., Caldarella, P., Richardson, M. J., \& Shatzer, R. H. (2009). Chinese elementary school teachers' perceptions of students' classroom behavior problems. Educational Psychology, 29(2), 187-201.

Shepard, L. A., \& Dougherty, K. C. (1991). Effects of high-stakes testing on instruction. Paper presented at the annual meeting of the American Educational Research Association and National Council on Measurement in Education, Chicago.

Shernoff, D. J., Csikszenthmihalyi, M., Schneider, B., \& Shernoff, E. S. (2003). Student engagement in high school classrooms from the perspectives of flow theory. School Psychology Quarterly, 18(2), 158-176. 
Shi, J., \& Zha, Z. (2000). Psychological research on the education of gifted and talented children in China. In K. A. Heller, F. J. Monks, R. J.Sternberg, \& R.F.Subotnik (Eds.), International handbook of giftedness and talent ( $2^{\text {nd }}$ ed., pp. 757-764). Oxford, UK: Elsevier.

Sigler, D., \& Kashyap, M. U. (2008, Summer). Human capital management: A new approach for districts. Voices in Urban Education, 20. Retrieved September 10, 2008, from http://www.annenberginstitute.org/VUE/summer08/Sigler.php

Smith, J. A., Flowers, P., \& Larkin, M. (2009). Interpretative phenomenological analysis: Theory, method and research. Thousand Oaks, CA: Sage.

Smith, M. L., \& Rottenberg, C. (1991). Unintended consequences of external testing in elementary schools. Educational Measurement, Issues and Practices, 10(4), 7-11.

Soh, C. K. (1999). East-west difference in views on creativity: Is Howard Gardner Correct? Yes, and no. Journal of Creative Behavior, 33(2), 112-125.

Stecher, B. M. (2002). Consequences of large-scale, high-stakes testing on school and classroom practice. In L. S. Hamilton (Ed.), Making Sense of Test-based Accountability in Education. Santa Monica: Rand Education.

Stecher, B. M., \& Mitchell, K. J. (1995). Portfolio Driven Reform: Vermont Teachers' Understanding of Mathematical Problem Solving. CSE Technical Report 400. Los Angeles: National Center for Research on Evaluation, Standards, and Student Testing. Stecker, P. M., Fuchs, L. S., \& Fuchs, D. (2005). Using curriculum-based measurement to improve student achievement: Review of research. Psychology in the Schools, 42(8), 795-819. 
Stevenson, H. W., Lee, S., \& Stigler, J. W. (1986). Mathematics achievement of Chinese, Japanese, and American children. Science, 231, 693-699.

Stevenson, H. W., \& Stigler, J. W. (1992). The learning gap: Why our schools are failing and what we can learn from Japanese and Chinese education. New York: Summit Books.

Stiggins, R. (2002). Assessment crisis: The absence of assessment for learning. Phi Delta Kappan, 83(10), 758-765.

Stiggins, R., \& DuFour, R. (2009). Maximizing the power of formative assessments. Phi Delta Kappan, 90(9), 640-644.

Stigler, J. W., \& Hiebert, J. (1999). The teaching gap: Best ideas from the world's teachers for improving education in the classroom. New York: Free Press.

Stigler, J. W., Lee, S. Y., Lucker, G. W., \& Stevenson, J. W. (1982). Curriculum and achievement in mathematics: A study of elementary school children in Japan, Taiwan, and United States. Journal of Educational Psychology, 74, 315-322.

Stigler, J., \& Stevenson, H. W. (1991). How Asian teaches polish each other to perfection. American Educator, 15(1), 12-21, 43-47.

Strauss, A., \& Corbin, J. (1998), Basics of qualitative research: Techniques and procedures for developing grounded theory ( $2^{\text {nd }}$ ed.). Thousand Oaks, CA: Sage.

Stronge, J. H. (2007). Qualities of effective teachers (2nd ed.). Alexandria, VA: Association for Supervision and Curriculum Development.

Stronge, J. H. (2010). Teacher effectiveness=Student achievement: What the research says. Larchmont, NY: Eye on Education. 
Stronge, J. H., Ward, T. J., Tucker, P. D., \& Hindman, J. L. (2008). What is the relationship between teacher quality and student achievement? An exploratory study. Journal of Personnel Evaluation in Education, 20(3-4), 165-184.

Stronge, J. H., Ward, T. J., Tucker, P. D., \& Grant, L.W. (In press). What makes good teachers good? A cross-case analysis of the connection between teacher effectiveness and student achievement. Journal of Teacher Education.

Sue, S., \& Okazaki, S. (1990). Asian-American educational achievement: A phenomenon in search for an explanation. American Psychologist, 45 (8), 913-920.

Sun, C. (2004). A study on effective classroom teaching under the background of new curriculum. Unpublished master's thesis, Shanghai Normal University, Shanghai, China.

Sun, Y. (2004). A study on teacher instructional effectiveness. Unpublished dissertation, East China Normal University, Shanghai, China.

Taylor, B., Pearson, P. D., Clark, K. F., \& Walpole, S. (1999). Beating the odds in teaching All Children to Read. Ann Arbor, MI: Center for the Improvement of Early Reading Achievement.

Thayer, Y. (2000). Virginia's Standards make all students stars. Phi Delta Kappan, 57(7), 7072.

Tomlinson, C. A. (1999). The differentiated classroom: Responding to the needs of all learners. Alexandria, VA: Association for Supervision and Curriculum Development. Tomlinson, C. A. (2001). How to differentiate instruction in mixed-ability classrooms (2nd ed.). Alexandria, VA: Association for Supervision and Curriculum Development. 
Tomlinson, C.A. (2007). Learning to love assessment. Educational Leadership, 65(4), 8-13.

Tomlinson, C. A., Brighton, C., Hertberg, H., Callahan, C. M., Moon, T. R., Brimijoin, K., et al. (2003). Differentiating instruction in response to student readiness, interest, and learning profile in academically diverse classrooms: A review of literature. Journal for the Education of the Gifted, 27(2/3), 119-145.

Tschannen-Moran, M., \& McMaster, P. (2009). Sources of self-efficacy: Four professional development formats and their relationship to self-efficacy and implementation of new teaching strategy. The Elementary School Journal, 110(2), 228-245.

Tsui, A. B. M. \& Wong, J. L. N. (2009). In Search of a Third Space: Teacher Development in Mainland China. In C. K. K. Chan \& N. Rao (Eds.), Revisiting the Chinese Learner: Changing Contexts, Changing Education (pp. 281-311). Hong Kong: Comparative Education Research Centre/Springer Academic Publishers.

Tweed, R. G., \& Lehman, D. R. (2002). Learning considered within a cultural context: Confucian and Socratic approaches. American Psychologist, 57(2), 89-99.

U.S. Department of Education. (2001). No Child Left Behind Act of 2001. Washington, DC: Author.

Van Manen, M. (1990), Researching lived experience: Human science for an action sensitive pedagogy. Ontario, Canada: The State University of New York.

Verloop, N., Van Driel, J., Meijer, P. (2001). Teacher knowledge and the knowledge base of teaching. International Journal of Educational Research, 35, 441-461.

Vogler, K. E. (2002). The impact of high-stakes, state-mandated student performance assessment on teachers' instructional practices. Education, 123(1), 39-56. 
Walls, R. T., Nardi, A. H., von Minden, A. M., \& Hoffman, N. (2002). The characteristics of effective and ineffective teachers. Teacher education quarterly, 29(1), 39-48.

Walberg, H. J. (1984). Improving the productivity of America's schools. Educational Leadership, 4l(8), 19-27.

Walberg, H. J. (1992). The knowledge base for educational productivity. International Journal of Educational Reform, 1(1), 5-15.

Walsh, J. A., \& Sattes, B. D. (2005). Quality questioning: Research-based practice to engage every learner. Thousand Oaks, CA: Corwin Press.

Wang, X. (2000). A comparative study on effective instructional practices and ineffective instructional practices. Theory and Practice of Education, 20(9), 50-53.

Wang, X. (2006). New curriculum's vision for the development of teacher's teaching capacity. Unpublished doctoral dissertation, East China Normal University, Shanghai, China.

Wang, M., Haertel, G. D., \& Walberg, H. (1993). Toward a knowledge base for school learning. Review of Educational Research, 63 (3), 249-294.

Wang, M. C., Haertel, G. D., \& Walberg, H. J. (1994). What helps students learn? Educational Leadership, 5l(4), 74-79.

Watkins, D. A., \& Biggs, J. B. (Eds.). (1996). The Chinese learner: Cultural, psychological, and contextual influences. Hong Kong: Comparative Education Research Center.

Watkins, D. A., \& Biggs, J. B. (Eds.). (2001). Teaching the Chinese learner: Psychological and pedagogical perspectives. Hong Kong: Comparative Education Research Center. 
Wayne, A. J., \& Youngs, P. (2003). Teacher characteristics and student achievement gains: A review. Review of Educational Research, 73(1), 89-122.

Webster, W. J., \& Mendro, R. L. (1997). The Dallas value-added accountability system. In J. Millman (Ed.), Grading teaches, grading schools: Is student achievement a valid evaluation measure? (pp. 81-99). Thousand Oaks, CA: Corwin Press.

Weiss, I. R., \& Miller, B. (2006, October). Deepening teacher content knowledge for teaching: A review of the evidence. Retrieved May 10, 2009, from http:/hub.mspnet.org/media/data/WeissMiller.pdf?media 000000002247.pdf.

Wenglisky, H. (2000). How teaching matters: Bringing the classroom back into discussion of teacher quality. Princeton, NJ: Millikan Family Foundation and Educational Testing Service.

Wenglinsky, H. (2002). How schools matter: The link between teacher classroom practices and student academic performance. Education Policy Analysis Archives, 10(12). Retrieved November 20, 2008, from http://epaa.asu.edu/epaa/v10n12/.

Wenglinsky, H. (2004). The link between instructional practice and the racial gap in middle schools. Research in Middle Level Education Online, 28(1), 1-13.

Wentzel, K. R. (1997). Student motivation in middle school: The role of perceived pedagogical caring. Journal of Educational Psychology, 89(3), 411-419.

Williams, R. (2010). Administrator and teacher perceptions of the qualities of effective teachers. Unpublished doctoral dissertation. The College of William and Mary, Williamsburg, VA. 
Willis, J. W. (2007). Foundations of qualitative research: Interpretive and critical approach. Thousand Oaks, CA: Sage.

Wright, S. P., Horn, S. P., \& Sanders, W. L. (1997). Teacher and classroom context effects on student achievement: Implications for teacher evaluation. Journal of Personnel Evaluation in Education, 11, 57-67.

Zahorik, J., Halbach, A., Ehrle, K., \& Molnar, A. (2003). Teaching practices for smaller classes. Educational Leadership, 61(1), 75-77.

Zhang, F. (2008). Effective instruction and new curriculum. Unpublished master's thesis, Inner Mongolia Normal University, Huhhot, Inner Mongolia, China. 


\title{
Appendix A Informed Consent Form - English
}

\section{Consent for Participation Form}

\author{
A Cross-Cultural Comparative Study of Teacher Effectıveness
}

Analyses of Award-Winning Teachers in the United States and China

$\mathrm{I}$, agree to participate in a research study involving national award-

winning teachers currently serving in a public elementary school in the United States and China The researcher is conducting this study as a part of her dissertation study at the College of William and Mary The purpose of this study is to compare the instructional practices and beliefs of award-winning teachers in the US and China I understand that the researcher has purposely selected individuals from public school settıngs in the United States and Chına for a comparatıve purpose I further understand that the researcher will use classroom observation, interviews, and artıfacts to investıgate the qualities that are critical to teacher effectiveness This study is designed to examıne the following questions

1 What are the similanties and differences between selected award-winning United States and China teachers in their instructional practices?

a) What types of instructional activities are used by selected award-winning U S and China teachers?

b) How are cognitive levels, based on Bloom's revised taxonomy (Anderson \& Krathwohl, 2001), represented in these teachers' classrooms?

c) To what degree is learnıng teacher-directed in the classrooms of selected award-wınnıng US teachers and Chına teachers?

2 How are selected national award-winning United States and Chına teachers' classroom practices - other than instructional activities - similar and different (such as their classroom management strategies)?

a) What are the student engagement levels in the classrooms of selected awardwinnıng U S teachers and China teachers?

b) What classroom management strategies are implemented by selected awardwinnıng U S teachers and Chına teachers?

3 What are the simılanties and differences in professional thinkıng between teachers in the US and China?
a) How do these teachers reflect on their practices, particularly about their instructional strategies, differentiation, and assessment and evaluation of students' learning? relationships with students, classroom environment, instructional plannıng,
b) What are the selected teachers' perceptions of why their practice mented recognition with a national award?

I have been informed that any information obtained in this study will be recorded with a pseudonym of my choosing that will allow only the researcher to determine my identity At the conclusion of this study, the key linking me with the pseudonym will be destroyed All 
efforts will be made to conceal my identity in the study's report of results and to keep my personal information confidential. I also understand that as a benefit I will receive a copy of the final product to further my understanding of the topic and to understand others' perspectives.

Because my classroom instruction will be observed and I will be asked questions regarding my perceptions of teacher effectiveness, there may be minimal to no psychological discomfort or risk involved with this research. I understand that I do not have to answer every question asked of me, and I am free to withdraw my consent and discontinue participation in this study at any time by informing the researcher by telephone or email. My decision to participate or not participate will not bring penalty or loss of benefits to which I might otherwise be entitled. If I have questions or concerns that arise in connection with my participation in this study, I should contact Dr. James Stronge, the academic advisor of the research at 757-221-2339 or jhstro@wm.edu. I understand that I may report any problems or dissatisfaction to Dr. Thomas Ward, chair of the School of Education Internal Review Committee at 757-221-2358 or tiward@wm.edu or Dr. Michael Deschenes, the chair of the Protection of Human Subjects Committee at the College of William and Mary at 757-2212778 or mrdesc@wm.edu.

My signature below signifies that $I$ am at least 18 years of age, that I have received a copy of this consent form that is mine to keep, and that I consent to participating in this research study,

Date

Participant

Date

Investigator 


\section{Appendix B Informed Consent Form - Chinese}

\section{邀请函}

亲爱的 老州:

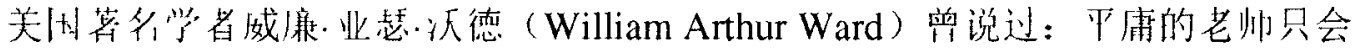

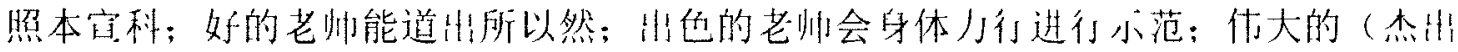
的）老帅则知道加们激发学牛的灵感。

一个老㺫对学牛的学习和牛活有极人的影响小，这一点无论怎么说都不会门过具

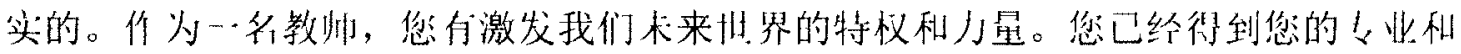

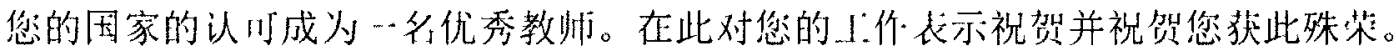

在此我想邀请您参加我们一个关可中关㹨奖教师的研究项 $\mathrm{F}$ 。在这个项目中1，我 将对来白中国和美国这两个国家的优秀教师进行个案斫究, 这此教师都获得了因家级 别的教堂奖。我的研究目的是想更加深刻的了解优秀教师及他们的 I. 作。这个研究最 核心的意义的是去发现究竟是什么使得他们的教学如此有效。我将探索优秀教师所具 有的素质，以及这些素质又是如何转化为紧生的学习。我还要探索卓越的教学在不同 文化和不同地域是否有区别。现今师界各国都在努力寻求各种方法和途行来收善我们 的学校和最大限度的为所有学牛提供学二机会, 我相倍这项研究的成果叮以为教育政

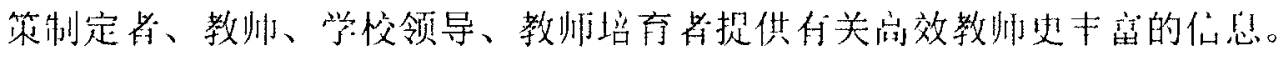

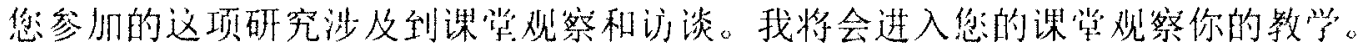

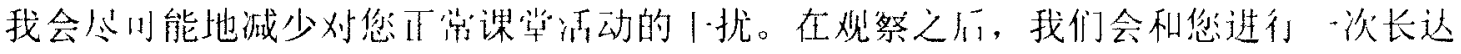

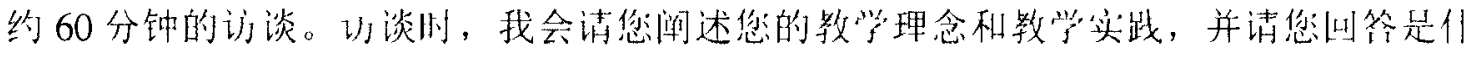

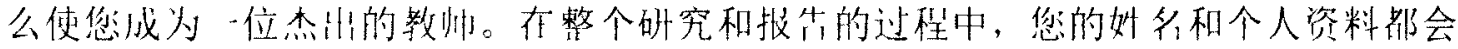

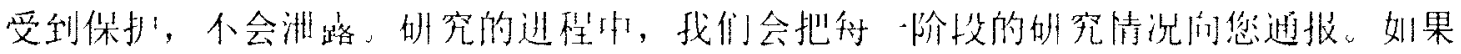

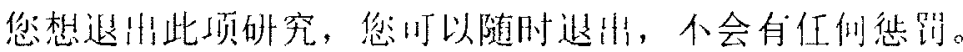

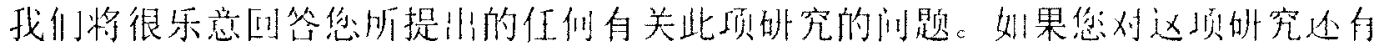
疑间, 您可以联系我, 电泞: 757-775-4082; 电子邮件: xxu@email wm edu。如果你在

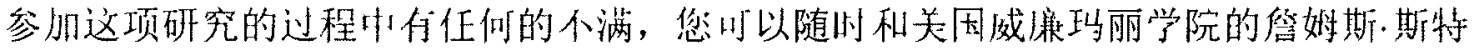
朗博士，电话：757-221-2339; 电子邮件： ihstro@wm.edu；或者是威康玛丽学院你护 人类被试委员会主席老克·德克尼斯, 电话：757-221-2778; 电子邮件 mrdesc@wm.edu。 如果根据以上伯想您愿意参加这项研究，请您在此签名 甘期

。我们相倍，我们的合作将会丰富有效教学的研究，对末来的教师索质做出

贡献。

徐姆轩

教育兴院

成唐玛丽兴院

成廉斯堡，弗古尼可州 23187

2010 伂 11 月 